


\section{NOTICE}

This report was prepared as an account of work sponsored by the United States Government. Neither the United States nor the United States Department of Energy, nor any of their employees, nor any of their contractors, subcontractors, or their employees, makes any warranty, express or implied, or assumes any legal liability or responsibility for the accuracy, completeness or usefulness of any information, apparatus, product or process disclosed, or represents that its use would not infringe privately owned rights.

Available from the National Technical Information Service, U.S. Department of Commerce, Springfield, Virginia 22161.

Price: Paper Copy $\$ 6.00$

Microfiche $\$ 3.00$ 


\section{DISCLAIMER}

This report was prepared as an account of work sponsored by an agency of the United States Government. Neither the United States Government nor any agency Thereof, nor any of their employees, makes any warranty, express or implied, or assumes any legal liability or responsibility for the accuracy, completeness, or usefulness of any information, apparatus, product, or process disclosed, or represents that its use would not infringe privately owned rights. Reference herein to any specific commercial product, process, or service by trade name, trademark, manufacturer, or otherwise does not necessarily constitute or imply its endorsement, recommendation, or favoring by the United States Government or any agency thereof. The views and opinions of authors expressed herein do not necessarily state or reflect those of the United States Government or any agency thereof. 


\section{DISCLAIMER}

Portions of this document may be illegible in electronic image products. Images are produced from the best available original document. 


\section{A CRITICAL LABORATORY AND FIELD EVALUATION OF SELECTED SURFACE PROSPECTING TECHNIQUES FOR LOCATING OIL AND NATURAL GAS}

By
R. J. Heemstra
R. M. Ray
T. C. Wesson
J. R. Abrams
G. A. Moore

Bartlesville Energy Technology Center

Bartlesville, Oklahoma

Date Published-January 1979

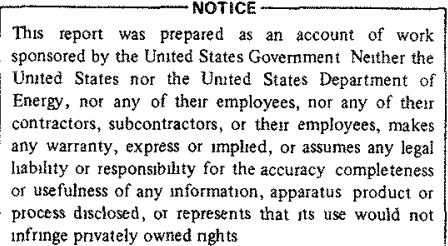

process disclosed, or represents that its use would not

infringe privately owned tights 


\section{CONTENTS}

Page

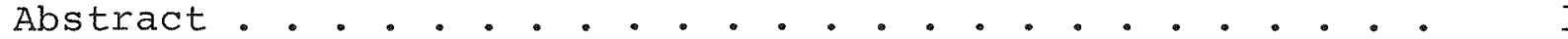

Introduction . . . . . . . . . . . . . . . . . . . . . . . 1

Purpose of investigation . . . . . . . . . . . . . . . 2

Theoretical concepts . . . . . . . . . . . . . . . . 3

Radiometric anomalies . . . . . . . . . . . . . . 3

Hydrocarbon anomalies . • . . . . . . . . . . . . 4

The geochemical significance . . . . . . . . . . . 4

Experimental apparatus and procedures . . . . . . . . . 5

Drilling apparatus . . . . . . . . . . . . . 5

Description . . . . . . . . . . . . . . 5

Sampling technique . . . . . . . . . . . . 5

Radiation measurement equipment . . . . . . . . . 6

Description of apparatus . . . . . . . . 6

Calibration . . . . . . . . . . . . . 7

Measurement techniques . . . . . . . . . . 9

Soil gas analysis . . . . . . . . . . . . . . . . 10

Description of apparatus . . . . . . . . . 10

Analysis procedure . . . . . . . . . . . . 11

Additional soil analysis apparatus . . . . . . . . . 11

Surface area equipment . . . . . . . . . . . 11

Conductivity equipment . . . . . . . . . . . 13

pH meter..................... . 13

Moisture measurement equipment . . . . . . . 14

Data processing equipment . . . . . . . . . . . . 14

Equipment description ............ . 14

Software description . . . . . . . . . . 15

Correction techniques . . . . . . . . . 16

Presentations ............... 17

Results and discussion . . . . . . . . . . . . . 18

General procedures . . . . . . . . . . . . 18

Soil gas analysis .............. 18

Radiometrics................. . . 18

Field Surveys . • • • • . • • . • • • • • • • . 22

Prerequisites . . . . . . . . . . . . 22

Sutherland area... . . . . . . . . . . . . 24

Geological description . . . . . . . . . . 24

Soil analysis . . . . . . . . . . . . . 25

Radiation survey . . . . . . . . . . . . 34

Additional investigative procedures . . . . . 40

Magnetic survey . . . . . . . . . . 40

Gravity survey ........... . . 47

Aerial hydrocarbon survey ...... . . 47

Cup survey . •. . . . . • . . • . 52

Deep soil tests . . . . . . . . . . . 53

Survey cross-comparison and analysis..... . 57

Additional survey area . . . . . . . . . . . 64 


\section{CONTENTS-Continued}

$\underline{\text { Page }}$

Rosalia field............. . . 64

Haskell area. . . . . . . . . . . . . 67

Survey cross-comparison and analysis - Haskeli . . . 78

Sutherland - Haskell area comparisons. . . . . . 78

Conclusions . . . . . . . . . . . . . . . . . . 80

Recommendations . . . . . . . . . . . . . . . 81

Acknowledgements. . . . . . . . . . . . . . . . . 82

References. . . . . . . . . . • • . • . . . . 83

\section{ILLUSTRATIONS}

\section{Figure}

1. Photograph of soil sample drilling equipment : . .

2. Photograph of survey truck with radiation equipment.

3. Pulge-height distribytion for gamma-ray spectrum of

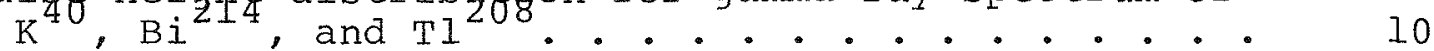

4. Soil gas extraction apparatus . . . . . . . . . . 10

5. Apparatus for determining surface area . . . . . . 12

6. Minicomputer with associated peripherals for processing geochemical data... . . . . . . . . I4

7. Gas sample sites in Sutherland . . . . . . . . . 19

8. Continuous strip chart radiation measurements from moving vehicle..... . . . . . . . . . . 21

9. Radiation sample sites in Sutherland. . . . . . . . 23

10. Survey areas of Rosalia and Sutherland in Kansas,
and Haskell in Oklahoma . . . . . . . . . . . 24

11. Frequency histogram of methane in sutherland. . . . 26

12. Contour map of methane in sutherland . . . . . . . 27

13. Contour map of ethane in sutherland . . . . . . . 28

14. Contour map of propane in Sutherland . . . . . . . . 29

15. Contour map of isobutane in sutherland . . . . . . . 30

16. Contour map of normal butane in Sutherland. . . . . 31

17. Frequency histogram of ethylene in sutherland . . . 32

18. Surface area contours in sutherland . . . . . . . 33

19. Moisture contours in Sutherland . . . . . . . . . 35

20. $\mathrm{pH}$ contours in Sutherland . . . . . . . . . . 36

21. Conductivity contours insfutherland . . . . . . . . 37

22. Frequency histogram of $k^{40}$ in sutherland . . . . . 38

23. Contour map of $\mathrm{K}^{4}$ in Sutherland . . . . . . . . . . 39

24. Frequency histogram of $\mathrm{Bi}^{214}$ in sutherland . . . . . 41

25. Contour map of $\mathrm{Bi}^{214}$ in Sytherland. . . . . . . . 42

26. Frequency histogram of $\mathrm{Tl}$ in Sutherland.... . . 43

27. Contour map of Tl $\mathrm{Tl}^{208}$ in Sutherland... . . . . . . 44

28. Total field magnetic contour map of Sutherland. . . 46 


\section{ILLUSTRATIONS-Continued}

$\underline{\text { Page }}$

29. First-order residual magnetic contour map of Sutherland.................. . . . 48

30. Bouguer gravity map of sutherland area. . . . . . . 49

31. Fifth-order residual gravity map of Sutherland. . . 50

32. Free hydrocarbon gas survey of Sutherland . . . . . 51

33. Methane gas contents of drill cuttings from four deep wells in Sutherland . . . . . . . . . 56

34. Topographic contour map of Sutherland area . . . . . 57

35. Three-dimensional topographic projection of Sutherland area .................. . . . 58

36. Three-dimensional display of hydrocarbon gas . . . 59

37. Three-dimensional projection of conductivity . . . . 59

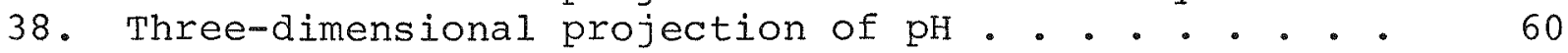

39. Correlation cloud cross-plot of log propane to log ethane..................... 61

40. Correlation cloud cross-plot of log ethane to log methane .................... 62

41. Cluster cloud cross-piot of moisture with surface area ................... . . 63

42. Cluster cloud cross-plot of normal butane to potassium-40.................. ... 64

43. Cluster cloud cross-plot of $\mathrm{C}_{2}-\mathrm{C}_{4}$ gases to $\mathrm{pH}$. . . . $\quad 65$

44. Cluster cloud cross-plot of log surface area to log

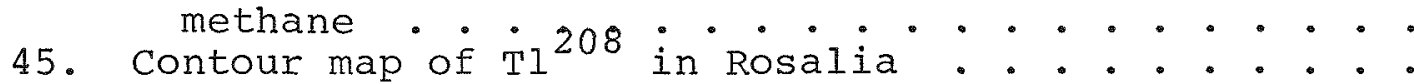

46. Contour map of airborne magnetic readings over Rosalia . . . . . . . . . . . . . . 69

47. Three-dimensional image of Rosalia magnetic data . . 70

48. Contour map of $\mathrm{K}^{4}$ in Haskell . . . . . . . . . . 72

49. Contour map of $\mathrm{Bi}_{208}^{214}$ in Haskel1. . . . . . . . . . . 73

50. Contour map of T1 208 in Haskel1. . . . . . . . . . . . 74

51. Contour map of methane in Haskell. . . . . . . . . . 75

52. Frequency histogram of methane in Haskell. . . . . . 76

\section{TABLES}

1. Electronic equipment list description . . . . . . . 8

2. Calibration energy levels . . . . . . . . . . . 9

3. Comparison of methane and n-butane contents with depth ..................... 20

4. Comparison of surface radiation to subsurface soil sample activity . . . . . . . . . . . . . 45

5. Summary of Sutherland and Haskell data . . . . . 79 


\title{
A CRITICAL LABORATORY AND FIELD EVALUATION OF SELECTED SURFACE PROSPECTING TECHNIQUES FOR LOCATING OIL AND NATURAL GAS
}

\author{
by
}

R. J. Heemstral, R. M. Ray ${ }^{2}$, T. C. Wesson
J.R. Abrams

\begin{abstract}
The theoretical basis for the "HALO" method in geochemical exploration for oil and gas is largely unproven but has been covered extensively in the literature. An evaluation of the method was conducted by direct field examination of some of the variables. The variables chosen were surface radiometry, magnetometry, gravity, and near-surface soil sampling. The radiometry included measurements of potassium-40, thallium-208, and bismuth214. The near-surface soil samples were analyzed for light hydrocarbon gases through $\mathrm{C}-4$, $\mathrm{pH}$, conductivity, surface area, and moisture.

Statistical evaluation and comparisons of these variables were made by computer from their data bases. High correlations between variables were confirmed by comparisons of contour maps on transparent overlays. The highest positive correlations were between the five normal gases over the entire eighteen-section map. A distinct relationship was found between conductivity, $\mathrm{pH}$, and the five normal gases. The role of field topography was also found to be significant. No relationship between the hydrocarbon and radiometric anomalies could be found. Radiometric patterns were heavily influenced, however, by the topographic features.

\section{INTRODUCTION}

The history of geochemical exploration includes many outstanding personalities, such as Laubmeyer of Germany, Aleksev of Russia, and Ludwig Blau of the United States. Many more who have written extensively on the subject are listed in a variety of bibliographies and reports. Work by a multitude of investigators shows the study of radiation anomalies and their possible relationships to any other geochemical patterns or lithographic structures is a very complex and illusive undertaking.
\end{abstract}

\footnotetext{
1 Acting Project Leader

2 Research Physicist

3 Project Manager

4 Electronics Technician

5 Geologist
} 
Project Halo began several years ago to seek the alleged significance of gamma radiation halos often observed above hydrocarbon deposits. Initially the projects' primary aim was to gather published information concerning the phenomenon 6 The result was the publication of a review of 237 papers (I).

Response generated by the publication led to field experimental work. Site selections had to be made, surface access permits obtained, ground vehicles, radiation detection equipment, and sophisticated laboratory equipment procured, and an airborne gamma-ray survey contracted. The goal was to attempt the correlation of radiation data with other geochemical data, including soil gas.

The development of an effective method of exploration for petroleum and natural gas with particular emphasis upon economy and directness of method is of primary importance. At first, research centered upon correlating gamma-ray surveys with the occurrence of hydrocarbons. Evidence obtained during the course of that investigation indicated surface perturbations greatly affected the radiation background in the field. The presence of light paraffin hydrocarbons absorbed on surface soils was studied next to determine their influence on the naturally occurring radioactive elements at the surface.

The possibility existed that a reducing environment created by the adsorbed hydrocarbons tended to solubilize salts of the radioactive elements from the uranium and thorium series. Then surface and subsurface water theoretically could transport these elements to areas or interfaces where a more oxidizing situation existed. Normally this interface is present at the edges of the field, where redeposition of the radioactive elements should occur, thus creating a "halo" effect. Upon this less conventional exploration method for petroleum, a coordinated study was begun involving measurements of gamma radiation intensity, light hydrocarbons, surface area, conductivity, $\mathrm{pH}$, and moisture in soil samples taken from the near surface of selected fields. In addition, the data on topography, well log information, aerial photography, multi-level magnetic surveys and gravity surveys needed to be collected and applied.

\section{PURPOSE OF INVESTIGATION}

The purpose of Project Halo is to determine the source and significance of the radiation halo often observed above hydrocarbon deposits. The postulate was made that the adsorptiondesorption isotherm of the naturally occurring radioactive ions

6 Underlined numbers in parentheses refer to items in the list of references. 
is influenced by the presence or absence of hydrocarbon gases. In conjunction with this, the presence of other geochemical anomalies and their relationships to the radiation halo become very important.

To determine the status of radiometrics as a method for petroleum exploration, some very important questions must be asked. First of all, does the radiation "halo" actually exist? Does a real phenomenon of this kind associate with any known petroleum production? Then, if such an anomalous pattern is detected, how reliable is the geochemical abnormality for exploration purposes?

The areal extent of known petroleum reservoirs are said to be log-normally distributed (4). Thus, the largest number of reservoirs yet to be found must be classified as small fields and only the most economic of exploration methods could be used to find them. Both the radiometric and the gasometric (hydrocarbon) surveys could be such methods.

\section{THEORETICAL CONCEPTS}

\section{Radiometric Anomalies}

Today's theories explaining causative relationships between anomalous gamma-radiation fields or other geochemical anomalies such as near-surface hydrocarbons and subsurface petroleum reservoirs are still as vague and unsubstantiated as they were when an earlier literature survey was made (I).

The theoretical concepts essential to justification of the radiometric method of surface prospecting for petroleum are limited to only a few. First, a significant association exists between heavy metals, including uranium, and petroleum hydrocarbons. Second, these elements tend to accumulate at the first reducing contact zone between an aqueous phase and any hydrocarbon deposit which the slow-moving ground water reaches. Third, the steady vertical movement of water of compaction carries radium-226, the radioactive daughter of uranium, and other water-soluble components to the surface. Any radium arriving at the surface from such a low strata source overlain by one of low permeability would be controlled by the areal extent of the low permeability, ground water movement, and formation fractures. The migration of radon from the surface is influenced by the radium source concentration, the source depth, the subsurface permeability, the daily variations in barometric pressure, the soil moisture content, and the subsurface temperatures. 


\section{Hydrocarbon Anomalies}

The containment of oil and gas deep in the earth is a dynamic process. Petroleum, whether in the form of an aqueous solution, in a colloidal state, or in a separate phase, migrates through permeable rocks during a continuous state of compaction, following the path of least resistance. Accumulations of petroleum occur when various barriers are encountered to both horizontal and upward movement. According to many geochemical theoreticians, the process of compaction is the driving force responsible for the upward movement of anomalous hydrocarbons identifying the leakage patterns from deeply buried petroleum reservoirs $(\underline{6}, \underline{13}, \underline{18)}$.

The fundamental concepts necessary to understand the presence of hydrocarbon anomalies in the vicinity of oil and gas deposits are also based on vertical fluid expulsion from the reservoir formation. One theory states that fluids and gases escaping to the surface with the ground water movement stay directly over the reservoir (8); while other theories provide a system of fracture patterns directing the hydrocarbons to the periphery of the reservoir $(15,17)$. Many theories consider the direct presence of hydrocarbons below the surface of the earth to be responsible for the presence of radioactive anomalies at the surface.

Some authors hold little hope for the hydrocarbon method of surface prospecting on land, unless residual soils and nearsurface hydrology is known (9).

\section{The Geochemical Significance}

In any geochemical investigation, whether the variable is radiometric, hydrocarbon, or soil pH, the question concerning the recognition of anomalous observed values must be answered. What is an anomaly? How do we know the data have anomalous values? These questions have been addressed by Rose by using the concept of normal or log-normal distributions and by establishing upper limits to the background population (14). A technique must be established for easily determining which values are anomalous and which are background. Is the anomaly higher or lower than the average?

The specter of false anomalies arising from the more simple procedure of uniform depth sampling is recognized by Levinson (9). Since all of our soil samples were collected at uniform depths, they were therefore not necessarily from the same horizon. It should be noted, however, that preliminary soil gas profiles appeared to be independent of depth down to at least the 13 foot level. For this reason a sample depth of nine feet was chosen as a compromise between the shallow vegetation level and the deep time-consuming level. 
There is no shortage of theoretical explanations proposed for the surface prospecting methods of radiometry and gasometry. The literature reveals many worthy theories of the relationship of oil and gas accumulations to a particular geochemical anomaly $(1,2)$. Some theories appear contradictory--for example, a radioactive high and a radioactive low observed over the center of the same oil field by different observers was each explained by theory $(15,8)$. As it turned out, the differences were likely due to soil corrections.

Generally speaking, radioactivity lows form over petroleum deposits during the period of formation development and probably indicate primary accumulations. These lows can remain even after the oil accumulation has migrated.

Where lack of ground cover permitted, some researchers found aerial photographic justification for radioactive anomalies in terms of geologic structures (3). However, daily variations and changes with humidity were also observed.

\title{
EXPERIMENTAL APPARATUS AND PROCEDURES
}

\author{
Drilling Apparatus
}

Description:

Equipment used to collect soil samples consists of a mobile drill and truck, shown in figure 1. The drill is a model B-30s Mobile Drill manufactured by Mobile Drilling Company, Incorporated, and is a trailer-mounted, hydraulically operated auger drill. This equipment is rated to drill up to a 100-foot hole with a 3.5-inch auger and uses five-foot auger sections with a 3.5-inch mining bit which permits drilling in rock as well as clay. The bit has two replaceable tungsten-carbide inserts which are used for the cutting surfaces of the bit.

Sampling Technique:

The sampling technique was designed to allow collection of noncontaminated soil samples from predetermined sampling sites. Topographic maps and enlarged aerial photos were used with a plastic overlay on which were marked the actual sampling site in the field. This allowed placement of the drill within a few feet on the intended sample site. After drilling to eight feet the drill string was pulled, the hole covered, and the complete drill string cleaned of all cuttings. The drill string was then

7 The names of manufacturers and their tradenames are used for clarity only and are not endorsements by the government. 


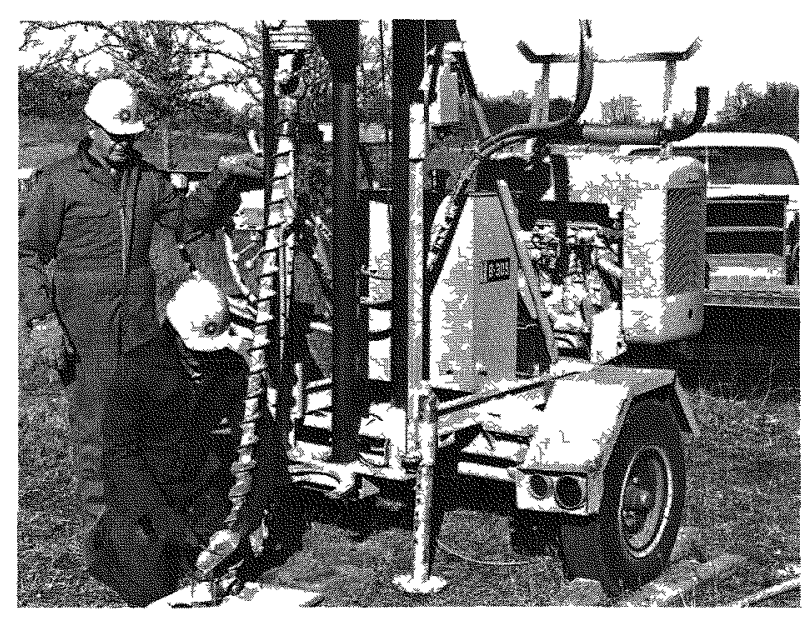

FIGURE 1. - Photograph of soil sample drilling equipment.

reinserted into the hole, and the hole drilled to nine feet. At nine-feet, the drill string was again removed from the hole. A sample (100-150 gram) was taken from the last auger section from six-inches above the bit to the bit. The sample was placed in a sample jar, sealed, and stored in an inverted position until analysis. The hole was then filled with cuttings to an original state.

Radiation Measurement Equipment

The radiation-measurement equipment was installed in a truck, and a series of calibration tests were performed. After calibration, the equipment was field tested to ensure it would operate as desired under the harsh conditions found in the field.

Description of Apparatus

The radiation-measuring instruments are mounted in a GMC "Jimmy" truck equipped with automatic transmission, transfer case, four-wheel drive, electric winch, and oversized tires and wheels. Special bumpers were made and installed to permit mounting a 2500-watt ONAN generator on the front bumper to provide 115-volt a.c. power to the electronic instruments. A measuring wheel was attached to the rear bumper. A steel plate was installed below the gasoline tank for protection.

The transfer case, operating in low gear, permitted travel at a low rate of speed over varying conditions of terrain with ample power to negotiate steep slopes and gullies.

The radiation detector is made up of an 11.5-inch diameter, 4-inch-thick, thallium-activated, sodium iodide crystal which has seven photomultiplier tubes attached. Gamma ray energy detected by the crystal is amplified and sorted by six singlechannel analyzers. The windows of the individul anglyzerfore

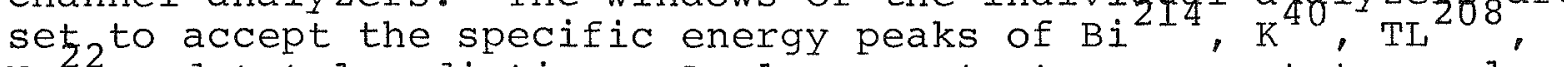
$\mathrm{Na}^{22}$ and total radiation. Analyzer outputs are sent to scalers for counting and to rate meters so that a strip-chart can be produced. The six scalers are interfaced to a teletype, and, at the end of the measurement period, each count associated with the individual analyzer is printed on paper and is also punched on a paper tape. The punched tape is used to input the data into the computer for data analysis and interpretation. 


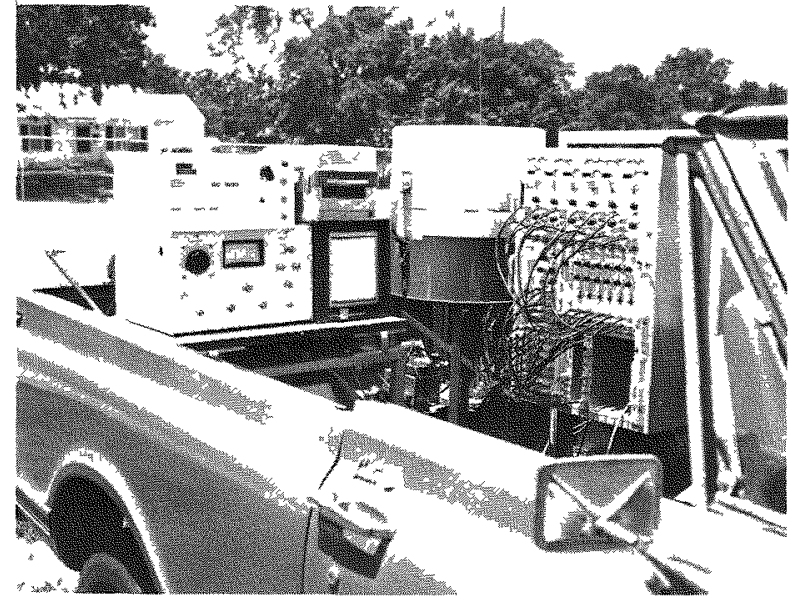

FIGURE 2. - Photograph of survey truck with radiation equipment.
Table 1 lists electronic components making up the radiation-measurement equipment. They are mounted in a rack (see figure 2) which is shock-mounted to the floor of the truck behind the driver's seat. The detector is shock-mounted, in a thermal shield, on an elevated base in the rear of the truck. A twolevel table, mounted adjacent to the detector, provides room for the teletype and stripchart recorder.

\section{Calibration:}

The six single-channel analyzers were individually calibrated by using a computerized pulse-height analyzer. The detector assembly was exposed to small sources of uranium, thorium, and potassium while the pulse-height analyzer was connected to the detector output. The peaks of interest were identified and, by using the precision pulser, the window widths of the single-channel analyzers were adjusted to measure a narrow band of gamma energies centered on the peak of interest. Table 2 lists the peaks of interest, the gamma energy of each daughter element, and the range of energies measured for each analyzer's window setting.

The detection of potassium is made through the $1.46 \mathrm{MeV}$ gamma radiation peak of potassium-40. The presence of uranium and thorium is measured from the $1.76 \mathrm{MeV}$ peak of bismuth-214 and the 2.6I Mev peak of thallium-208, respectively. A small sodium source was used to monitor the gain of the spegtrometer. The analyzer, calibrated for the $1.28 \mathrm{Mev}$ peak of $\mathrm{Na} 2( \pm 230$ source. The amplifier gain was adjusted to keep the $1.28 \mathrm{MeV}$ peak centered in the window.

No method was initially available to measure possible interference effects of elements other than the elements of interest. In June of 1977, the Office of the Energy Research and Development Administration, Grand Junction, Colorado, allowed the use of their spectrometer calibration facility to calibrate the radiation detection equipment. The facility consists of five pads with known concentrations of potassium, uranium, and thorium. After measuring each pad, a complete analysis of the data was performed and a set agreement of proportionality constants was determined for the detection assembly. These constants, when applied to the raw data measured in field surveys, are used to calculate the amount of potassium, uranium, and 
TABLE 1. - ELECTRONIC EQUIPMENT LIST DESCRIPTION

\begin{tabular}{|c|c|c|c|}
\hline $\begin{array}{l}\text { NO. } \\
\text { USED }\end{array}$ & $\begin{array}{l}\text { MODEL } \\
\text { NO. }\end{array}$ & MANUFACTURER & DESCRIPTION \\
\hline 1 & - & Bicron & $\begin{array}{l}\text { Thallium-activated, sodium } \\
\text { iodide detector crystal }\end{array}$ \\
\hline 1 & TC 940 & Tennelec & $\begin{array}{l}\text { Variable, high-voltage } \\
\text { power supply }\end{array}$ \\
\hline 1 & $\mathrm{TC} 145$ & Tennelec & Scintillation preamplifier \\
\hline 1 & TC 202BLR & Tennelec & Linear amplifier \\
\hline 3 & TB 3 & Tennelec & NIM-BIN's \\
\hline 3 & TC 966 & Tennelec & Power supplies \\
\hline 6 & $\mathrm{TC} \quad 441$ & Tennelec & Single-channel analyzers \\
\hline 6 & TC $546 \mathrm{P}$ & Tennelec & $20 \mathrm{MHz}$ scalers \\
\hline 6 & TC 590 & Tennelec & Precision ratemeters \\
\hline 1 & TC 541 & Tennelec & Timer \\
\hline 1 & TC $560 \mathrm{~A}$ & Tennelec & Precision Timebase \\
\hline 1 & TC 570 & Tennelec & $\begin{array}{l}\text { Automatic recycle control } \\
\text { and teletype interface }\end{array}$ \\
\hline 1 & TC 812 & Tennelec & Precision pulser \\
\hline 1 & $E U-205-11$ & Heath/Schlumberger & Strip-chart recorder \\
\hline 1 & $E U-200-01$ & Heath/Schlumberger & Potentiometric amplifier \\
\hline 1 & ASR -33 & Teletype, Corp. & Teletype \\
\hline 1 & - & BETC & $\begin{array}{l}\text { Preset counter (for } \\
\text { measuring wheel). }\end{array}$ \\
\hline
\end{tabular}


TABLE 2. - CALIBRATION ENERGY LEVELS

\begin{tabular}{lcc}
\hline $\begin{array}{c}\text { Radiation } \\
\text { Element }\end{array}$ & $\begin{array}{c}\text { Gamma } \\
\text { Energy } \\
\text { (Mev) }\end{array}$ & Window Width, energy \\
in Mev \\
\hline $\begin{array}{l}\text { Total Radiation } \\
\mathrm{Bi}^{214}\end{array}$ & - & $0.45 \mathrm{Mev}$ to $3.02 \mathrm{Mev}$ \\
$\mathrm{K}^{40}$ & 1.12 & $1.06 \mathrm{Mev}$ to $1.25 \mathrm{Mev}$ \\
$\mathrm{Bi}^{214}$ & 1.46 & $1.32 \mathrm{Mev}$ to $1.62 \mathrm{Mev}$ \\
$\mathrm{TI}^{208}$ & 1.76 & $1.62 \mathrm{Mev}$ to $2.04 \mathrm{Mev}$ \\
$\mathrm{Na}^{22}$ & 2.61 & $2.39 \mathrm{Mev}$ to $3.02 \mathrm{Mev}$ \\
\hline
\end{tabular}

thorium actually measured. Using this approach, all positive interference effects were neutralized. The analyzer used for the total radiation count was adjusted to discriminate against low energy, noise pulses only. Figure 3 shows the computerized pulse-height analyzer output with markers for peak identification.

Measurement techniques

The first radiation survey was conducted in Butler County, Kansas, and the method of data collection differed somewhat from the second survey taken in Greenwood County, Kansas.

In the Butler County survey a continuous scan of the surface was made. Each 2 minute count covered an $1 / 8$ mile segment of the surface. The segments were numbered and the direction of travel noted so that the information could be related to a map or grid of the area.

In Greenwood County, the truck was simply driven to the sample site, and a 2 minute stationary count was made. Sample points were identified by the section number and the grid number.

A readily accessible sample point was selected to use as a control and was counted at the start and end of each day. These data were used to show effects of weather, soil condition, and diurnal variation on the radiation pattern. 


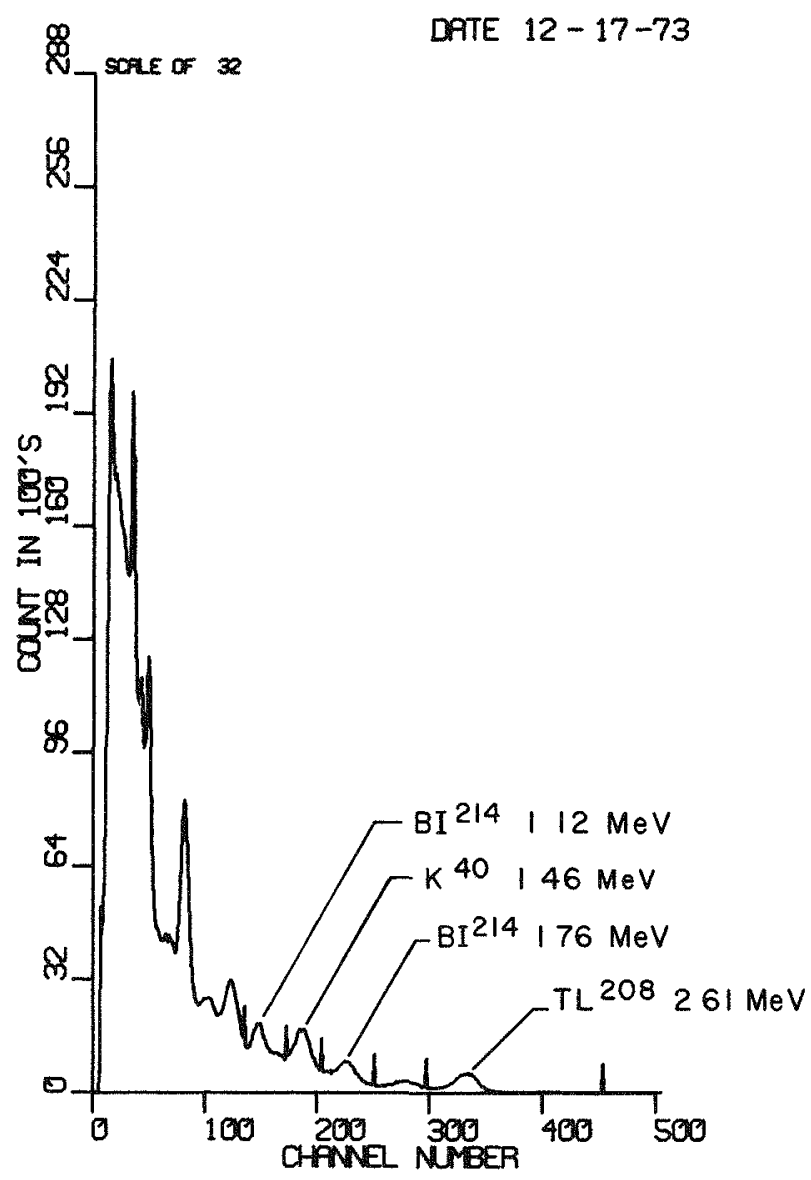

FIGURE 3. - Pulse-height distribution $\frac{f}{4} 8^{r}$ gamma-ray spegtrum of $\mathrm{K}^{41}, \mathrm{Bi}^{214}$, and

column which is maintained at $30^{\circ} \mathrm{C}$ and packed with 80-100 mesh Durapak (phenylisocyanate on Porasil C) and are measured by the flame ionization detectors.

The analog output from the gas chromatograph is processed through a model $3380 \mathrm{~A}$ HewlettPackard reporting integrator. The integrator contains over 5,000 preprogrammed instructions and word selects in 20 ROM (read-only-memory) chips which contain all necessary routines for all data evaluation
Soil Gas Analysis

Description of Apparatus

The soil gas/extraction apparatus has been described in detail (19). Briefly, an allglass system composed of a reaction flask, cold-water condenser, $\mathrm{CO}_{2}$ scrubber flask, collector bottle, mercury manometer, glass tubing and valves is used to extract the adsorbed hydrocarbon gases from the soil. Figure 4 shows a schematic diagram of the sysstem. The extracted gases are concentrated in the collector bottle by flooding the entire apparatus (except the collector) with deionized water.

After extraction and collection the sample gas is injected into a model $5711 \mathrm{~A}$ Hewlett-Packard, dual-flame chromatograph. The components of the sample gas are separated on a 6-foot by 3/16-inch teflon

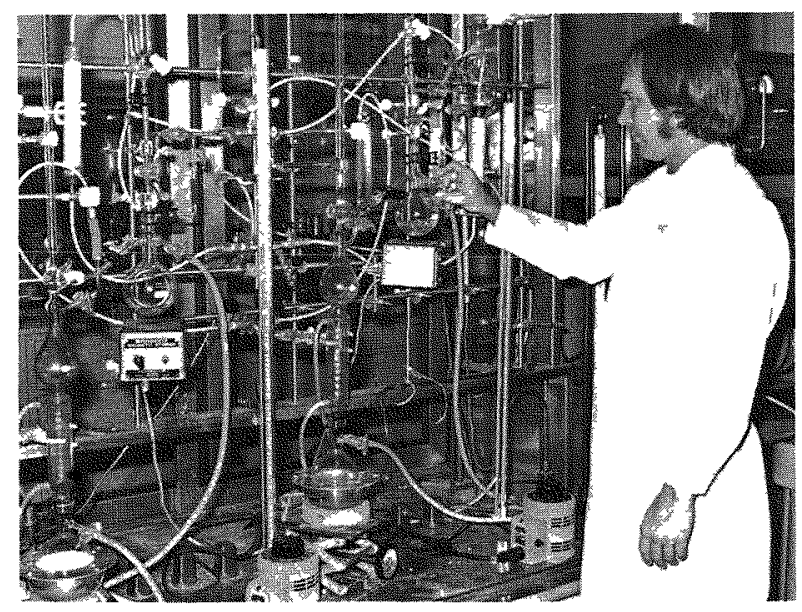

FIGURE 4. - Soil gas extraction apparatus. 
capabilities (i.e. integration, data reduction; calibration, etc.) and data presentations. This, in conjunction with 16 RAM (random-access-memory) chips, allows the operator to calibrate the chromatograph equipment to output the concentrations of the peaks of interest.

Calibration of the chromatograph output was performed by injecting a 6-component hydrocarbon-in-air blend into the chromatograph. The output for each gas component was integrated and automatically stored. The retention times and single-component concentrations $(1.0 \mathrm{ppm})$ were input to the integrator with the integrator in its calibration mode. Thus the chromatographic system was calibrated and the output was reported in ppm by volumes for each gas of interest.

Analysis Procedure

The routine laboratory analysis of soil samples was relatively simple and dependable. A raw soil sample of about 50 grams was placed in the extraction flask and the flask was sealed in the extraction apparatus. Fifty milliliters of potassium hydroxide (50 percent solution) was poured into the $\mathrm{CO}_{2}$ scrubber flask. The apparatus was evacuated, purged with filtered air, and re-evacuated. Filtered air was then bled into the apparatus until an absolute pressure of 60 torr was measured. Seventy-five milliliters of $2 \mathrm{~N}$ hydrochloric acid was then added to the soil in the extraction flask, and the acid-soil mixture was boiled for 30 minutes. The heating source was then removed, and hydrocarbonfree, deionized water was used to flood the apparatus up to the input value of the collector. The gollector valve was then shut and the collector removed. A $10-\mathrm{cm}^{3}$ sample of gas was removed by syringe from the collector and injected into the chromatograph. Prior to the first sample injection, the chromatographic system was calibrated with the 6-component hydrocarbon in air blend.

\section{Additional Soil Analysis Apparatus}

Surface-Area Equipment

The instrument used to measure surface areas of unconsolidated soil samples has been described in detail (12). Briefly, the instrument consists of three general assemblies: a pre-test conditioning assembly, a flow system, and a data-recording assembly. These assemblies represent an assembly-line approach of rapid movement through a test cycle.

The pre-test conditioning assembly prepares the samples for testing. The samples are heated to remove water and then cooled to room temperature before testing. During preconditioning and at all stages of testing, dry, filtered helium flows continuously through the sample. After cooling, the test sample is inserted 
into the flow system assembly.

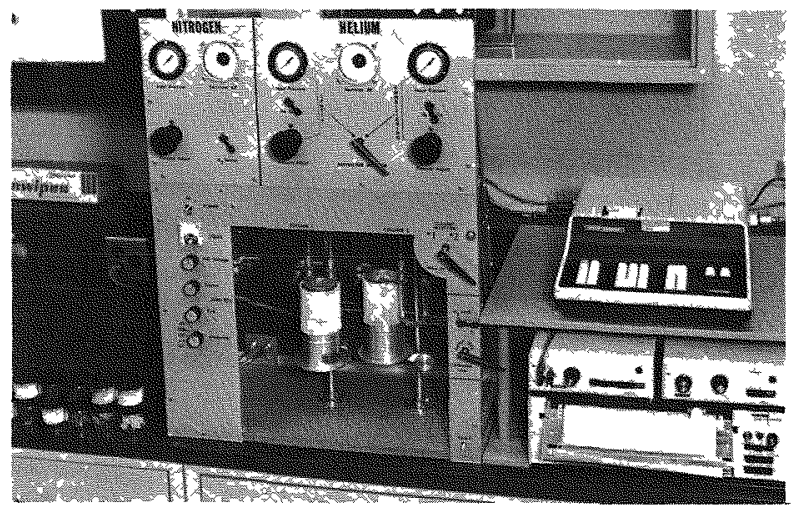

FIGURE 5. - Apparatus for determining surface area.
The flow system is designed to dynamically produce accurate, stable flows of $\mathrm{He}$ and $\mathrm{N}_{2}$ for conditioning and test purposes. The flow system, shown in figure 5, produces three precisely measured flows of gases, two of He and one of $\mathrm{N}_{2}$. On the test side, $\mathrm{N}_{2}$ is mixed with $\mathrm{He}$ and the combination passed through the sample to the detector. Until the sample is tested, the conditioned state of the sample is maintained by a flow of $\mathrm{HE}$ from the assembly.

The gas measurement and recording assembly consists of a thermal-conductivity chromatograph, an integrator, and a recorder. The amount of $\mathrm{N}_{2}$ adsorbed and desorbed is detected by the chromatograph. The chromatograph output signal is integrated and monjtored on the recorder. This combination of output produces a permanent record of the test and simplifies data analysis and processing.

For an analysis, a sample is put in a preweighed, glass sample-cell. The sample cell is inserted in a three-position manifold and placed inside an oven at $100^{\circ} \mathrm{C}$ for 30 minutes. The manifold is then removed from the oven and inserted in a helium source to cool. Both during the heating and cooling conditions, the sample is purged by dry, filtered, tank helium at about 30 $\mathrm{cm}^{3}$ per minute. After cooling, the sample cell is sealed and weighed for determination of net sample weight. The sample cell is then inserted in the flow system where an additional 15 minutes of conditioning with He at $30 \mathrm{~cm}$ per minute is performed. During this time the sample $\mathrm{N}_{2}$ / He gas flows have been set and the chromatograph baseline has stabilized. The sample gas is then diverted to flow through the sample being tested. About $3 \mathrm{~min}$ utes after observing a stable baseline on the recorder, the sample (in the sample cell) is submerged into liquid $\mathrm{N}_{2}$ at which time $\mathrm{N}_{2}$ from the sample gas is adsorbed on the sample surface. Three minutes after the recorder baseline returns to normal, the liquid $\mathrm{N}_{2}$ is removed, and, simultaneously, the start button of the integrator is depressed. As the sample warms up, $N_{2}$ is desorbed from the sample surface and is measured by the thermal conductivity detector. The detector output is recorded and integrated. Immediately after the desorption peak is completed, the calibration valve is rotated so the sample gas is flowed 3 through the calibration loop which in turn, pushes a $4.96 \mathrm{~cm}^{3}$ 
plug of pure $\mathrm{N}_{2}$ to the detector for measurement, recording, and integration. By comparing the calibration and test $\mathrm{N}_{2}$ peaks (integrated counts), the operator can readily determine the amount of $\mathrm{N}_{2}$ desorbed.

At the start of the test procedure, a second sample cell is inserted in the flow system in the conditioning section. At the completion of testing one sample at one $\mathrm{N}_{2}$ :He ratio of sample gas, the sample selector valve is rotated which interchanges the conditioning and sample flows so the sample tested is now in the conditioning section and the conditioned sample is in the test section of the flow system. Testing is routinely performed at two $\mathrm{N}_{2}$ :He ratios for each sample. After a sample is tested at both $\mathbb{N}_{2}$ levels, it is replaced with a new sample.

\section{Conductivity Equipment}

Conductivity measurements were performed using a model RC16B2 Conductivity Bridge made by Industrial Instruments, Incorporated. The unit was set up, tested for routine operational parameters, and used to routinely measure the conductivity of the soil samples.

The procedure used was determined experimentally. A soilto-water extraction ratio of $1: 240$ was used for all measurements. One gram of dried, powdered soil was placed in a 250-milliliter flask. About 40 milliliters of deionized water was added to the flask and the contents were mixed for 10 seconds. The rest of the water (200 miliiliters) was then added and the flask contents mixed thoroughly. After mixing, the flask and contents were set aside for 3 minutes to allow the suspended soil particles in the solution to settle. The conductivity of the solution was then measured by immersing the probe into the solution.

pH Meter

The pH meter used was a model 701 digital pH meter manufactured by Orion Research. The electrode was a model 07-01-10 ATC probe. This unit had a reported range of 0.00 to $13.99 \mathrm{pH}$ with $0.01 \mathrm{pH}$ precision and \pm 1 LSD (least significant digit) accuracy.

The $\mathrm{pH}$ of the soil samples was measured immediately after the conductivity measurements. Thus, the soil:water extraction ratio was $1: 240$ as used for conductivity tests. Usually, 2 minutes after immersing the $\mathrm{pH}$ probe in the soil-water solution, the $\mathrm{pH}$ was measured. If the solution was clouded by suspended soil particles, erratic readings occurred. The procedure then was to set the solution aside until the particles settled out or the solution was centrifuged to quickly separate the solution so reliable readings could be taken. 
Moisture Measurement Equipment

Moisture of the samples was determined by a simple method and reported as moisture weight percent (MWP). About 50 grams of raw field-sample was weighed and put in a drying dish. The sample was then heated for 24 hours at $110^{\circ} \mathrm{C}$ to thoroughly dry the sample. The sample was then weighed. The difference in weights, wet and dry, as compared to the raw weight and expressed as a percentage, is the MWP. The specific equipment used was a model OV-520C-2 Constant Temperature Cabinet manufactured by BIue M Electric Company and a model Pl000N balance manufactured by Mettler Instrument Corporation.

\section{Data Processing Equipment}

Equipment Description

The selection of the data processing system for the geochemical survey work was based on the availability of a Pulse Height Analyzer that had been used in Neutron Activiation Analsis, the heart of which is a Digital Equipment Corporation (DEC) PDP8/I, 8K central processing unit. The PDP8/I is a highly sophisticated minicomputer capable of performing many useful tasks at high speed.

To use the PDP8/I capability, additional peripheral hardware was incorporated into the system and is shown in figure 6 . The added peripheral features are:
a.
A $24 \mathrm{~K}$ add-on core memory
b. A data channel multi- plexer
c. A disk drive
d. A magnetic tape
e. A line printer
f. An incremental plotter
g. A graphics terminal and digitizing tablet.

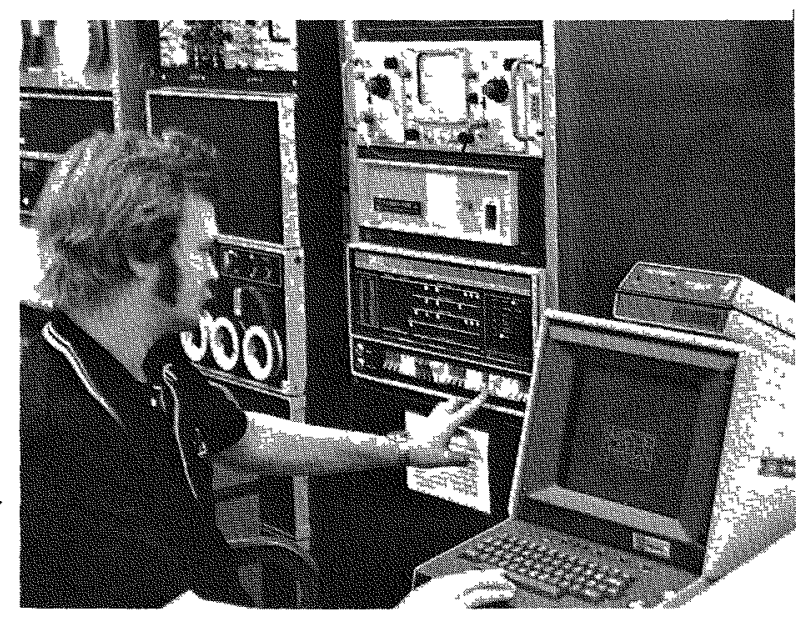

FIGURE 6. - Minicomputer with associated peripherals for processing geochemical data. 
The major features in the hardware configuration are named and described in the following list.

CPU - DEC PDP8/I, a one-address, 12-bit, fixed-word-length, parallel computer with $8 \mathrm{~K}$ memory which utilizes a MC8/IA memory extension control, KE8/I EAE automatic multiply/divide option, and the KA8/IB positive bus option as added options.

Add-On Memory - Fabri-tek Model 8/I 24K core memory

Mux - DEC DM04 data channel multiplexer

Disk - Systems Industries Model 4500 Disk System with Diablo Model 44 moving-head disk drive. This system contains two disks, one removable and one fixed, for a total storage of $6,684,672$ words. Each disk system is divided into 4-addressable disks such that the fixed disk contains disks 0 through 3 and the removable disk contains disks 4 through 7 .

Mag tape - DEC TU56 dual transport and TC08 control, which offers a 2.7-million-bit information capacity per tape reel.

Line printer - Odec Model 2423, chain-type, impact printer, with 132 column output.

Plotter - Houston Complot, digital incremental (0.01 inch) plotter.

Graphics - Tektronix Model 4010 CRT terminal and Model 4954 tablet.

Software Description

The software programs used to collect, store, and interpret the geochemical data obtained from field samples and field instrumentation were compiled using DEC's version of fortran II (FORT) and fortran IV, supported on an OS/8 V3D software operating system.

A universal file system was developed in which the collected field data could be stored; edited; graphed as histograms, location maps, and correlation clouds; contoured; listed; and projected as three-dimension models. These stored-data files included gamma radiation, soil gas, soil moisture, soil conductivity, soil $\mathrm{pH}$, and soil surface area and are filed into universal data files. This means that the structure of the files are self-describing for the purpose mentioned above. These data files may be summed from multiple input files or a file made of the ratios of one 
file to another file. Correlations may be also made of one file to another. A detailed description of both the hardware and the software configurations and the specialized software programming used can be found in a recent report (5).

A contouring program allows these same universal files to be plotted in map form which includes section lines and numbers plotted, as well as contour levels labeled. Histograms of any data file may be displayed on the plotter or on the screen. Three-dimensional projection data files are also produced from the same universal format, for later plotting or display.

Batch-like operations were permitted by a master file program for dumping, contouring, histograms, or three-dimensional modeling. The data-file header structure included self-describing terms of map orientation such as section numbers, numbers of rows or columns, number of rows or columns per mile, type of data pattern (whether five spot or rectangular), map display parameters, and the history of the data.

A software program is included which converts the universal files to a form for random data smoothing and contouring by a program written in fortran IV, or the data form used by the fortran IV program may be converted back to the universal file form.

The data processing procedure varied depending on the type of data. All data were input to the computer in like manner -a file was created and the data were input to this file. The file format was determined by the type storage in that the individual data entries were stored according to their relative position in the whole sampling area (row and column storage) or they were also entered by sample number (section and hole numbers). Each data entry was verified and edited for accuracy of value and sample position. The raw data were then corrected and stored, individually, under different file names. Complete listings, histogram plots, contour maps, and three-dimensional plots were then processed from the corrected files.

Correction Techniques

Two sets of data, soil-gas analysis data and radiation data, required additional processing to standardize the results.

The raw soil-gas data were measured as parts-per-million gas (by volume) in air. The initial amount of air in the processing system depended upon air allowed in the system after evacuation and the total volume of the system, and was measured by pressure. Thus, this volume of air was significantly affected by the volumes of soil, $\mathrm{CO}_{2}$ scrubber solution, and initial glassware volume which changed whenever glassware was replaced due to breakage. 
The raw data had to be standardized to allow contour, histogram, graph, and listing presentations.

Each set of glassware was measured for total volume before testing resumed during processing of all samples analyzed. Eighteen different glassware volumes were used during the time for processing the 584 soil-samples. To analyze the conditions for determining the total amount of hydrocarbon gas liberated and correlating these conditions to each analysis for correction of each gas would be a very long and tedious task. A computer subroutine was written which used the input or raw data (ppm values), glassware volume, soil volume, scrubber solution volume, initial pressure, and the final pressure (pressure used to determine the volume of gas forced into the collector) and output a data file in absolute volume of hydrocarbon gas evolved for each soil analysis. The output data were reported in micro-liters gas per 50gram sample for each of methane, ethane, ethylene, propane, isobutane, and normal-butane.

The raw radiation data were measured as counts per twominute time, but diurnal variations and positive interferences due to cross-channeling were not calculated. A specified calibration sampling site was measured periodically during each working day to allow for corrections due to diurnal variations. Additionally, the calibration procedure for determining the amounts of potassium-40, bismuth-214, and thallium-208 from the raw data measurements would require considerable time and effort. Thus, computer analysis of the raw data using corrections for diurnal variations and cross-channeling effects would be advantageous.

Two subroutines were written to correct the radiation data. The first subroutine was used to calculate the individual amounts of potassium, bismuth, and thallium for each data point taken including the data taken at the calibration site. After calculaing these individual quantities, separate values were corrected in the second subroutine using the measured and calculated calibration values to correct for daily variations. The final corrected values were output to their respective files and stored as percent potassium, parts-per-million (ppm) bismuth, and ppm thallium.

\section{Presentations}

Large amounts of field data were received on radiometrics, hydrocarbons, and other soil parameters from the sutherland field, Kansas. The data transfer between the field instrumentation and the minicomputer was made with punched paper tape while the soil data were input from a keyboard. The use of a graphics tablet and a CRT display terminal combination permitted easy entry of digitized map features and also instant visual authentication of the input data as well, so immediate corrections modifications 
to the entered data could be made. In the universal data file system, all types of geochemical data are obtained in a grid form. From these files, the data may be edited, graphed as histograms, contoured onto a map, or correlated with other universal files. Three-dimensional presentations can be plotted or displayed for easier interpretation. If the data are randomly located, the universal $f i l e$ is converted to an $X-Y$ coordinate format on which a random smooth is made, then contours of the smoothed, the trend, and the difference maps are made.

\section{RESULTS AND DISCUSSION}

\section{General Procedures}

Soil-gas analysis

Figure 7 shows the map for the Sutherland field sample sites for the n-butane gas file, which is a typical pattern for the soil gas files in general. A change can be seen from a linear pattern of sample locations on the right to a five-spot pattern as seen on the left. The five-spot pattern was selected midway in the study because of a more efficient data spacing with a given number of locations. This file is a merging of the two types of patterns used.

A correlation could exist between the near-surface formation outcrops and anomalous hydrocarbon or anomalous natural radiation or both. Possibly, the nature of the soil or rock type could influence the amount of hydrocarbon capable of being adsorbed and consequently such influence, if any, would also have direct bearing on the occurrence of other geochemical anomalies. A classification of the different sample sediment types might reveal a role that each type plays in the geochemical anomaly.

To find if correlation of hydrocarbons continues beyond the 2, 5, 9, and 13-foot depths, a series of 50-foot holes were drilled. These holes were sampled every 10 feet. The results are shown in Table 3 .

From the data shown, a correlation between methane and nbutane (and also other gases not shown) is very apparent. Also apparent is the total lack of a trend in hydrocarbon content with depth down to the 50-foot level.

Radiometrics

The first radiation data were collected early in the program from a moving truck giving integrated readings for each of four energy windows over a two-minute period. At the rate the truck was moving, this permitted a one-eighth-mile spacing between data points. Each energy window could also be recorded on a continuous 


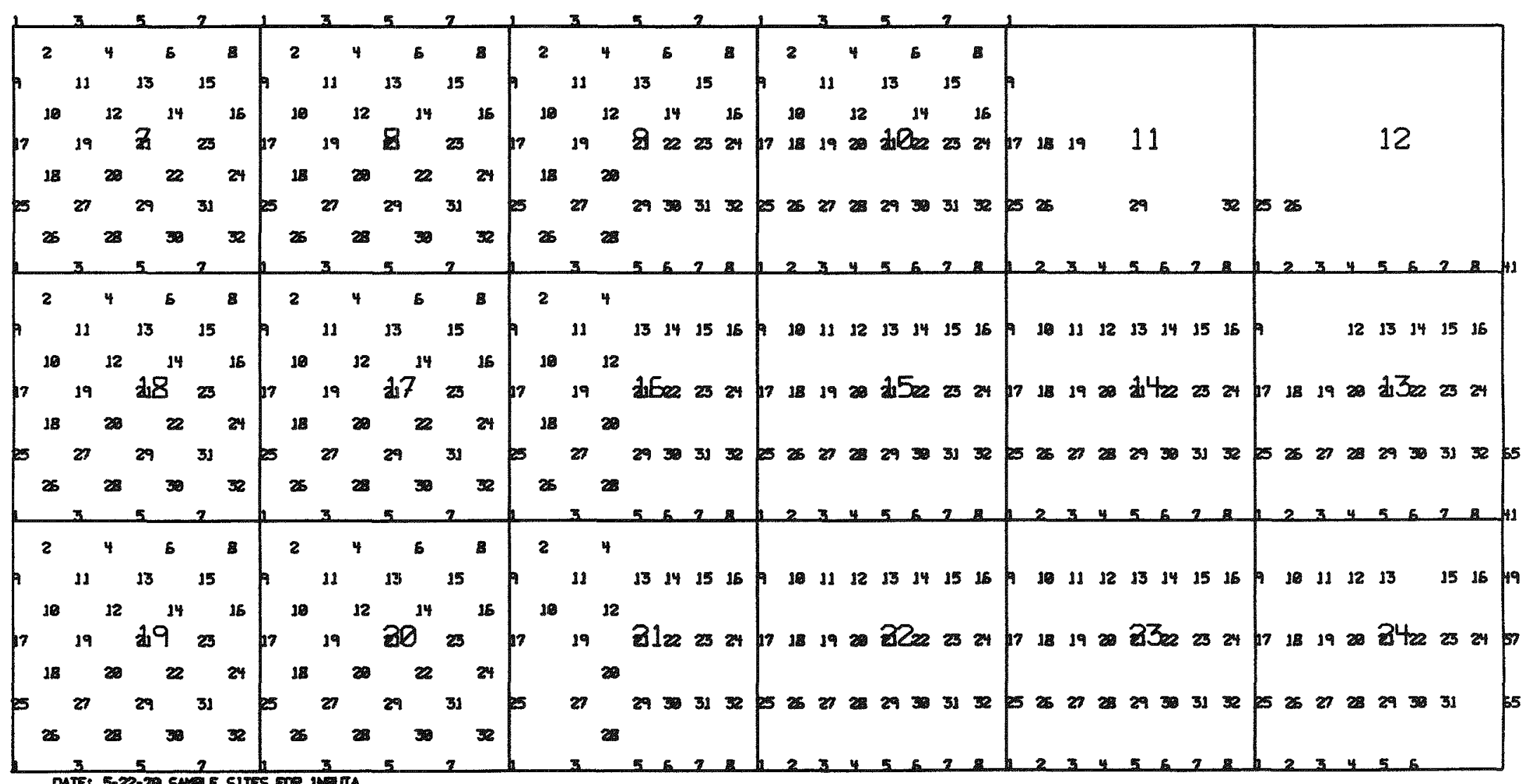

FIGURE 7. - Gas sample sites in Sutherland. 
TABLE 3. - COMPARISON OF METHANE AND N-BUTANE CONTENTS WITH DEPTH

\begin{tabular}{|c|c|c|c|c|c|c|c|c|c|c|}
\hline \multirow{2}{*}{$\begin{array}{c}\begin{array}{l}\text { Depth } \\
\text { feet }\end{array} \\
9\end{array}$} & \multicolumn{2}{|c|}{$\begin{array}{c}\text { Hole \#1 } \\
\text { Methane n-butane }\end{array}$} & \multicolumn{2}{|c|}{$\begin{array}{c}\text { Hole \#21 } \\
\text { Methane n-butane }\end{array}$} & \multicolumn{2}{|c|}{$\begin{array}{c}\text { Hole \#8 } \\
\text { Methane n-butane }\end{array}$} & \multicolumn{2}{|c|}{$\begin{array}{c}\text { Hole } \# 9 \\
\text { Methane n-butane }\end{array}$} & \multicolumn{2}{|c|}{$\begin{array}{c}\text { Hole \#22 } \\
\text { Methane n-butane }\end{array}$} \\
\hline & 139.3 & 3.49 & 113.6 & 3.38 & 30.0 & 0.73 & 21.7 & 0.22 & 162.2 & 2.39 \\
\hline 10 & 57.2 & 0.90 & 90.4 & 9.42 & 183.8 & 9.06 & 33.3 & 0.09 & 255.1 & 3.53 \\
\hline 20 & 198.0 & 5.75 & 89.0 & 14.53 & 33.4 & 0.76 & 142.4 & 1.79 & 102.2 & 1.09 \\
\hline 30 & 148.7 & 6.04 & 18.4 & 1.48 & 25.5 & 3.81 & 174.6 & 2.27 & 134.0 & 2.37 \\
\hline 40 & 58.9 & 3.58 & 67.8 & 6.21 & 21.9 & 2.58 & 186.8 & 2.24 & 149.8 & 2.13 \\
\hline 50 & 173.5 & 6.11 & 74.8 & 1.61 & 24.3 & 3.92 & - & - & 185.4 & 2.37 \\
\hline $\begin{array}{c}\text { Surface } \\
\text { Elevation }\end{array}$ & \multicolumn{2}{|c|}{1060.8} & \multicolumn{2}{|c|}{1073.8} & \multicolumn{2}{|c|}{1107.2} & \multicolumn{2}{|c|}{1160.3} & \multicolumn{2}{|c|}{1220.0} \\
\hline
\end{tabular}


chart while the truck was moving. Figure 8 shows the tracings of three of the windows while the truck was moving for a one-mile segment in section 7 of the sutherland field. These recordings were oriented east and west and usually were made of the total gamma radiation. However, one particular mile cross-section, located $1 / 8$ mile north of the southern section line of section 7 , was selected for comparative measurements of Tl-208, Bi-214, and the total radiation profiles. The comparison between the three types of measurement and the topography cross-section are shown in the figure with detailed explanations of major anomalies noted on the chart. As seen in this illustration, the low radiation points correspond usually to rocky outcrops along ridges or in draws and gullies. The lack of perfect alignment between the curves is caused by a variation in the velocity of the survey truck. High radiation is observed on the flat sections of the field that have deeper and richer soil or basins in which water stands. In this sense, there appears to be a topographic correlation to the radiation profile.
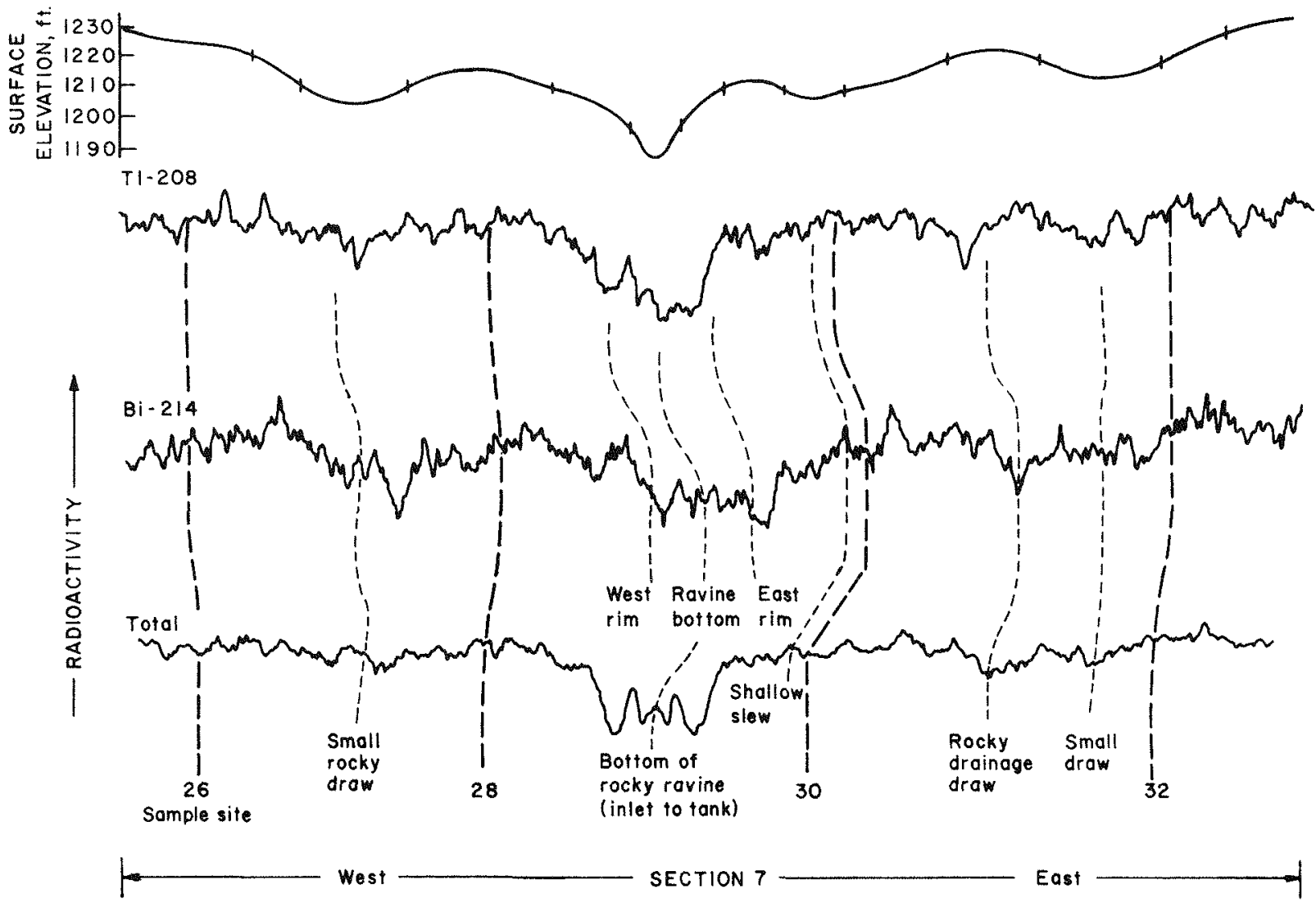

FIGURE 8. - Continuous strip chart radiation measurements from moving vehicle. 
The Sutherland field contains areas of severe erosion, deep ditches, creeks, heavy woods, and multiple fencing patterns. These conditions severely limited any possibility of continuous (moving) radiation measurements. Thus, the radiation measurements were taken in grid form, using stationary counting techniques for remaining radiation surveys.

All radiation data for the sutherland field area were collected at two-minute counting intervals in a five-spot pattern. Figure 9 shows the sample grid map for the radiation-data locations. The radiation data were corrected for window cross interference with a calibration matrix taken from standard radiation pads at Grand Junction, Colorado, and was also corrected for daily variation through the use of a standard reference location in the sutherland area. Potassium, which has a very low specific activity, is a macroconstituent of soils and is present in orders-of-magnitude higher concentrations than are uranium or thorium components.

\section{Field Surveys}

Prerequisites

Field testos were performed in two areas in Kansas and one area in Oklahoma. The original prerequisites for choosing a specific test area were relatively simple: 1) The area should not be heavily drilled; 2) If production was within the test area, the production area should preferably be a new-production area; 3) The test area should preferably be isolated from major producing areas; 4) The area should be easily traversed; 5) The area preferably would be convenient to Bartlesville.

The first area chosen for testing was in the Rosalia field located in Butler County in Southeastern Kansas (figure 10). Radiation measurements of this area showed no significant anomalous areas. Later investigation showed this area was new production, but the production was by waterflood. Since the known producing area had reduced reservoir pressures, the locality was not considered a good geochemical prospect. The sutherland Field in Greenwood Co., Kansas was selected as an alternate candidate for geochemical testing (figure 10).

After completion of the geochemical survey of the Sutherland area, a third area, near Haskell, oklahoma, in Muskogee County, (figure 10) was initiated. This area was surveyed as a cooperative agreement with the major landowner in the area. The landowner agreed to drill all wells after the survey was performed. 


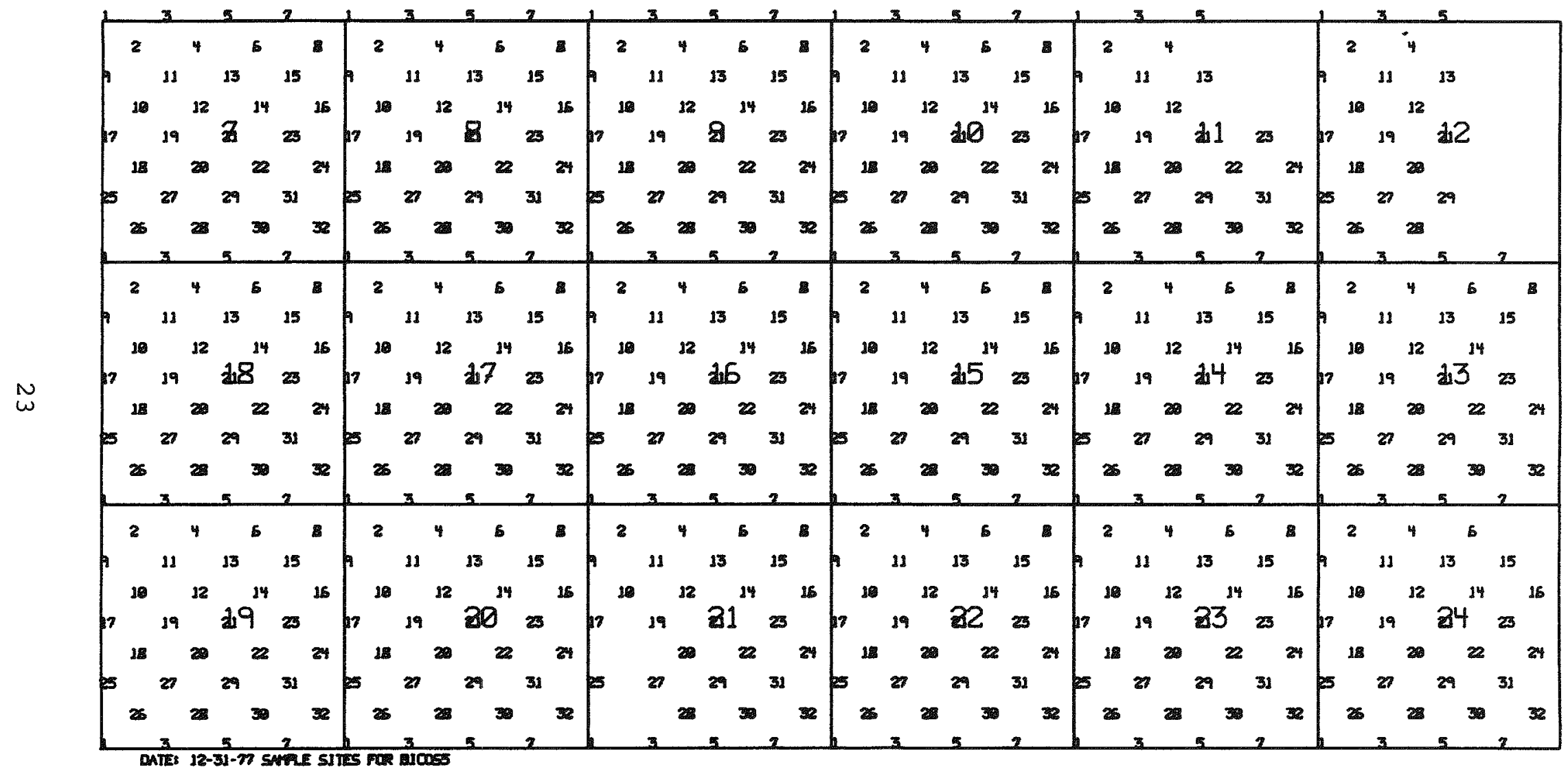

FIGURE 9. - Radiation sample sites in Sutherland. 

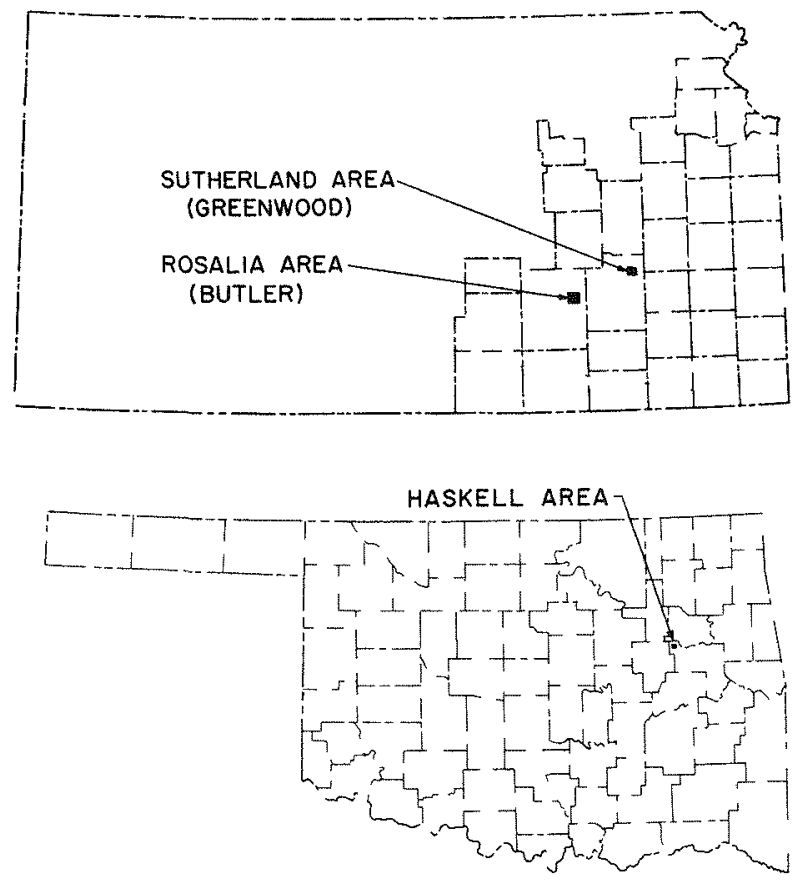

FIGURE 10. - Survey areas of Rosalia and Sutherland in Kansas, and Haskell in Oklahoma.

\section{Sutherland Area}

Geological Description

The sutherland field, Township $23 \mathrm{~N}$ Range $12 \mathrm{E}$ in Kansas, was originally produced in 1964 from one well in the Arbuckle formation. During 1966-1972 no production was reported. In september of 1973, five new wells were drilled within $3 / 8$ miles of the original producing well. These five wells in section 14 were reported producing from the viola.

The Halo survey area includes the sutherland field and several other sections surrounding that field. Sections 7-24 were covered by magnetic, gravity, radiometrics and soil gas surveys conducted by BERC personnel and contractors to the center.

The survey area varies from deep soil development to bedrock outcrops and from streams to dry ridges. The soil appearance changes in several areas and vegetation in uncultivated areas varies from grassy meadows to deciduous trees. All areas of the survey are accessible by vehicle. The Verdigris river flows through the survey field in sections 12,13 and 24.

A well location map shows 29 dry holes and the five producing wells mentioned in the foregoing. Sections 15 and 20 are the only two sections in which no previous tests were made. Most of the 29 holes were drilled to the cherokee shales, short of the Viola formation, the interval presently producing in the Sutherland field.

The present land surface in eastern Kansas has developed as a result of regional uplift centered in the ozark area. Most of this gentle tilting developed after Permian deposition and the structure is properly called the Prairie plains Homocline (commonly Monocline).

The geology of the Sutherland area appears to have developed before the cherokee sea encroachment and after (or during) the chautauqua arch development. The reservoir appears to be limited to vugular and/or fractured dolomite limestone underlying 
uncomformably with the overlying Mississippian strata. This formation does not have any of the "shoestring" and lenticular sand reservoir characteristics seen in classic deposits of the Cherokee formation of Pennsylvanian age.

Viola production in sutherland field appears to be from a dolomite limestone of a middle ordovician age consisting of gray, buff to brown, medium to coarse crystalline, vugular dolomite (11).

Pre-Viola deposition in early ordovician through Cambrian consists of the Simpson and Arbuckle groups and two Cambrian formations.

According to well-log interpretation, there remains over $400 \mathrm{ft}$. of Mississippian and earlier sediment between the Viola reservoir and the base of the Pennsylvanian (the next important structural period). The development of the chautauqua arch, and subsequent exposure to solution, allowed for the development of a fractured reservoir. The broad and gentle arching appears to preclude local fracturing as opposed to faulting in reservoir development.

The Mississippian is predominantly limestone. Recognizing the different units in the subsurface depends on differences in insoluble residues. The basal Mississippian is the Chattanooga shale which is either uppermost Devonian or lowermost

Mississippian. Because of the wldespread unconformable relation of the Chatanooga to underlying rocks, (caused by the Chautauqua arch development) the chatanooga is often considered part of the Mississippian.

Both the Pennsylvanian and Permian are relatively monotonous layers of cyclic deposits. The importance in reservoir potential is seen in the stratigraphic traps formed in drastic facies changes (i.e. offshore bars and strand-sand deposits in the Cherokee shale) and traps against unconformities. The Sutherland field, although in an area of high clastic development, is not producing from the Pennsylvanian sands of the Cherokee interval.

\section{Soil Analysis}

Soil Samples were obtained from 559 sample sites, the positions of which are shown in figure 7. Each sample was analyzed for adsorbed gas, moisture, and surface area, and about one-half the samples (east side only) were also analyzed for pH and conductivity.

The rules and techniques for anomaly interpretation are well presented by Rose (I4). Recognition of anomalies through 
examination of log-normal frequency distribution plots of the population parameters is a satisfactory approach and was used in this study. Anomalies in the concentrations of both radioactive nuclides and of light hydrocarbon gases in subsurface soil samples were observed in the collected data.

Soil-gas analyses show about the same configuration of high and low gas areas for each gas (except ethylene) tested. Figure 11 shows the frequency histogram for the methane data collected. The anomalous-gas region appears to be centered around $32 \mu I$ of gas per $50 \mathrm{~g}$. sample. This area corresponds to contour levels of about 6 through 9 in the contour map of methane, figure 12 . These areas are found in the northeast corner in section 8 , the southwest corner in section 9 , the southwest corner of section 17, and as a broad ridge on the eastern edges of sections 10, 15,

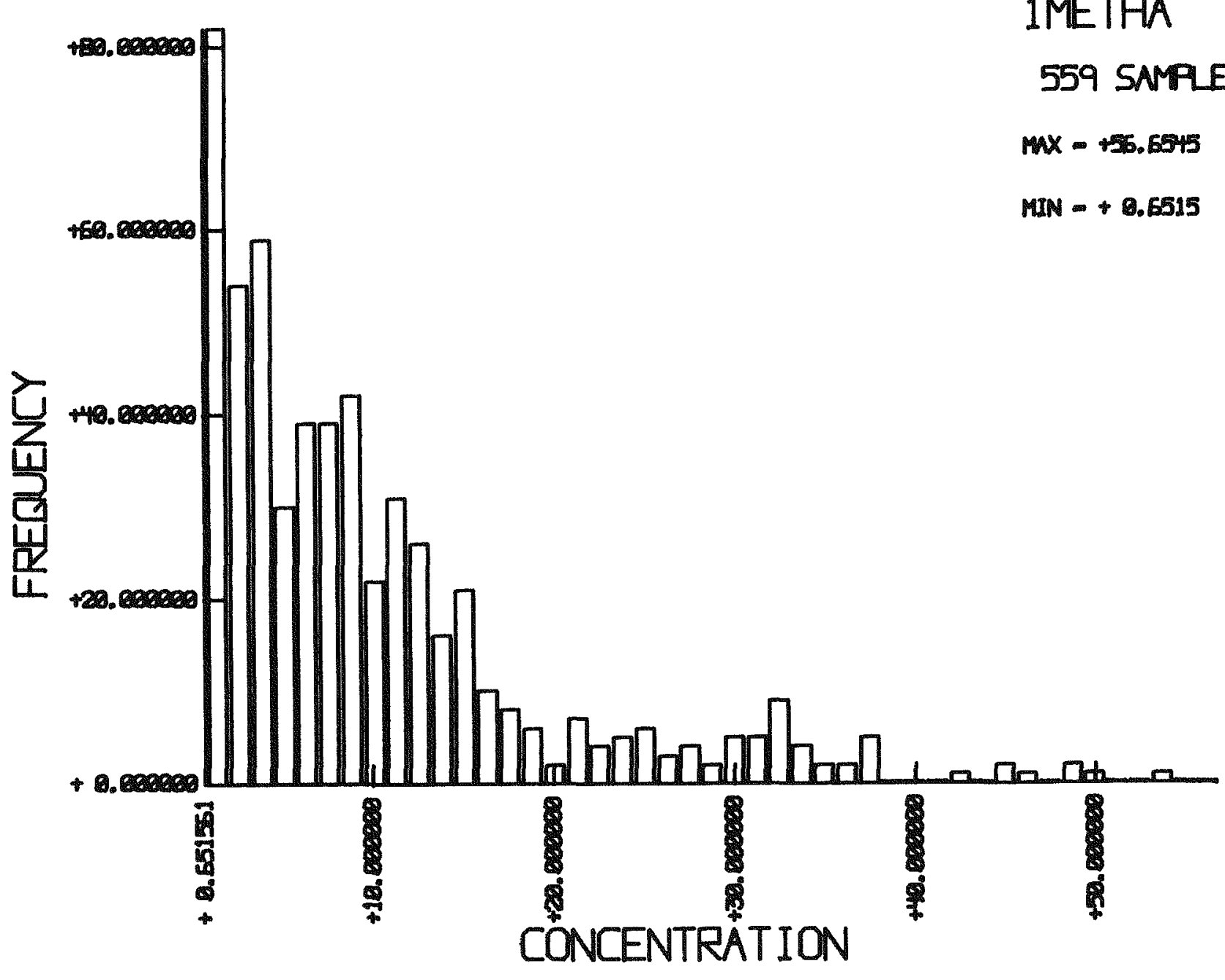

FIGURE 11. - Frequency histogram of methane in sutherland. 


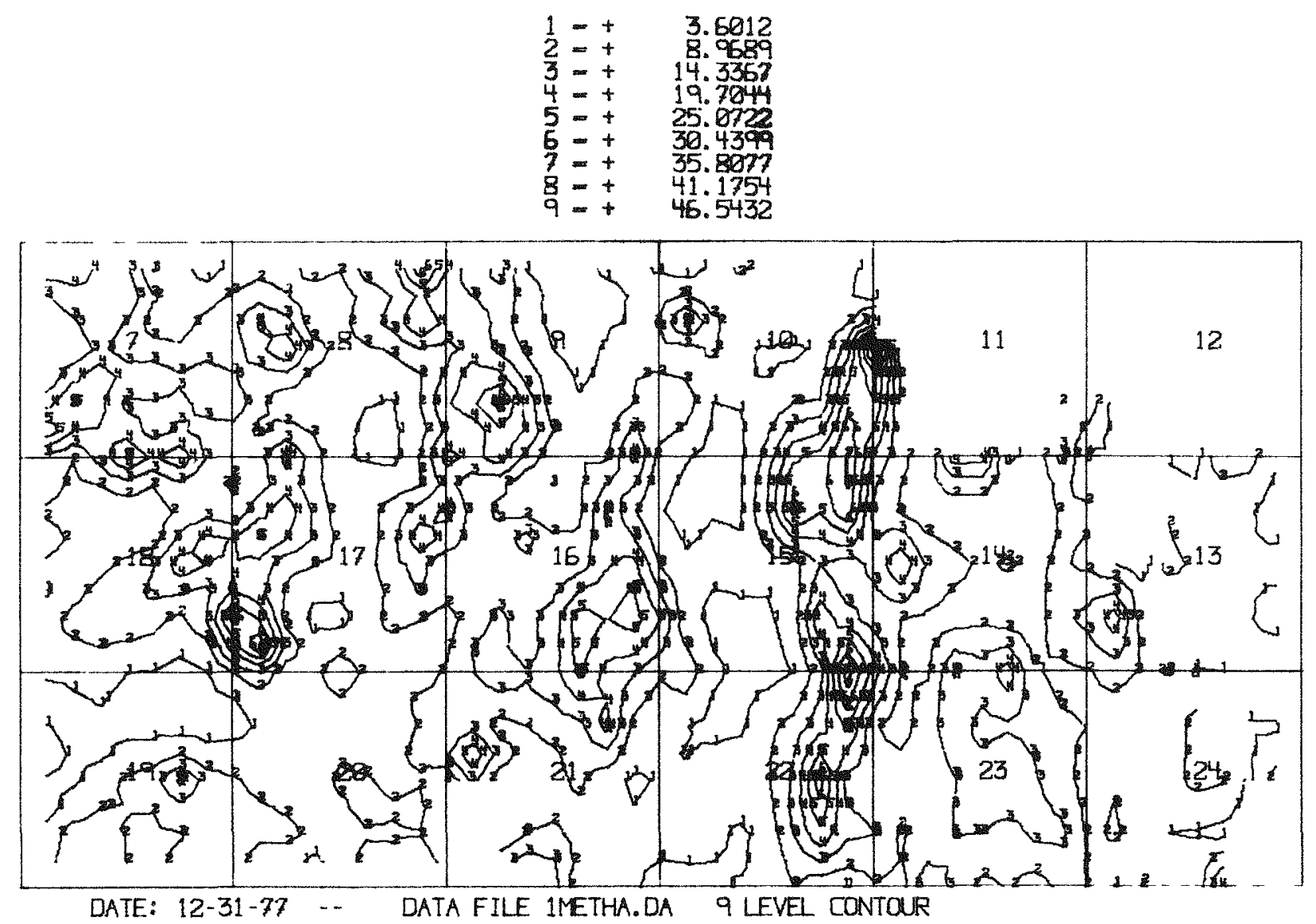

FIGURE 12. - Contour map of methane in Sutherland.

and 22. If we include contour level 5 as the effective lower limit of the anomalous region, we add areas in the southeast quarter of section 16 and a small area on the south-central section line of section 7. The frequency plots (histogram) for each gas, with the exception of ethylene, are relatively the same shape as for methane. The positions of the anomalous regions for each gas are quite similar. The noted exception is in the south-central part of section 20. Methane does not show an anomalous region in section 20, but ethane (figure 13), propane (figure 14), isobutane (figure 15), and normal butane (figure 16), show such a region which grows in size from ethane through normal-butane and includes a sizeable portion of the section in the butane maps. Also noted was the region on the south-central section-line of section 7. As the carbon weight increases, the ccntour value decreases in this area.

Ethylene is considered to be biologically derived gas and, as such, was not expected to show any particular anomalous zone. Figure 17, a frequency histogram of the ethylene data, shows no anomalous region. Increasing the number of contour levels of 


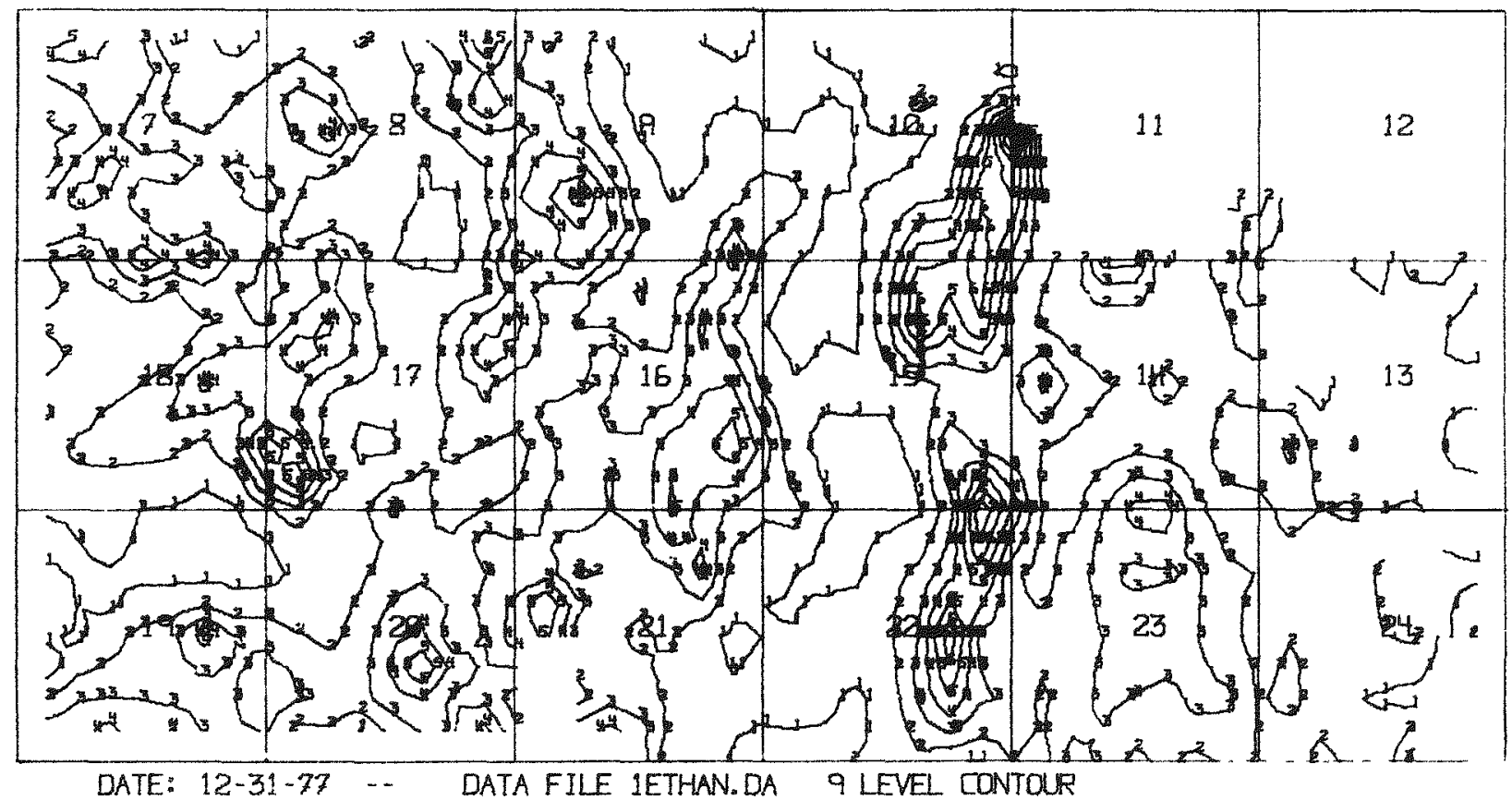

FIGURE 13. - Contour map of ethane in sutherland. 

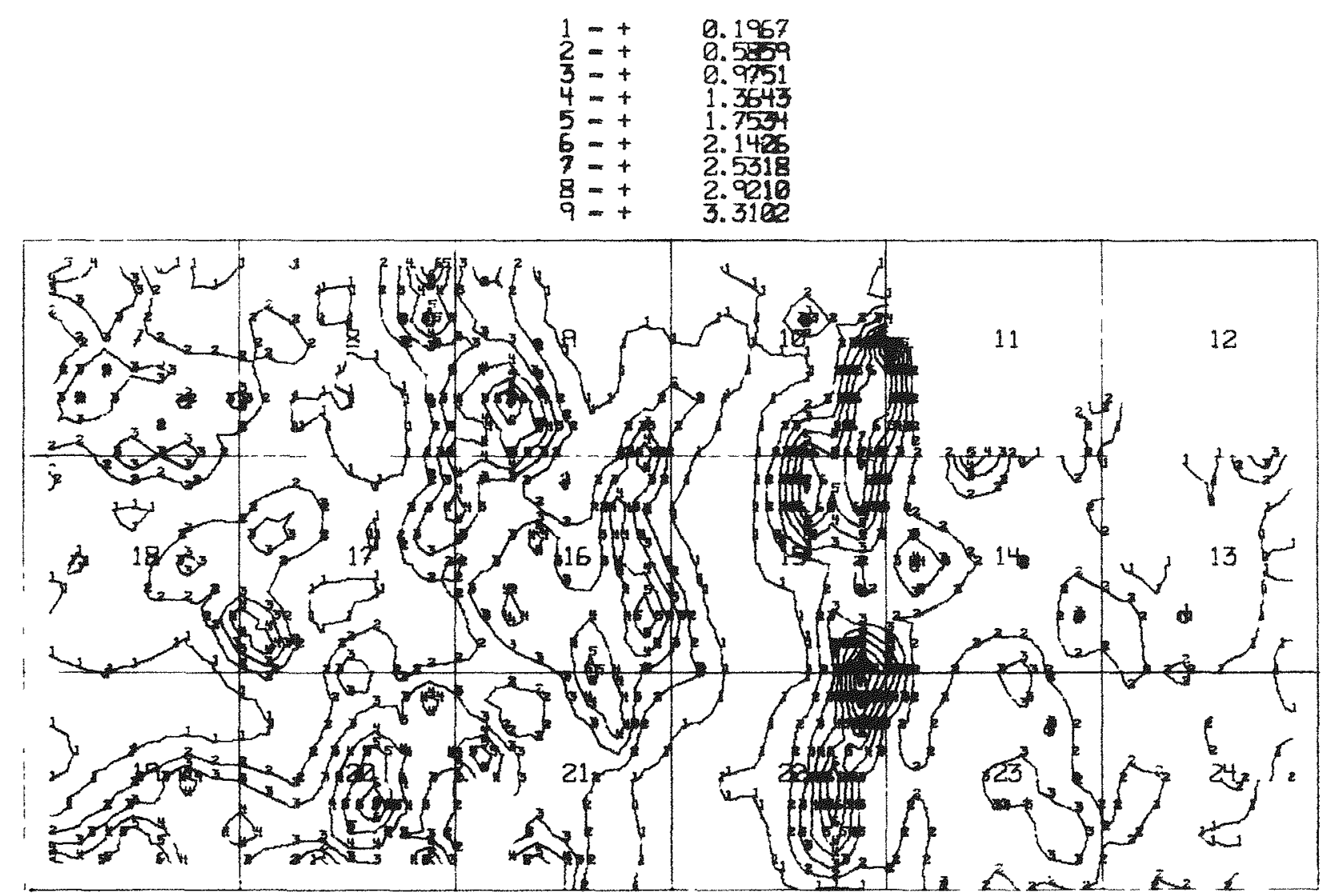

DATE. $12-31-77 \cdots$ DATA FILE IPROPA.DA 9 LEVEI CONTOUR

FIGURE 14. - Contour map of propane in sutherland. 


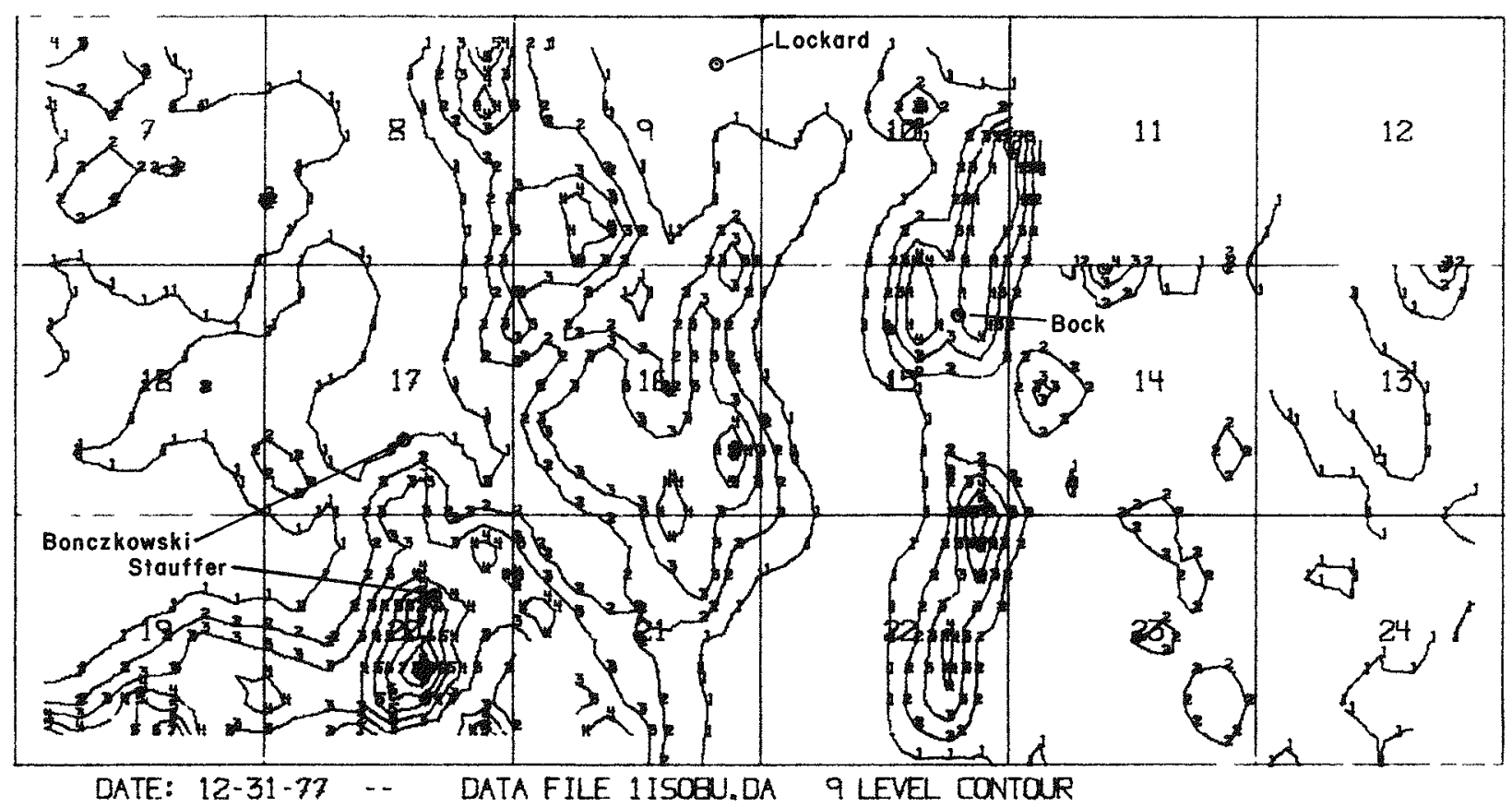

FIGURE 15. - Contour map of isobutane in Sutherland. 



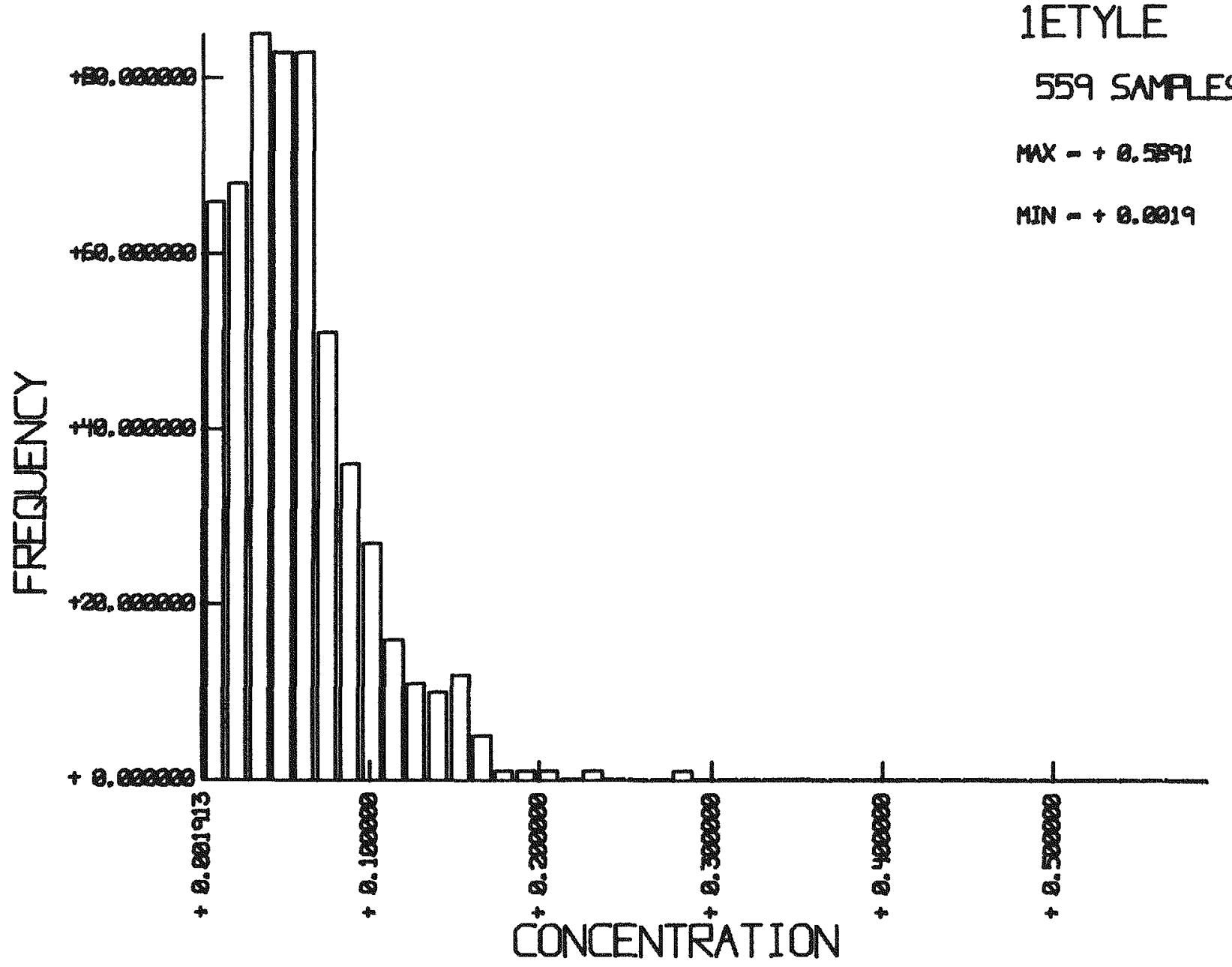

FIGURE 17. - Frequency histogram of ethylene in Sutherland.

ethylene to 30 brought out striking similarities to the other hydrocarbon gases in the non-anomalous regions. However, ethylene's lack of correlation with the other gases is also seen in histograms of the frequency distributions for each gas and their associated anomaliess at the high end except for ethylene.

Analysis of $\mathrm{C}^{12} / \mathrm{C}^{13}$ isotope ratios in a few samples revealed that where there is a large biologically derived fraction of the methane present, there is also a high content of ethylene gas present. The fact that there appears to be a small degree of association of ethylene to methane indicates a possible common origin of the two gases to recent vegetation or humus.

A contour plot of the surface area measurements of the Sutherland field soil samples is shown in figure 18. The trend of the data shows a ridge effect from southwest to northeast 

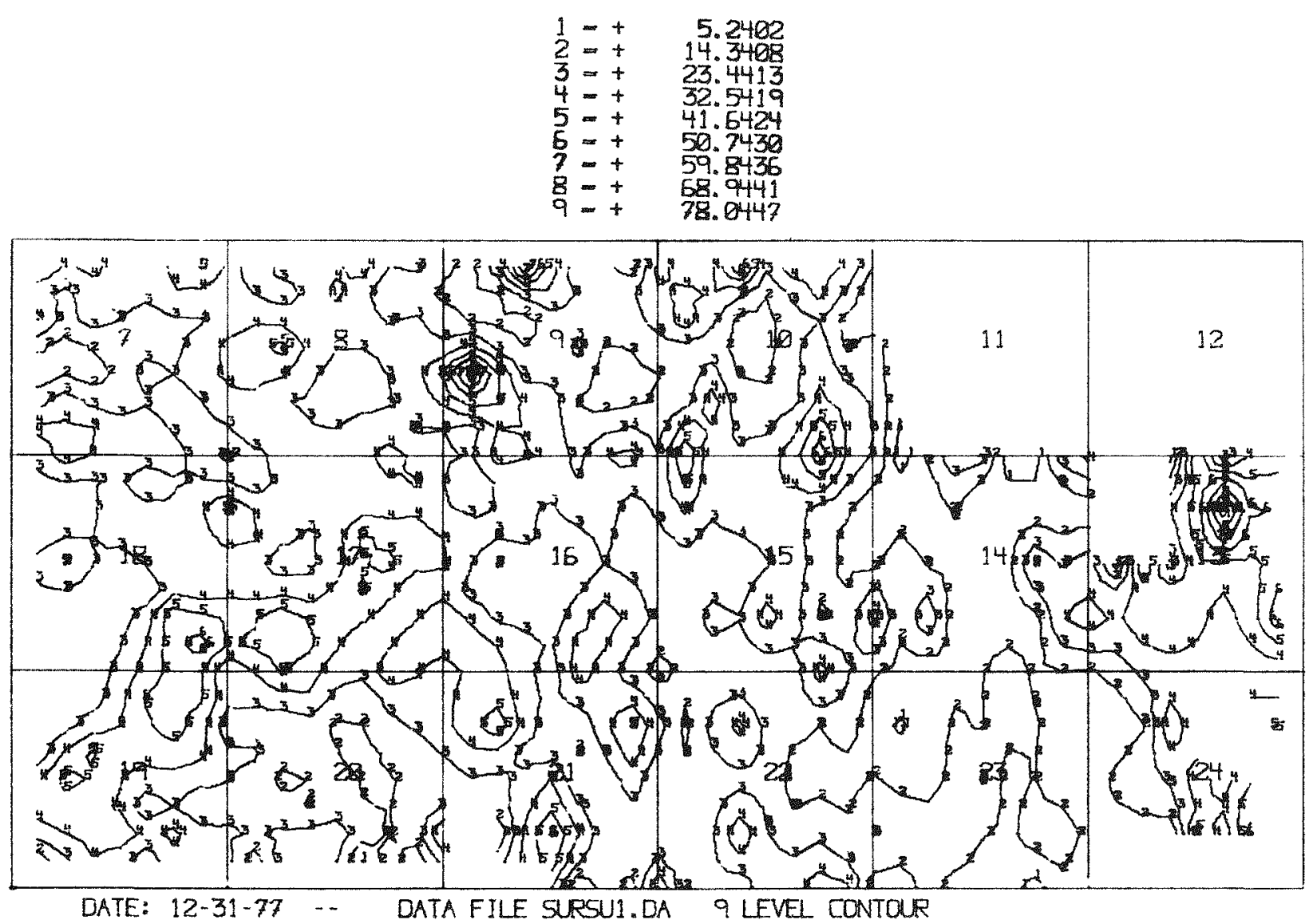

FIGURE 18. - Surface area contours in Sutherland. 
through the center of the survey area. The northwest and southeast portions are relatively low, and sections 9 and 10 are relatively high in surface area. The higher surface area regions somewhat coincide with the anomalous soil-gas regions.

The moisture data are shown contoured in figure 19. The moisture data appear to be relatively flat and ranges between contour levels 3 and 5. High moisture content is found and expected near the river in sections 13 and 24. High areas near the west-center section line of section 10 and in the westcentral portion of section 8 are also present. Contour levels of 5 and 6 correspond generally to the anomalous soil-gas areas.

The $\mathrm{pH}$ and conductivity (figures 20 and 21 , respectively) contour maps show a high degree of similarity. The high soilgas ridge through sections 10,15 and 22 correspond to the high gradients of $\mathrm{pH}$ and conductivity. The same phenomenon appears west of this area in the north-south ridge of high soil-gas in the eastern edges of sections 9, 16, and 21. The high soil-gas apparently occurs in the $\mathrm{pH}$ range of about 8.0 to 9.0 and conductivity of 36 to 60 mhos. These relationships do not hold true for the river area in sections 13 and 24 .

\section{Radiation Survey}

The radiation survey was performed entirely using the fivespot pattern of sampling. These data have more sample sites due to land access problems encountered after the radiation survey was completed, and include sample counts for most of the sites in sections 11 and 12. Figure 9 shows the survey sample sites tested.

The frequency histogram for potassium-40, shown in figure 22, indicates the data are normally distributed. No particular anomalous region is shown. The areas lower than 1.1 and above $2.5 \mathrm{ppm}$ are most likely to include an anomalous region. The areas above $2.5 \mathrm{ppm}$, as seen in figure 23, are located near the south section line of section 7 , center of section 8 , southwest quarter of section 17, and northwest corner of section 20 . The area below $1.1 \mathrm{ppm}$ is in the southwest quarter of section 10 .

Bismuth-214, is a short-lived descendant from radon-222 which comes from radium-226, a daughter product of natural uranium. Uranium is said (7) to be tightly bound to soil and is in isotopic equilibrium with radium, even over an oil-bearing structure. Because of this, and the fact that the radium ascends too slowly to arrive intact at the surface from any petroleum reservoir, the only migratory radiation anomalies probable over an oil field must be a uranium one. The chemistry of the uraniumhydrocarbon association does permit such an anomaly. The 


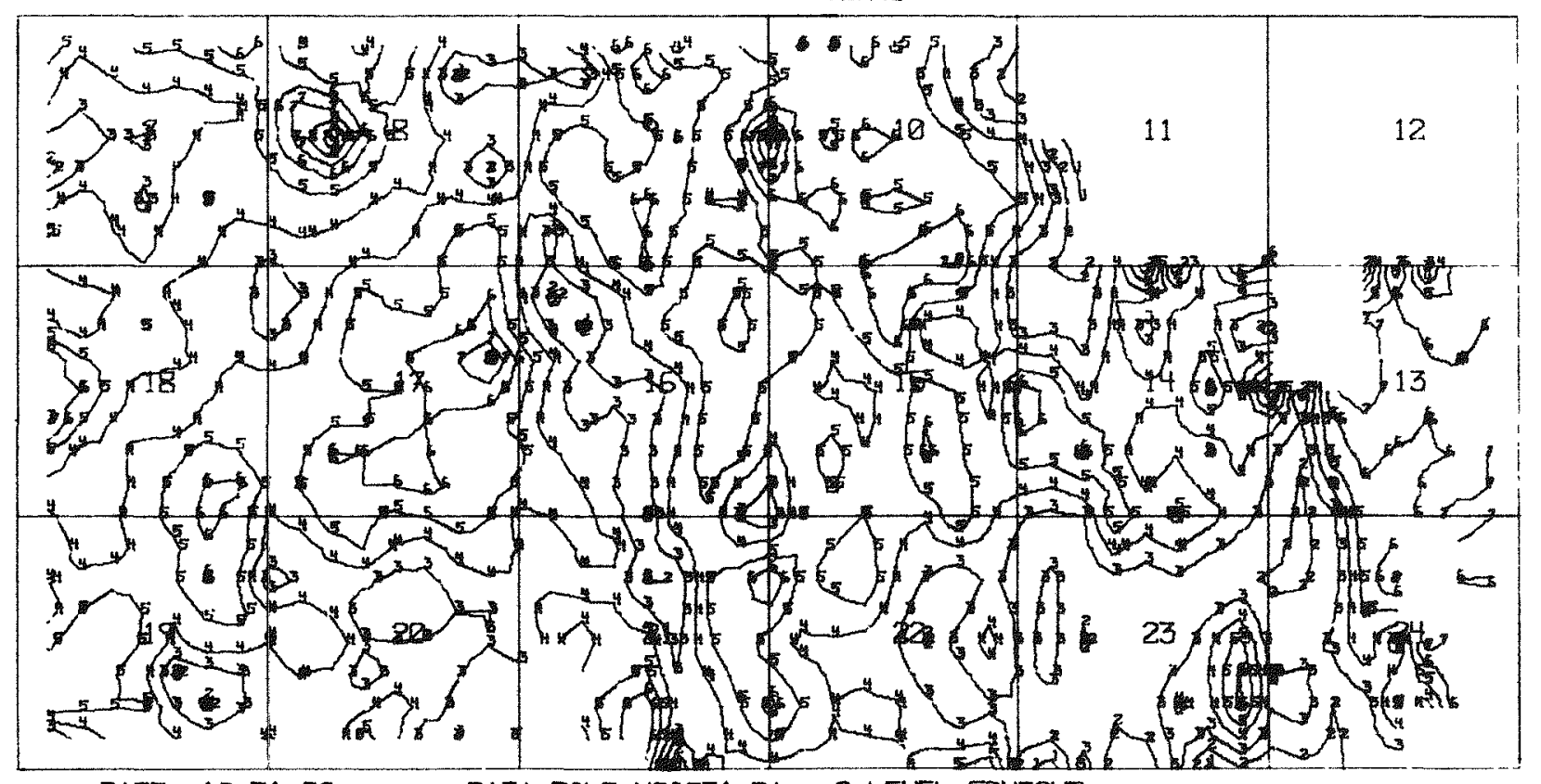

DATE: $12-31-77$-. DATA FILE MOIST1.DA 9 LEVEL CONTOUR

FIGURE 19. - Moisture contours in sutherland. 


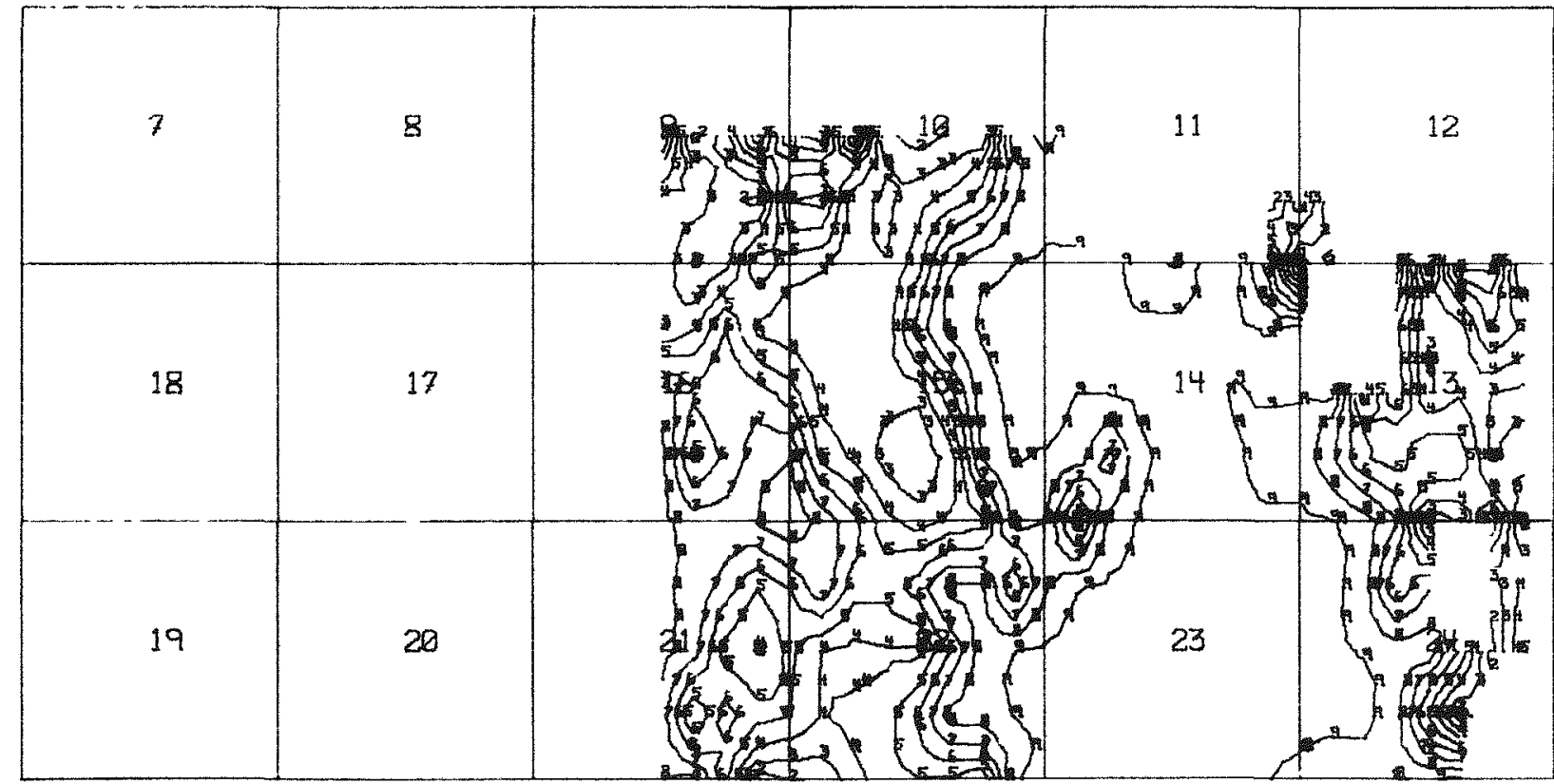

DATE: $12-31-77 \cdots$ DATA FILE PHDIRI.DA 9 LEVEL CONTOUR

FIGURE 20. - $\mathrm{pH}$ contours in Sutherland. 

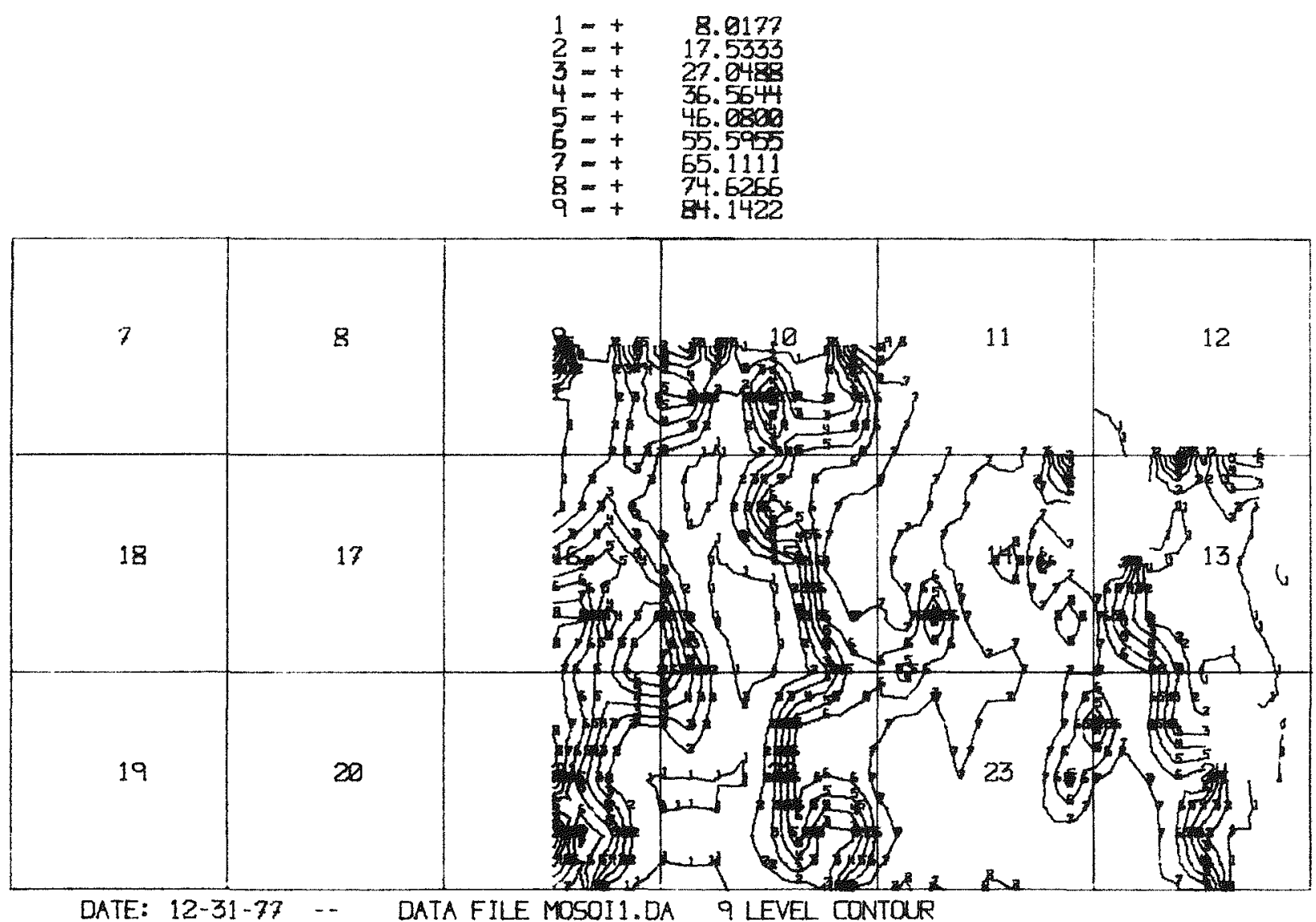

FIGURE 21. - Conductivity contours in Sutherland. 


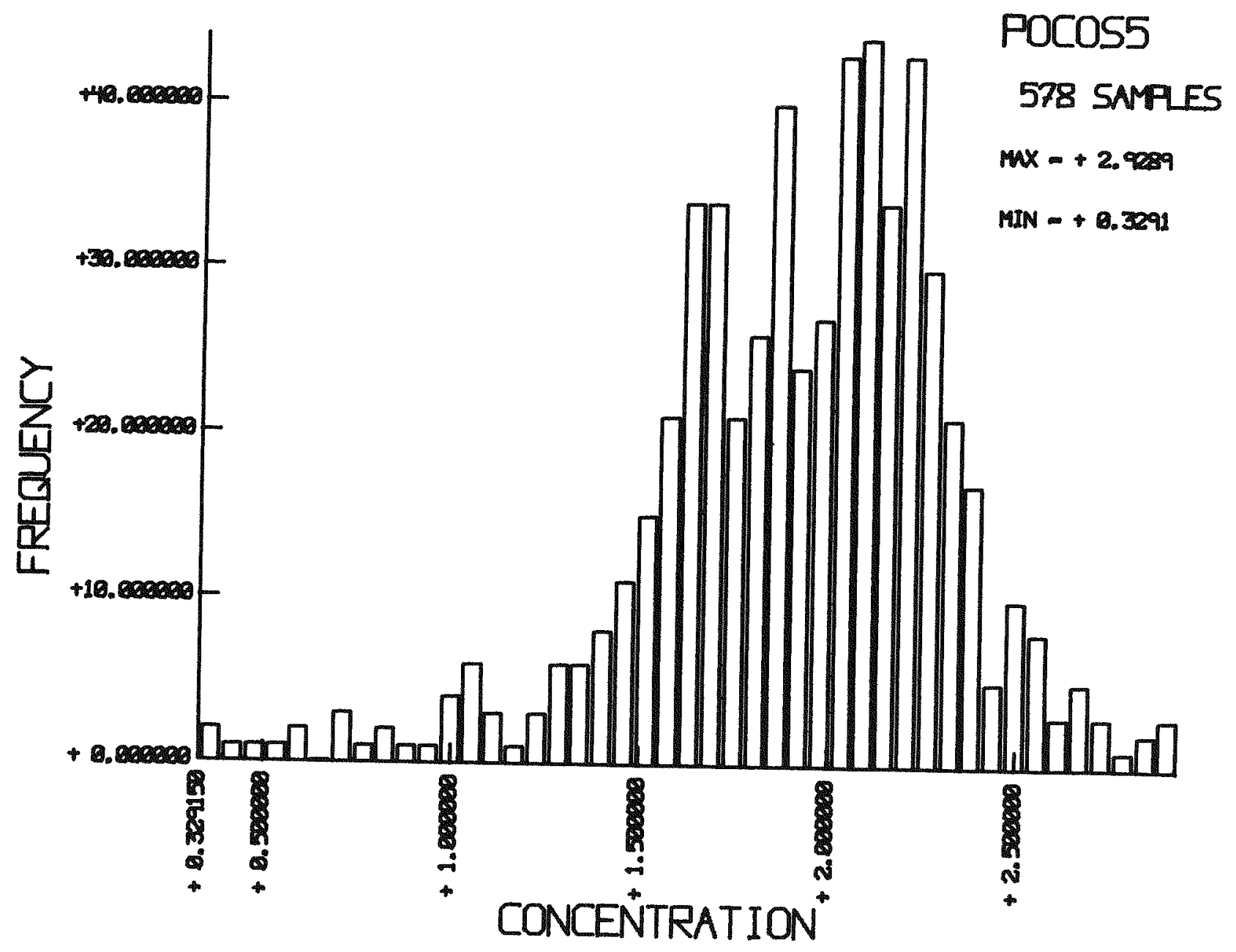

FIGURE 22. - Frequency histogram of $\mathrm{K}^{40}$ in Sutherland. 

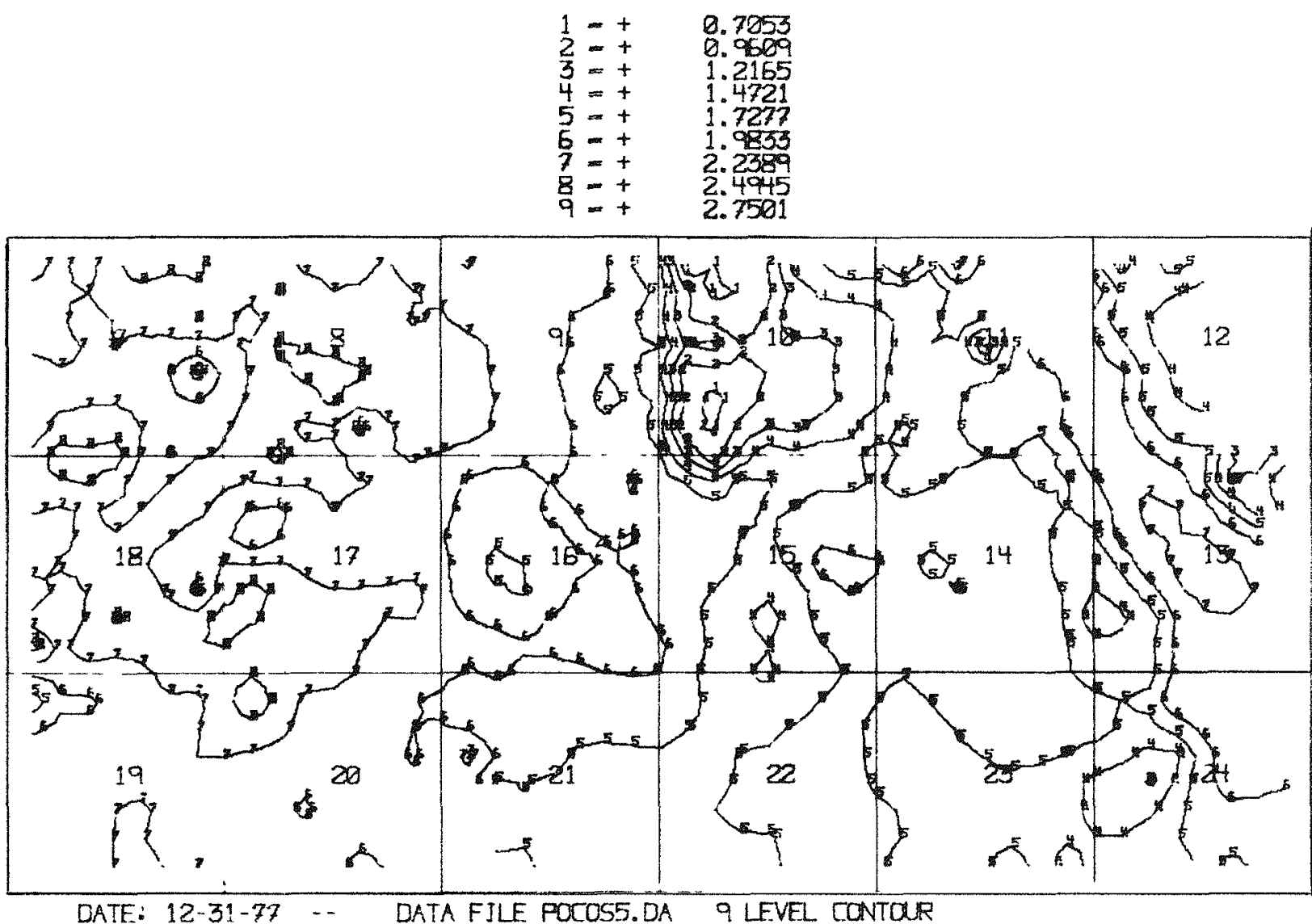

FIGURE 23. - Contour map of $\mathrm{K}^{40}$ in sutherland. 
frequency histogram for bismuth-214 is shown in figure 24 and shows a bimodal distribution. For clarity, designate the concentrations between 2.0 and $4.3 \mathrm{ppm}$ as mode $A$ and the concentration from 5.1 to $7.5 \mathrm{ppm}$ as mode $B$. In figure 25, the contour levels corresponding to mode A are levels 1 through 4. These levels are predominantly found in the west half of the survey area. The dividing line is the east section line of sections 9 and 16 and the north and west section lines of section 21 . The only exceptions observed to this division are found in the eastcentral part of section 15 (a mode $A$ is present) and the westcentral part of section 16 (a mode $B$ is present). The highradiation areas in the mode $B$ half (east-half) are found in the southwest quarter of section 10 and the west-central part of section 23. The low-radiation areas in the mode $A$ half (westhalf) are in the southwest quarter of section 8 and northwest quarter of section 17 .

Figure 26 shows the frequency histogram for the thallium-208 data. The region between $14 \mathrm{ppm}$ and $20 \mathrm{ppm}$ is normally distributed. Assuming the anomalous region is between 11.0 and $14.0 \mathrm{ppm}$ which corresponds to contour levels of 2 through 4 (see figure 27), many areas are depicted as anomalous. These areas are in the south-central part of section 8 , southeast quarter of section 7 , southwest quarter of section 12 , southeastern edge of section 14, northwestern quarter of section 17, southeastern quarter of section 18, and the west-central part of section 24 .

A comparison was made of the radiation measured on the surface in terms of specific nucleides and total uncorrected count to the total specific gamma activity measured in selected soil samples taken at nine foot depth. The counting data are given in table 4. The values suggest that nine feet of soil can make a large difference between the radiation pattern as measured on the surface, compared to that measured nine feet deep under the surface.

\section{Additional Investigative Procedures}

Magnetic Survey ${ }^{8}$

A helium magnetometer survey was flown on a one-half mile grid over Township 23S, Range 12E. Nine north-south profiles and ten east-west profiles were flown over the 25-square-mile area at a constant elevation of 2500 feet above sea level. The flight lines were doppler controlled in addition to being flown over the section and half-section lines. Magnetic readings were taken at

8 All interpretations of magnetic and gravity data were made by personnel of Senturion sciences. Permission to reproduce contour maps of this data was granted by senturion sciences, Tulsa, OK. 


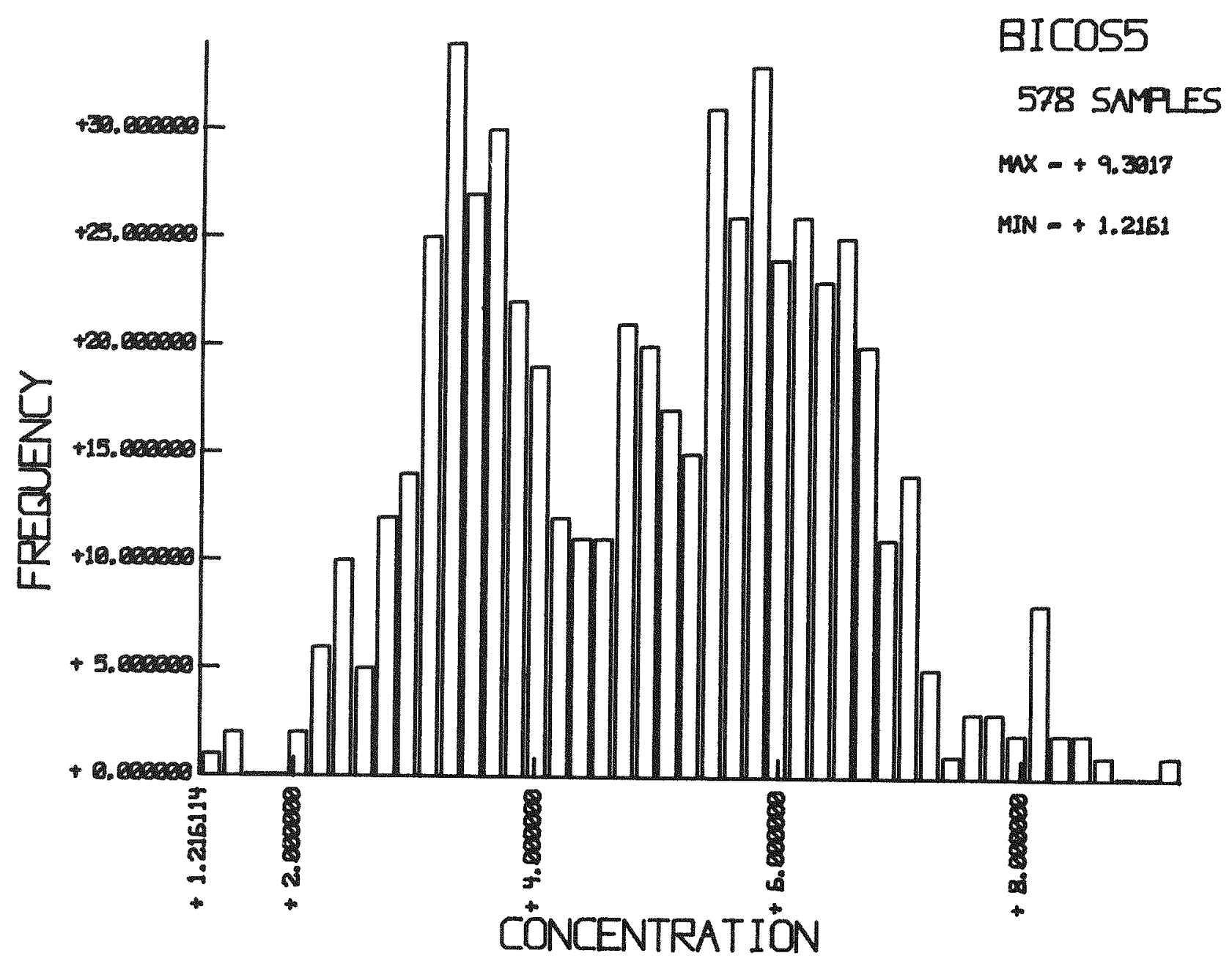

FIGURE 24. - Frequency histogram of $\mathrm{Bi}^{214}$ in Sutherland. 

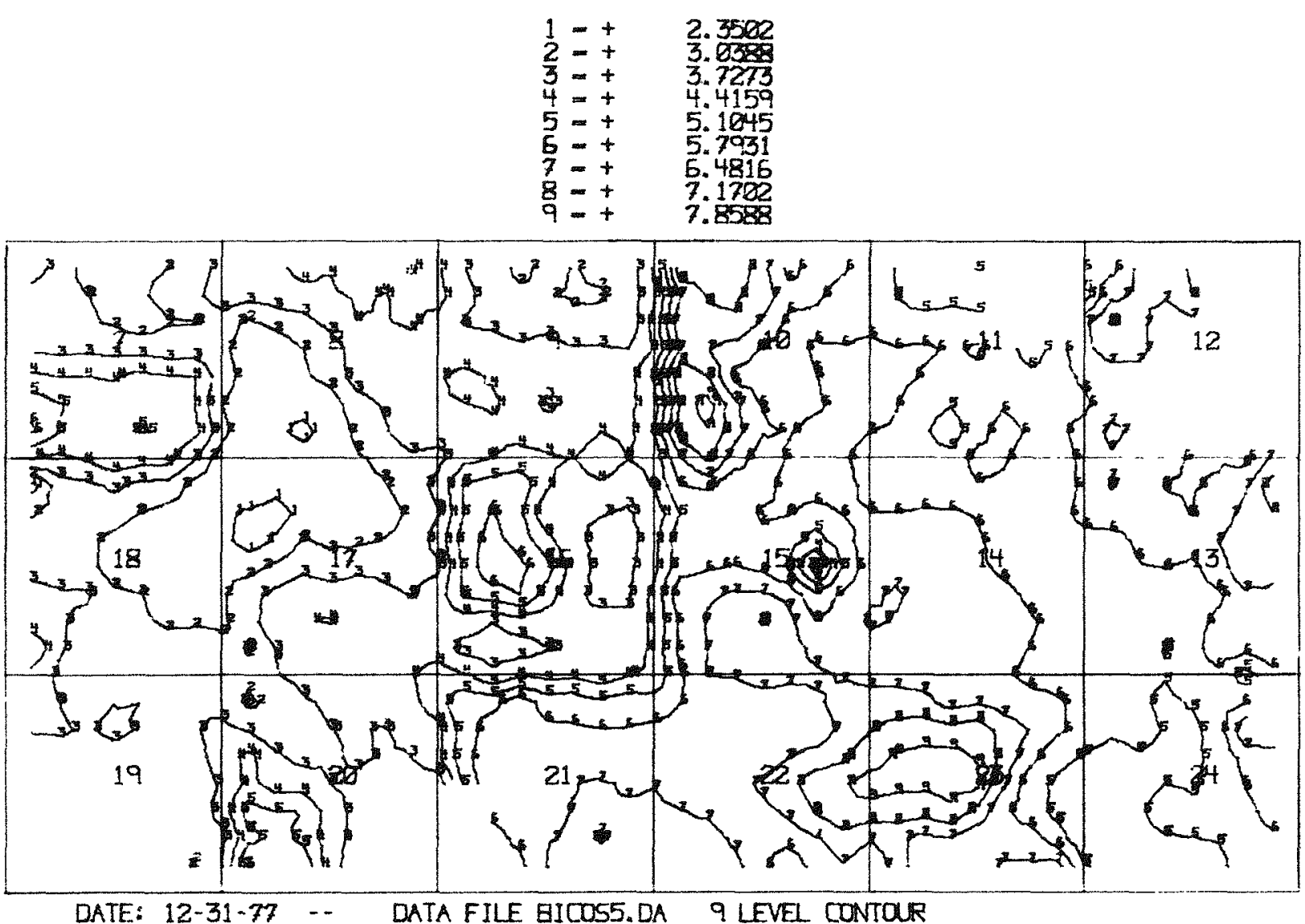

FIGURE 25. - Contour map of $\mathrm{Bi}^{214}$ in Sutherland. 


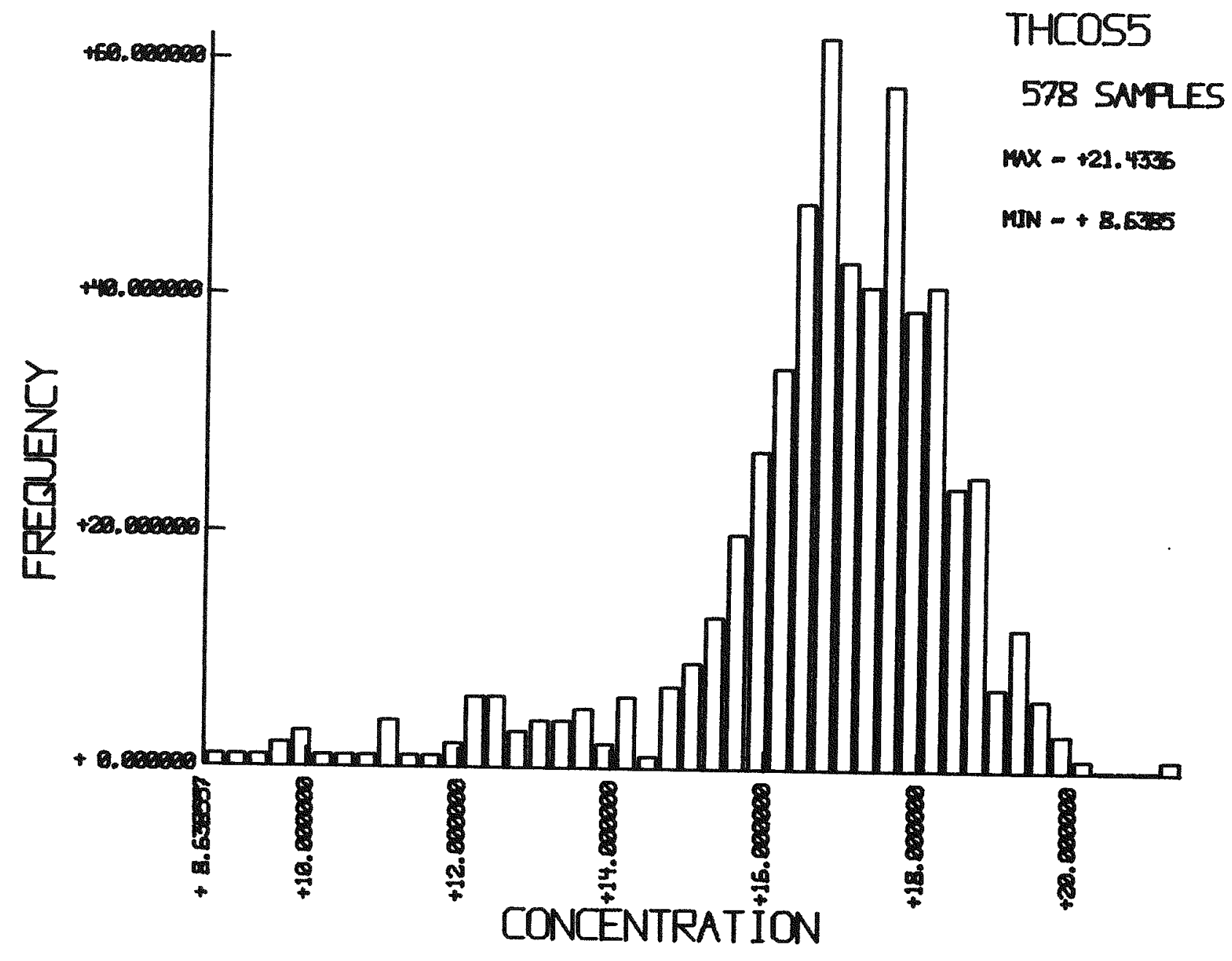

FIGURE 26. - Frequency histogram of $\mathrm{Tl}^{208}$ in Sutherland. 


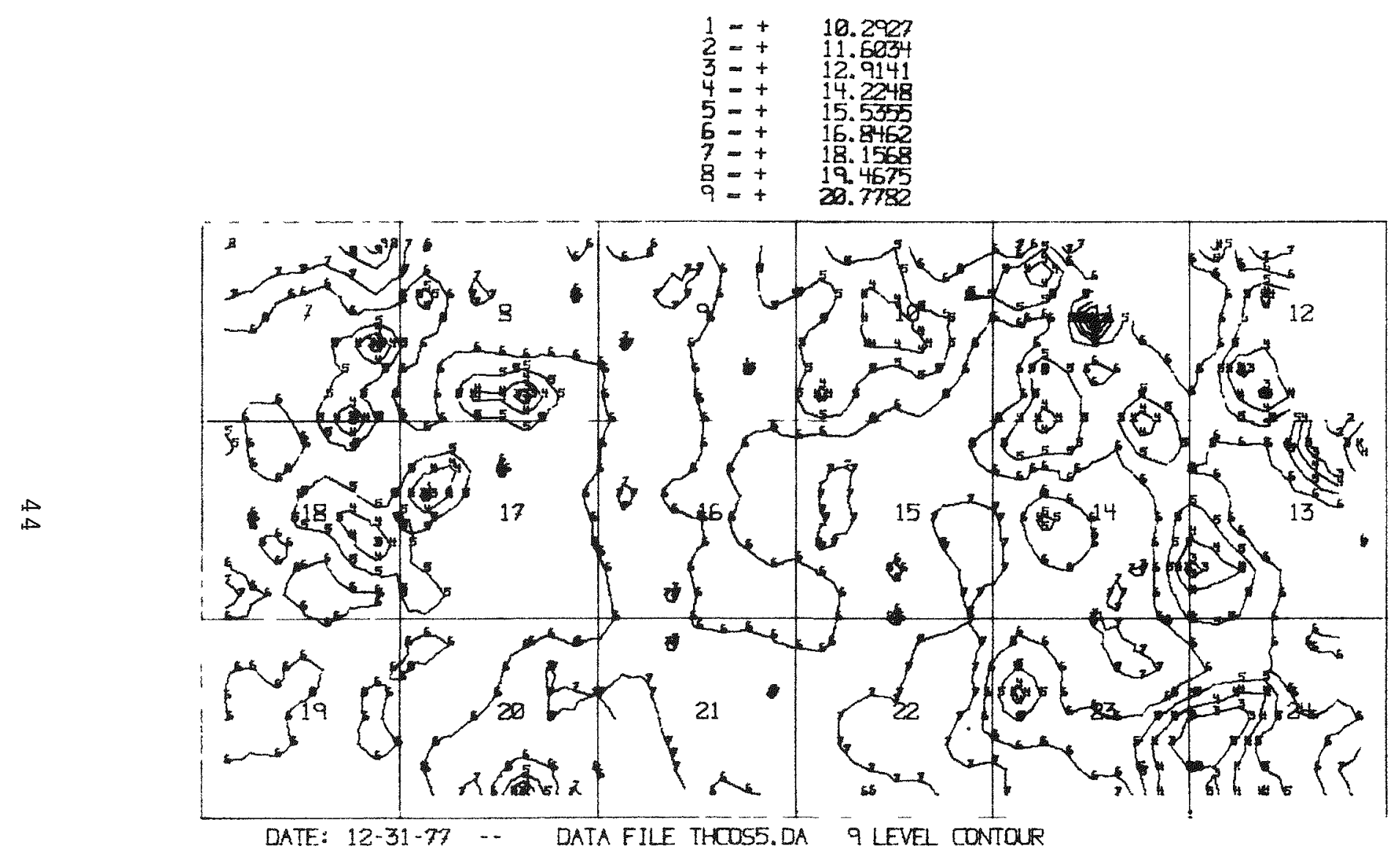

FIGURE 27. - Contour map of $\mathrm{TI}^{208}$ in Sutherland. 
TABLE 4. - COMPARISON OF SURFACE RADIATION TO SUBSURFACE'SOIL SAMPLE ACTIVITY.

\begin{tabular}{llcccc}
\hline & & Surface Radiation & & $\begin{array}{c}\text { Subsurface Soil } \\
\text { Sample Activity }\end{array}$ \\
\hline $\begin{array}{c}\text { Sample } \\
\text { No. }\end{array}$ & oK & ppm U & ppm Th & Raw Total & total counts/gm. \\
\hline $23-17$ & 1.67 & 8.5 & 16.2 & 70711 & $11.2 \pm+1.0$ \\
$23-19$ & 1.73 & 8.0 & 16.8 & 72681 & 20.3 \\
$14-23$ & 1.83 & 5.5 & 18.5 & 67061 & 22.3 \\
$17-10$ & 1.56 & 1.6 & 9.9 & 42335 & 28.9 \\
$10-27$ & 0.45 & 9.3 & 15.7 & 72977 & 35.7 \\
$15-23$ & 2.30 & 1.2 & 19.2 & 64432 & 11.8 \\
$17-11$ & 1.81 & 1.4 & 12.3 & 47991 & 38.1 \\
$13-17$ & 1.26 & 5.0 & 13.5 & 52610 & 29.9 \\
\hline
\end{tabular}

the rate of 18 values per mile. The readings were recorded on magnetic tape. Additional data also recorded were clock time, doppler down-track, and doppler off-track information. Photographs were taken of every data point to firmly fix the ground position of each magnetic reading. The ground position of each flight line and data point was established from the photograph and each data point was given an $x$ and $y$ coordinate position.

The peripheral profiles were loop-tied to each other to eliminate heading effects and diurnal variations in the earth's geomagnetic field. An 880-foot grid of the total field values minus 50,000 gammas was computed for contouring. Figure 28 shows the total field magnetic map from data provided by Senturion Sciences, Incorporated.

The interpretation of the magnetic map by personnel at Senturion sciences revealed a strong south gradient which is in opposition to the regional dip (west to northwest) on the east flank of the Forest City Basin. Part of the south magnetic gradient was attributed to the regional gradient in the earth's geomagnetic field, but this only accounts for about 40 gammas. The total field map shows a gradient of 100 gammas which reflects a deep-seated subcrustal change unrelated to the tectonic 

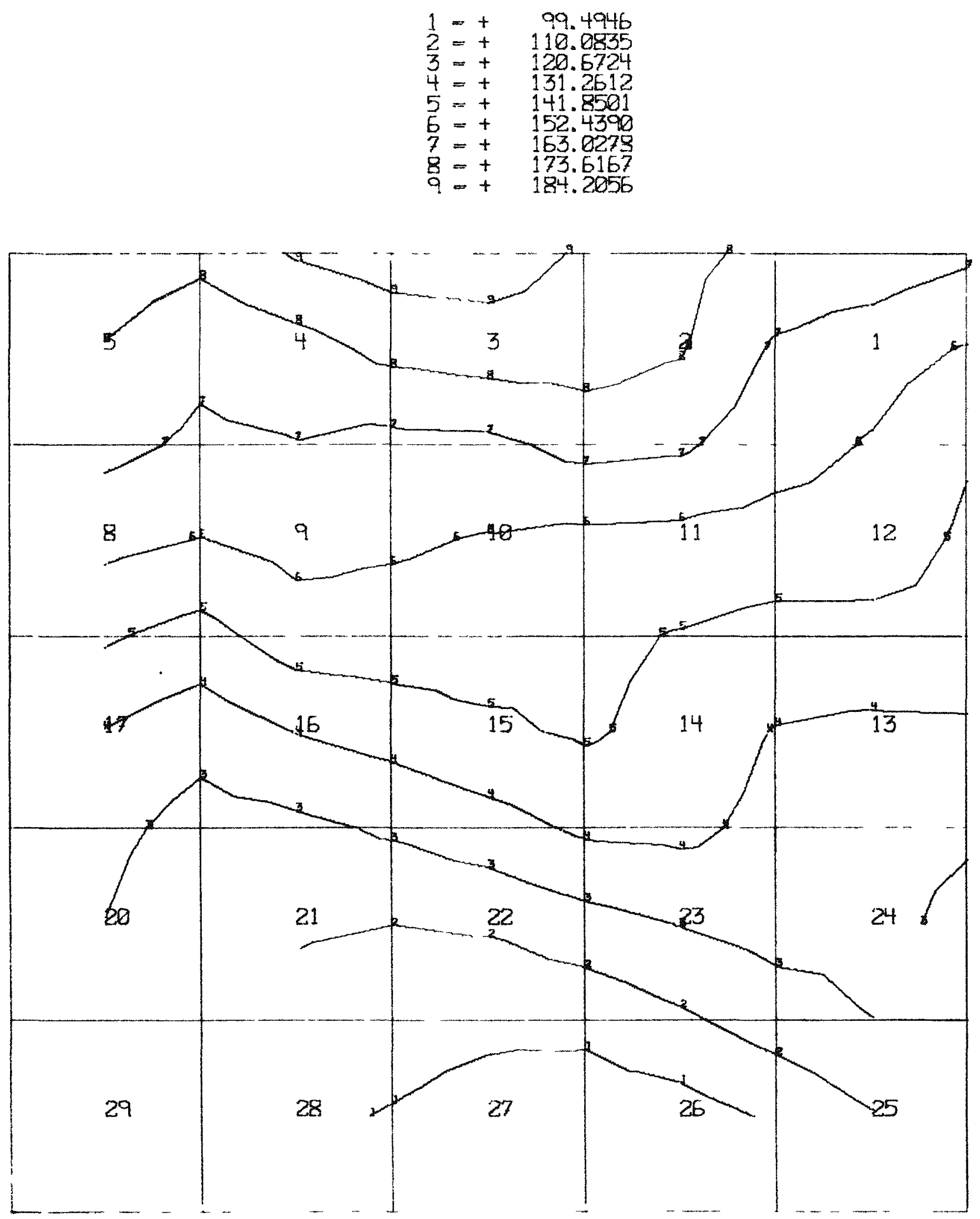

DATE: $12-31-77 \ldots$ DATA FILE SMAONT. OA

$\Gamma \quad R E$ 28. - Total field magnetic contour map of sutherland. 
configuration of the Forest City Basin. This deep-seated effect was removed by applying a first-order polynomial to the magnetic values which should reflect changes within the crustal rocks, and possibly, within the sedimentary section. The first-order residual map shows a pronounced northwest to southeast trend in spite of the NNE-SSW tectonic trends within this part of the basin (see figure 29). This trend was attributed to density and susceptibility changes within the basement rocks.

\section{Gravity Survey}

About 300 gravity readings were taken using a Worden gravimeter. The readings were taken partly at 500-foot intervals and partly at 0.1-mile intervals. The elevation of each gravity station was determined to 0.01 foot with a transit level. Density profiles were plotted from the station valves up or down the terrain corrections. A value of 2.2 was selected as being the most representative. The normal corrections for latitude, free air, Bouguer, terrain, and tidal effects were made to each gravity reading.

A contour grid of the corrected gravity values was computer calculated, and a Bouquer gravity map of the area surveyed was contoured at a contour interval of $0.2 \mathrm{milligal}$ (see figure 30 ).

The Bouguer gravity map also shows a strong southerly gradient. First-order, fifth-order, and eighth-order residual maps were calculated and contoured as with the magnetic data. Personnel from senturion sciences indicated the fifth-order residuals should begin to reveal trends controlled by structural or lithologic changes within the sedimentary section, as indicated in the fifth-order residual gravity map (see figure 31). The northeast trend of the small Mississippian oil field in section 14 of the survey area becomes apparent as well as a similar trend through sections $I$ and $I I$.

Aerial Hydrocarbon Survey

A survey by Geophysical Systems Corporation, Dallas, Texas, to determine hydrocarbon gas seepage in the Greenwood county survey area used an airborne hydrocarbon gas sensor which measures "ground level" methane by irradiating the surface with pulsed radio waves, and measuring the reradiated radio waves characteristic for methane. The apparatus is operated from a helicopter.

This survey shows minor gas seepages in the southwest and southeast sections of the survey area (see shaded areas of figure 32). Highest concentrations of gas seepage are in the southwest portion of sections 17 and 19 , and the south-central portion of section 24. Additional minor seepages occur in the northeast portion and east-central portion of section 9 and south-central 


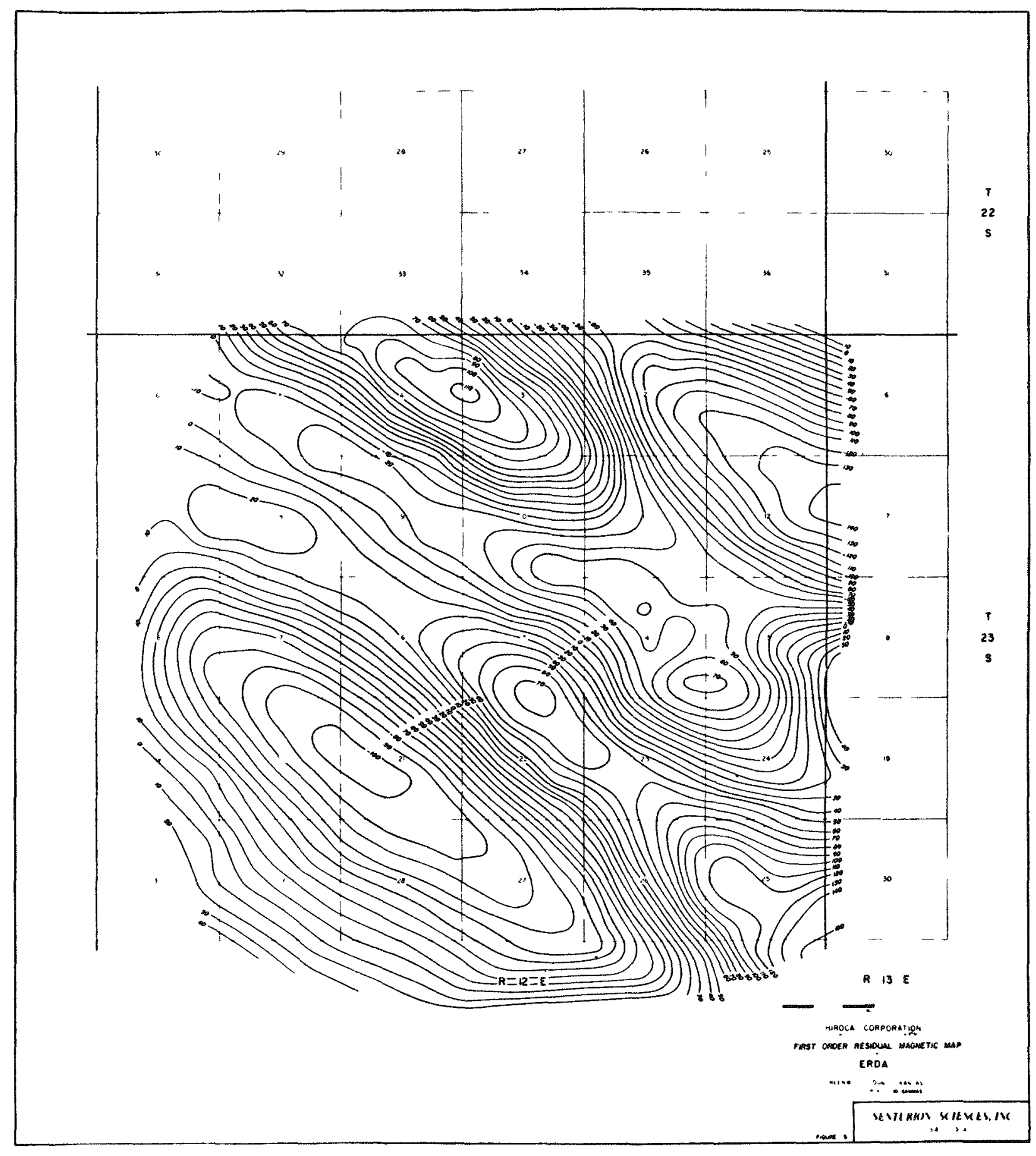

FIGURE 29. - First-order residual magnetic contour map of Sutherland. 


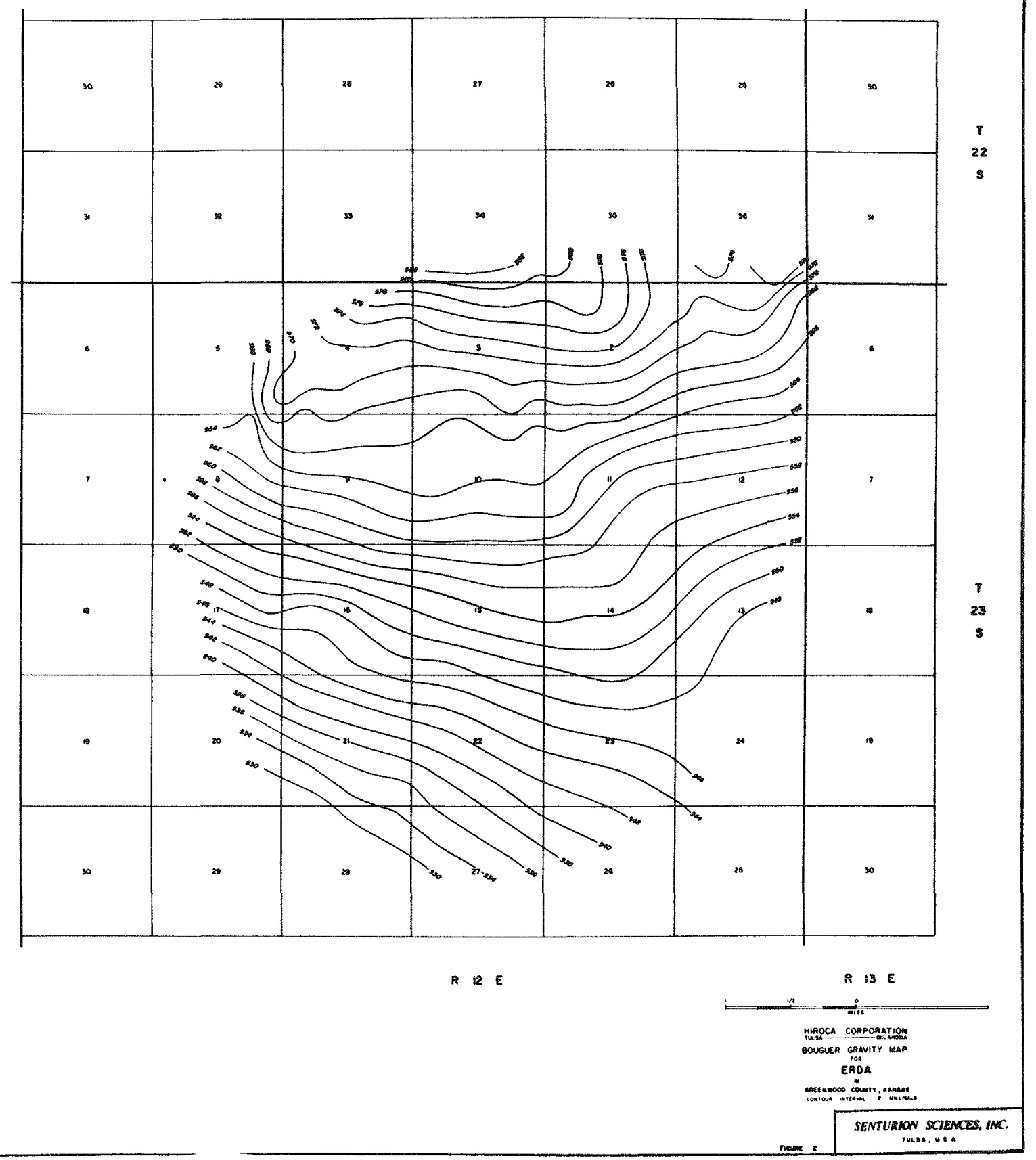

FIGURE 30. - Bouguer gravity map of sutherland area. 


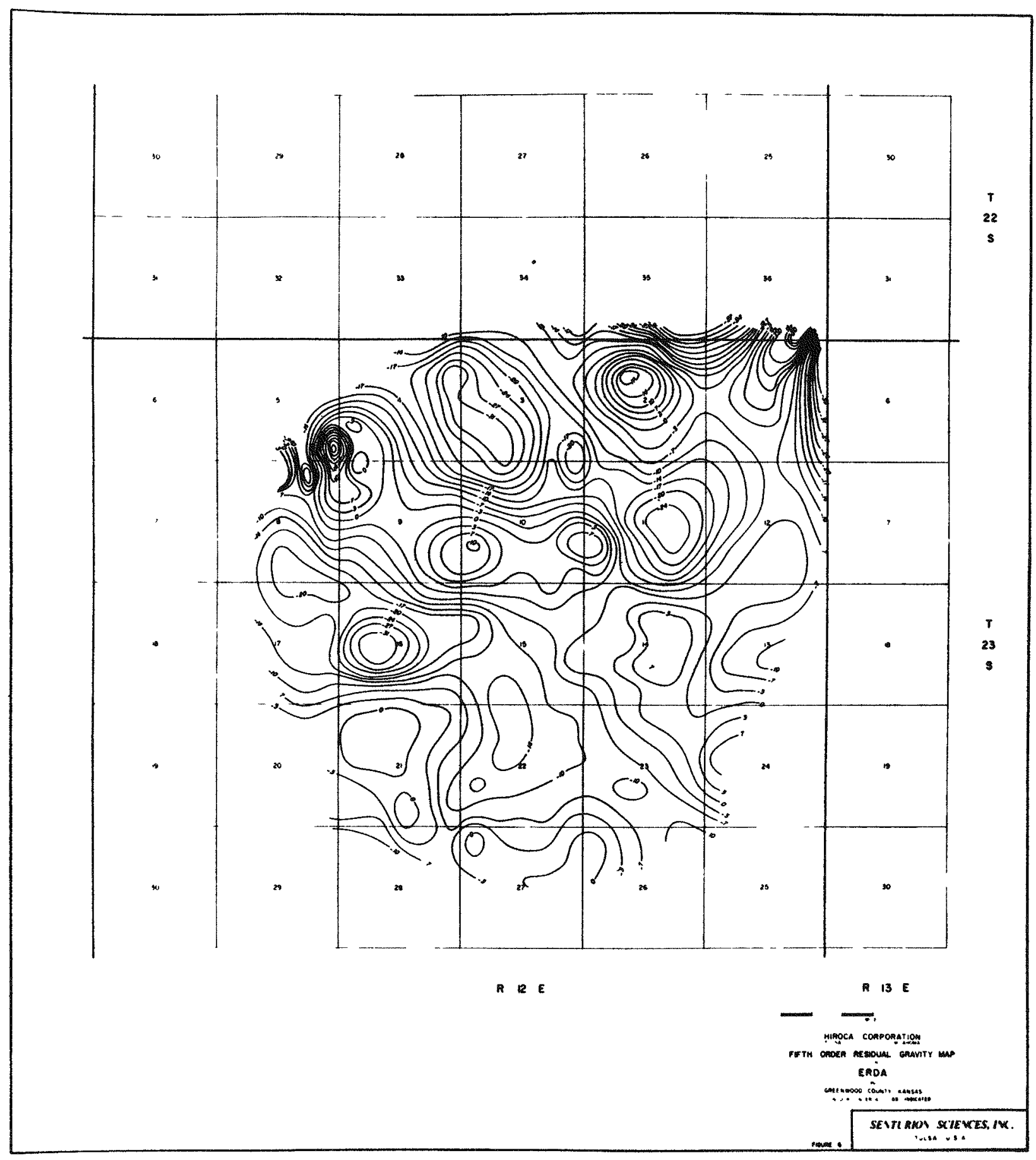

FIGURE 31. - Fifth-order residual gravity map of Sutherland. 


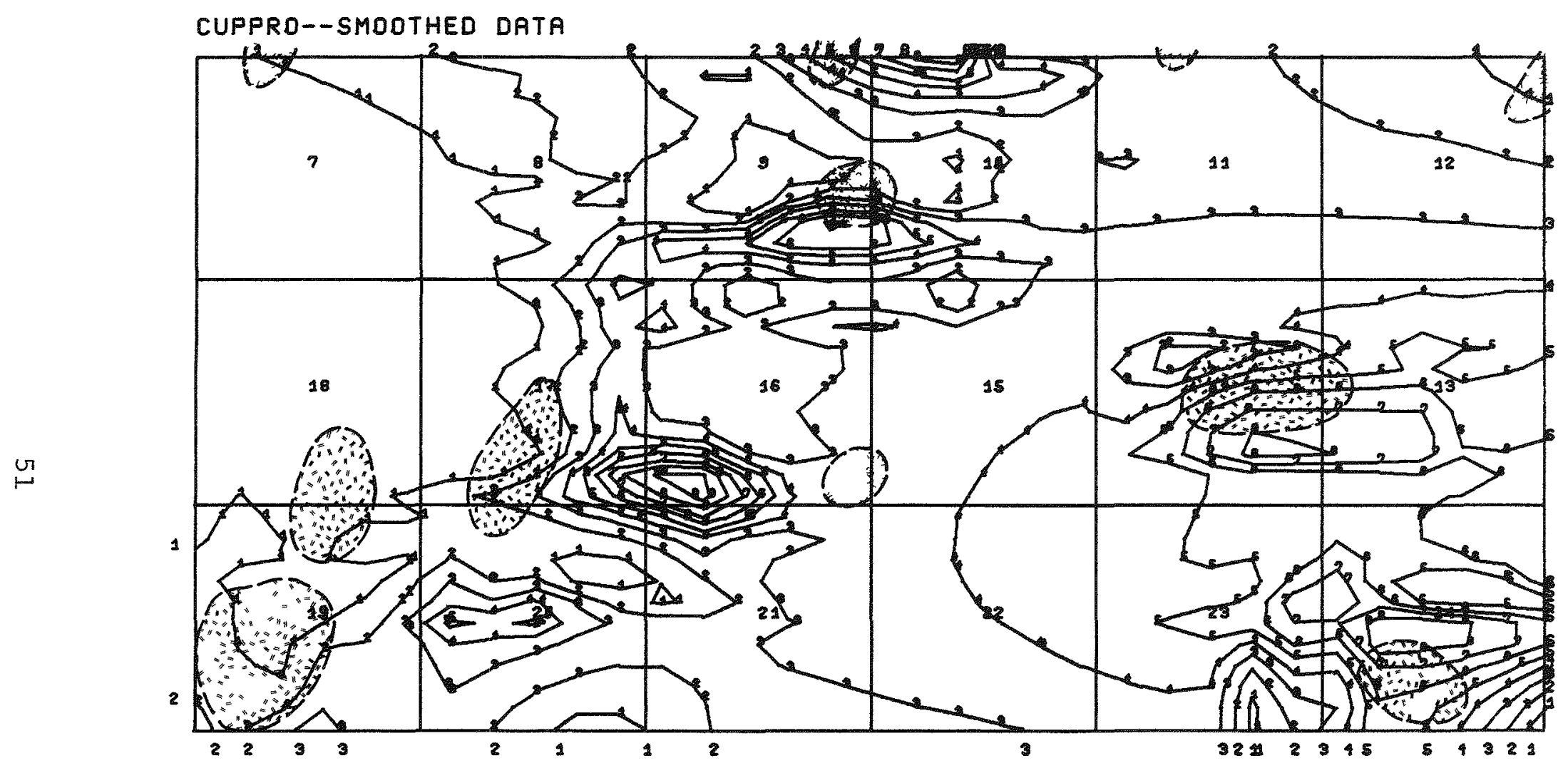

FIGURE 32. - Free hydrocarbon gas survey of sutherland. 
portion of section 18. The heavier shading indicates a higher relative amount of methane measured.

Cup survey

A report by Tripp (18) that told of measured rates of hydrocarbon gas and radioactive material movement through the earth to the surface partly instigated a brief program of measuring the amount of gas permeating from the soil. A theory was postulated concerning the saturation of gas in various types of soils which would limit the amount of gas liberated during the soil gas analysis procedure. Specifically, the maximum amount of hydrocarbon material the soil could adsorb would possibly be a function of soil type, pH, moisture, and mineral content. Thus, the background level of hydrocarbon gas would be a very complex value to obtain. Since the soil is saturated with hydrocarbon material over and near a hydrocarbon reservoir, then the additional quantities of hydrocarbon material -- mainly gas -- diffusing from the reservoir must pass through the soil and evaporate into the atmosphere.

A simple procedure was devised to briefly test this theory. A Hewlett-Packard chromatograph, model 5711A and the HewlettPackard integrator, model $3380 \mathrm{~A}$, that was used in the soil-gas analysis program were mounted in the radiation measurement truck. Various sampling sites were chosen which included all of sections 9 and 20, about one-half of section 24, and selected sites in sections 13, 14, 16, 17, and 19 .

The chromatograph was warmed-up and calibrated by injections of a known-concentration hydrocarbon blend. (The chromatograph response was calibrated about every two hours in the field.) After the instruments were at operating temperature and calibrated, the operators drove to a sample site, dug a hole about four inches deep, took an air sample which was injected into the chromatograph, placed and sealed an inverted sample cup in the hole, filled in the dirt around the hole, and proceeded to the next sample site. The air sample analysis was recorded and integrated with the integrator output showing concentrations of $\mathrm{C}_{1}$ to $\mathrm{C}_{4}$ hydrocarbons. After about 24 hours, research personnel returned to the sample-site, inserted a syringe needle through the top of the cup, and withdrew a sample from the cup using the syringe. The sample was injected into the chromatograph for analysis. The difference between the clean-air and sample analysis was used to calculate the amount of hydrocarbon permeating from the soil per unit area per 24-hour period.

The integrated output was read into the computer and contour maps were produced from these data. Figure 32 shows the contour map (smoothed) for the cup-data. Many areas shown as highs in the cup-data correlate to shaded areas which represent minor 
seepages in the aerial hydrocarbon survey. The northeast corner and east-central portions of section 9, east-central portion of section 14, and southwest portion of section 24 show this correlation. The cup-data map is somewhat misleading in that the hydrocarbon highs are enhanced due to the relatively few datavalues taken. The areas where data were taken will show high contour lines whereas the remainder of the map will show nothing.

Several problems were encountered using the cup-sampling techniques. No sampling cups with desirable characteristics -characteristics such as nonabsorptive to hydrocarbons, not affected by water or heat, and nondestructible -- were readily available. The cups used were large soft-drink containers which were shown to have none of the desirable features. Subsequent testing showed the cups did adsorb hydrocarbons, were affected by water and heat as they became soft and pliable, and were destroyed when removed from the sample areas. Several of the cups were crushed or otherwise destroyed by livestock at the sampling sites during the 24-hour permeation period.

Another problem encountered was due to heavier hydrocarbons $\left(\mathrm{C}_{5}\right.$ and heavier) being present in the samples. The chromatographic column and carrier flowrates used were identical to that used in the soil-gas analysis equipment. Normal-butane required about four minutes to elute from the column and be measured. Frequently, heavier hydrocarbons would be measured from the samples but they required considerable time -- up to two hours in many cases -to elute and thus allow the chromatograph output to return to a normal background level.

The "cup" problem can be eliminated quite easily. There are numerous plastic cups, flasks, and buckets which are economical, nonreactive, and sturdy enough to promote testing in this manner.

A back-flush valve can be installed between the column and detector to eliminate the heavy hydrocarbon problem. A second method would be to install a short column at the injection port to filter the heavy hydrocarbon material out during injection of the sample. The short columns could be replaced whenever complete contamination occurred.

\section{Deep Soil Tests}

Four deep tests for producible hydrocarbons were conducted in sections $9,15,17$ and 20 of the sutherland field. The four drilling sites were chosen on the basis of the results from the soil gas analysis and the magnetic survey conducted. Sections 15 and 20 were associated with hydrocarbon high zones, and sections 9 and 17 with hydrocarbon low zones. Section 15 was also selected on the basis of magnetic interpretation (2). The locations are indicated on the isobutane contour map shown in figure 15. Each 
test involved drilling to the Arbuckle Formation. Each test had a mud-logging, hydrocarbon "sniffer" from surface to total depth and cuttings were collected every 10 feet from surface to total depth. Each test involved a core interval from the lower Kinderhook through the Misener and Viola members into the Arbuckle lime. After the test was at total depth, a suite of open hole logs were run. Schlumberger ran a continuous dipmeter, dual induction-laterolog, compensated neutron-formation density log, and a borehole compensated sonic log on all four tests. A microlog-proximity log was run on the first test. After logging each test, the logs for the four tests were analyzed by Schlumberger's computer processed interpretation log system known as Coriband.

Berentz Drilling Co. of Eureka, Kansas, was contracted to do drilling of the tests. Drilling depth averaged around 2300 feet per test. Baroid mud loggers were contracted to perform the mud logging and sample collection. Kansas Core Laboratory from Wichita performed the coring on the last three tests and Christensen from oklahoma city did the coring on the first test.

The first test drilled was Bock \#1, SW, NE, NE of Section 15, T23S, Rl2E, Greenwood County, Kansas. Elevation was 1065 feet K.B. (measured from the Kelly bushing) and the total depth drilled was 2223 feet. The cored interval was from 2170 to 2223 feet.

The target formation, Viola, was hard dolomite lime, fractured and with some vugs in it. The cracks fluoresced when under ultraviolet light and the core bled some oil when it was first removed. A drill stem test was run by Halliburton Company, but no oil was recovered.

The second test drilled was the stauffer $\# 1, N E, S W, N E$ of section 20, T23S, RI2E, Greenwood Co., Kansas. Elevation was 1136 feet K.B. and the total depth drillled was 2334 feet. The cored interval was from 2313 to 2349 feet.

The target formation, Viola, was found from 2321 to 2326 feet. The Viola was microcrystaline, light gray with a few vugs and fractures. The vugs were filled with crystals and the core in this area fluoresced under ultraviolet light. This core did not bleed much and a drill stem test proved low pressure and a tight formation.

The third test drilled was the Lockard \#1, SW,NE, NE, section 9, T 23S, Rl2E, Greenwood County, Kansas. The elevation was at 1106 feet K.B. and the total depth drilled was 2297 feet. The cored interval was from 2255 to 2297 feet (drilling depth from K.B.). 
The Viola was encountered in the core at 2257 feet and ran to 2266 feet. The Viola was very vugular, pink, microcrystaline dolomite with frequent fractures. The core did not bleed oil upon removal from the core barrel, but did bleed after it was bagged and boxed for shipment. A drill-stem test later proved the formation of no interest to oil production.

The fourth test drilled was the Bonczkowski \#l, SW, NW, SE, section 17, T.23S, RI2E, Greenwood Co., Kansas. The elevation was 1157 feet K.B. and the total depth drilled was 2348 feet. The cored interval was from 2313 to 2348 feet (drilling depth from K.B.).

The Viola was very thin in this core and was encountered at 2322.5 feet and ran to 2328 feet. There was no Misener sand above it, but the Viola itself was vuggy and had free oil in the vugs. The core did not bleed upon removal from the barrel, but did bleed light brown oil after it was bagged, boxed, and shipped to the Research center.

On all four deep tests, the mud logging showed that there are no areas of pressured gas or direct paths of concentrated, migrating gas from surface to total depth. The Lockard and Bonczkowski tests showed the most gas during drilling and, when tested, these proved to have very little pressure.

The lack of traceable gas from total depth to the surface shows a possible displacement or spreading effect that fractured strata over oil accumulations may impose on gas migrating to the surface. Since water was used for drilling fluid from surface to 1600-1700 feet, dissolution of the gas from the water before passing through the mud-logging "sniffer" was possible. Changes in the base line of the mud logs after chemicals were added to the water to create drilling fluids may be a result of gas entrapment and an inability of the gas to escape before measurement, or the change in base line may result from changes in the fluids which created a hydrocarbon effect. In either case, a traceable gas source could not be firmly established.

In both the Lockard and Bonczkowski tests, synergetic log interpretations run by schlumberger showed concentrations of hydrocarbons in the footage drilled. These combined with water saturations, porosity and formation analysis showed that neither test had an optimistic chance of producible hydrocarbons.

Since some gas "kicks" were found in the mud logging, the cuttings from the four deep tests were analyzed. Samples from 50 feet above and below each "kick" were processed using the soilanalysis technique to determine whether these samples showed a preferential adsorption which compared to the "kicks" received by the mud loggers. 
The results of the chip gas analysis for the four wells may be seen in figure 33. Below the 1000-foot level, the concentration of adsorbed methane gas found in the drill cuttings generally increases with depth. The cuttings taken at the first ten feet correlated with the soil gas from the regular drill holes in the same area. Intervals sample were: Bock test, 1350-1540 feet; Stauffer test, 1470-1930 feet; Lockard test, 1070-1220 and 13201680 feet; Bonczkowski test, 1400-1530, 1570-1800, and 1850-1950 feet.

Intervals having high gas concentrations and high sandstone percentages undoubtedly represent high gas potential when correlated with valid mud log kicks. High gas concentrations do not correlate well with high shale percentages. The reasoning behind a high analyzed gas concentration and a high limestone percentage must be investigated further.

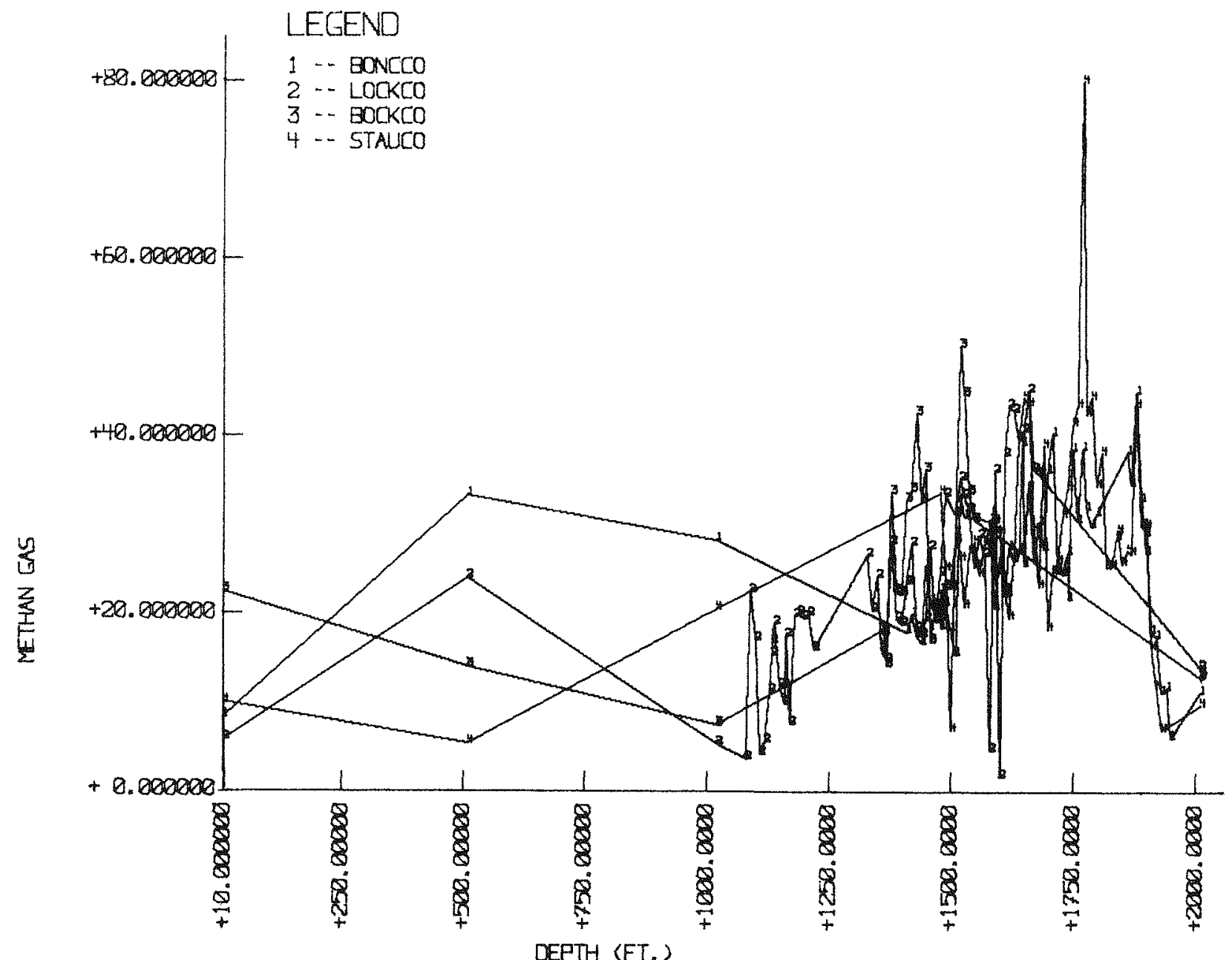

FIGURE 33. - Methane gas contents of drill cuttings from four deep wells in Sutherland. 


\section{Survey Cross-Comparisons and Analysis}

Many areas within the survey boundaries show some promise as representing geochemical anomalies. For a detailed discussion of the data and their interrelationships, one additional test parameter must be shown -- topography.

A contour map of the topography (elevation) is shown in figure 34. The high area in section 7, running south along the section line between sections 17 and 18, drops to a relatively flat area to the east. A creek runs north to south through section 9. The flat area or first plateau drops again to the east at the "ridge-line" through sections 10, 15, and 22. This second plateau which is seen best in the three-dimensional projection (figure 35), extends east to the Verdigris River in section 11,13 , and 24 .

As discussed earlier, the hydrocarbon gas highs, as easily seen in the three-dimensional display of figure 36, corresponded to large gradients of $\mathrm{pH}$ and conductivity. These large gradients are both on top of and just below the "drop" in elevation -- the ridge -- through sections 10,15 , and 22. The elevation gradient is low in soil gas, low in conductivity, and low in $\mathrm{pH}$ (between 7.3 and 8.0 ), and three-dimensional projections of the soil gas

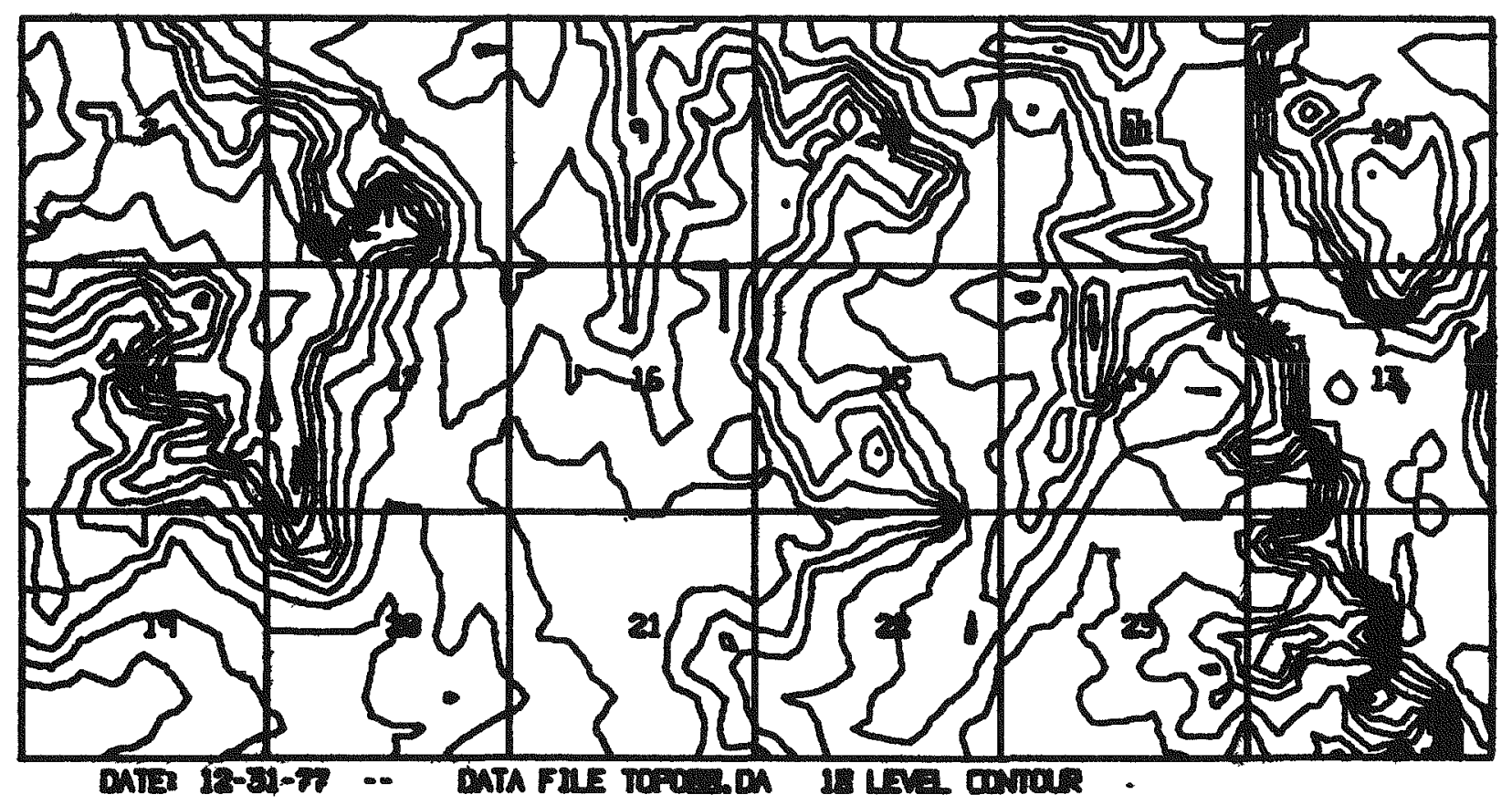

FIGURE 34. - Topographic contour map of Sutherland area. 


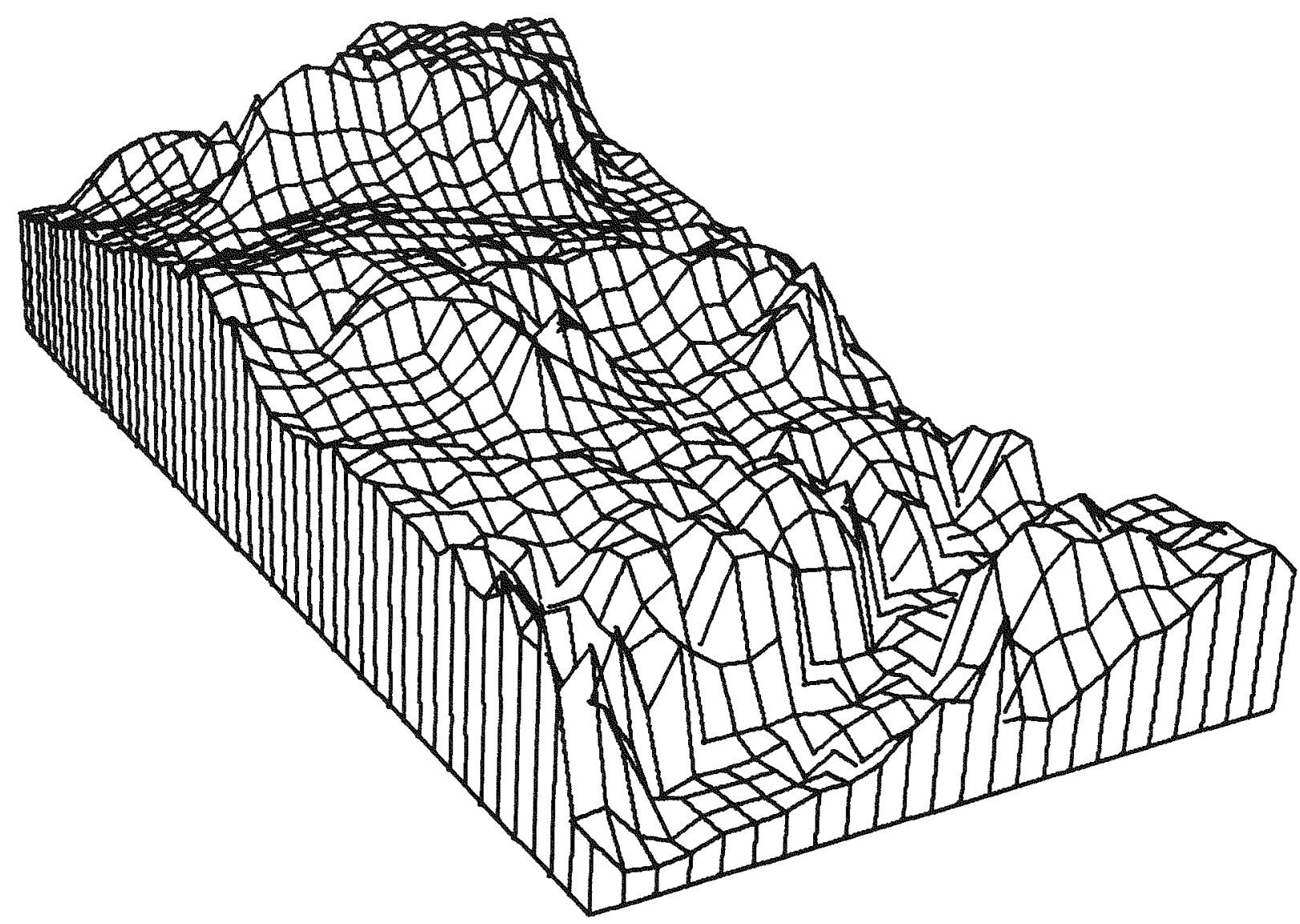

FIGURE 35. - Three-dimensional topographic projection of sutherland area.

(figure 36), conductivity (figure 37), and pH data (figure 38) show this area to be relatively flat. The second topographical plateau area through sections 11,14 , and 23 shows another flat area for soil-gas, conductivity, and $\mathrm{pH}$. The differences between these flat areas are guite pronounced in that the $\mathrm{pH}$ is 9.7 and above and the conductivity is high (between 65 and 74 mhos) on the topographical plateau versus a pH of 7.0 to 8.0 and conductivity of about 8.0 mhos for the topographic gradient. The soilgas is only slightly higher in value for the plateau area compared to the gradient area. The large differences in $\mathrm{pH}$ and conductivity are apparently related to topographical features -high $\mathrm{pH}$ and conductivity values are found on the plateau and low $\mathrm{pH}$ and conductivity values are found in elevation gradient areas. The high gas content, which correlates to large gradients in $\mathrm{pH}$ and conductivity, would thus also be affected by or correlated to topographical features.

This relationship between topography, $\mathrm{pH}$, and conductivity, and soil gas was developed with the different map features 


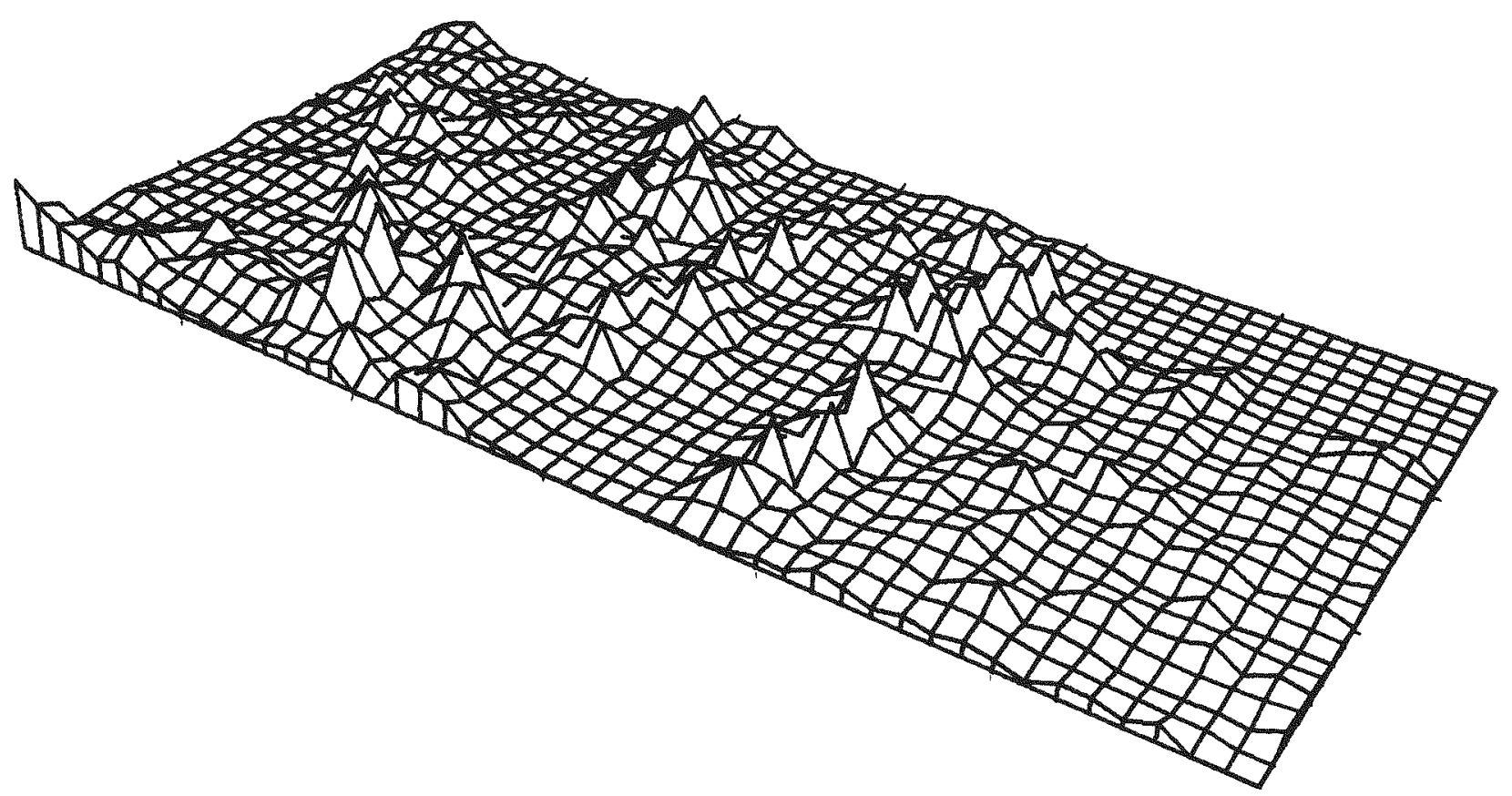

FIGURE 36. - Three-dimensional display of hydrocarbon gas.

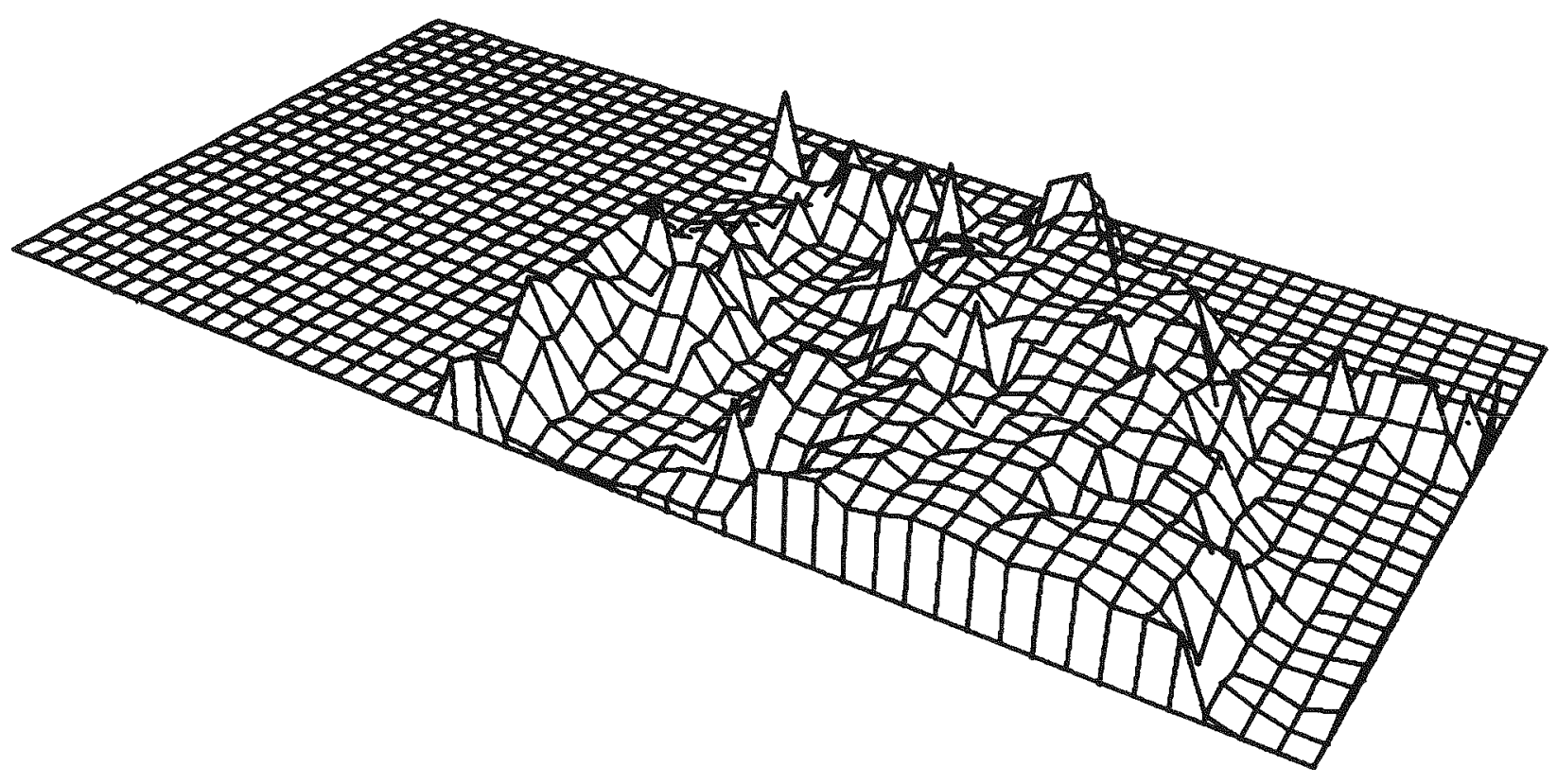

FIGURE 37. - Three dimensional projection of conductivity. 


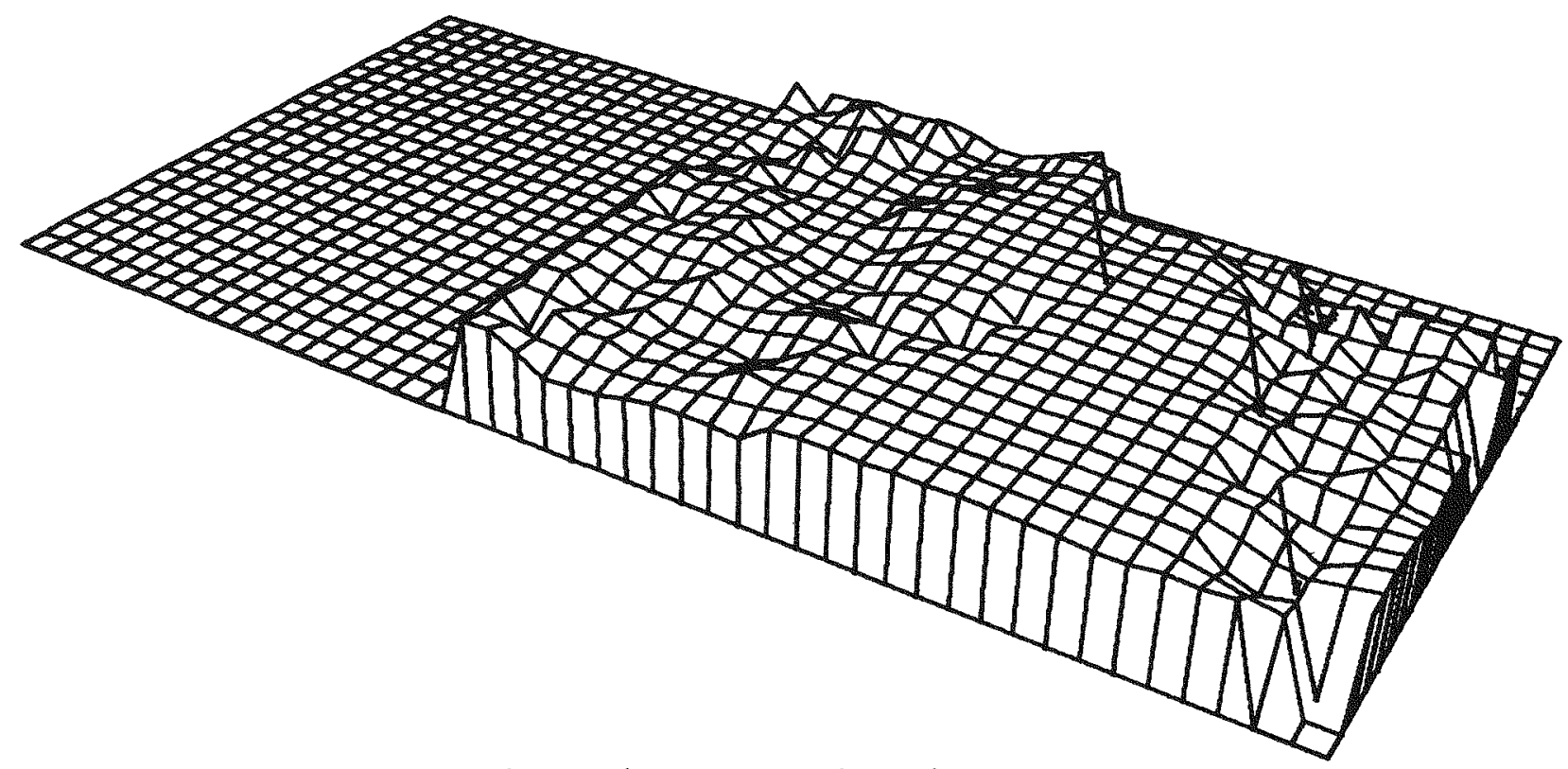

FIGURE 38. - Three-dimensional projection of pH.

through section 10, 15, and 22. The large topographical gradient in sections 12, 13, and 24 show the same type of effect on pH and conductivity - high values above the elevation gradient. The soil gas does not increase in the large gradients of $\mathrm{pH}$ and conductivity.

A large elevation gradient in sections $8,17,20$, and 18 shows little in verifying the relationship between topographical features and soil-gas. (Unfortunately, pH and conductivity data were not obtained for this area.) The $\mathrm{C}_{2}$ to $\mathrm{C}_{4}$ gas highs in section 20 are on a plateau below the elevation gradient, but the remainder of the area shows no such relationship. The methane data show low gas values below the elevation gradient for the entire area. Possibly the low values are shifted due to the larger gradient in elevation. We can extrapolate the relationship of $\mathrm{pH}$ and conductivity gradients to topographical features in this area, but no high gas values are present below the "hill" where the $\mathrm{pH}$ and conductivity gradients would be expected. One logical conclusion is that the two high-gas areas (ridges), one in the east part of sections 10, 15, and 22 and the other in the east part of sections 9, 16, and 21, are unique features in the area.

A technique used to establish relationships between the various geochemical variables is the correlation cloud plot. This cross-plotting of the two variables log (propane) to log (ethane) in figure 39 immediately shows a direct relationship. A regression line of propane onto ethane is drawn and a correlation coefficient of 0.964 indicates a good fit. Figure 40 gives 


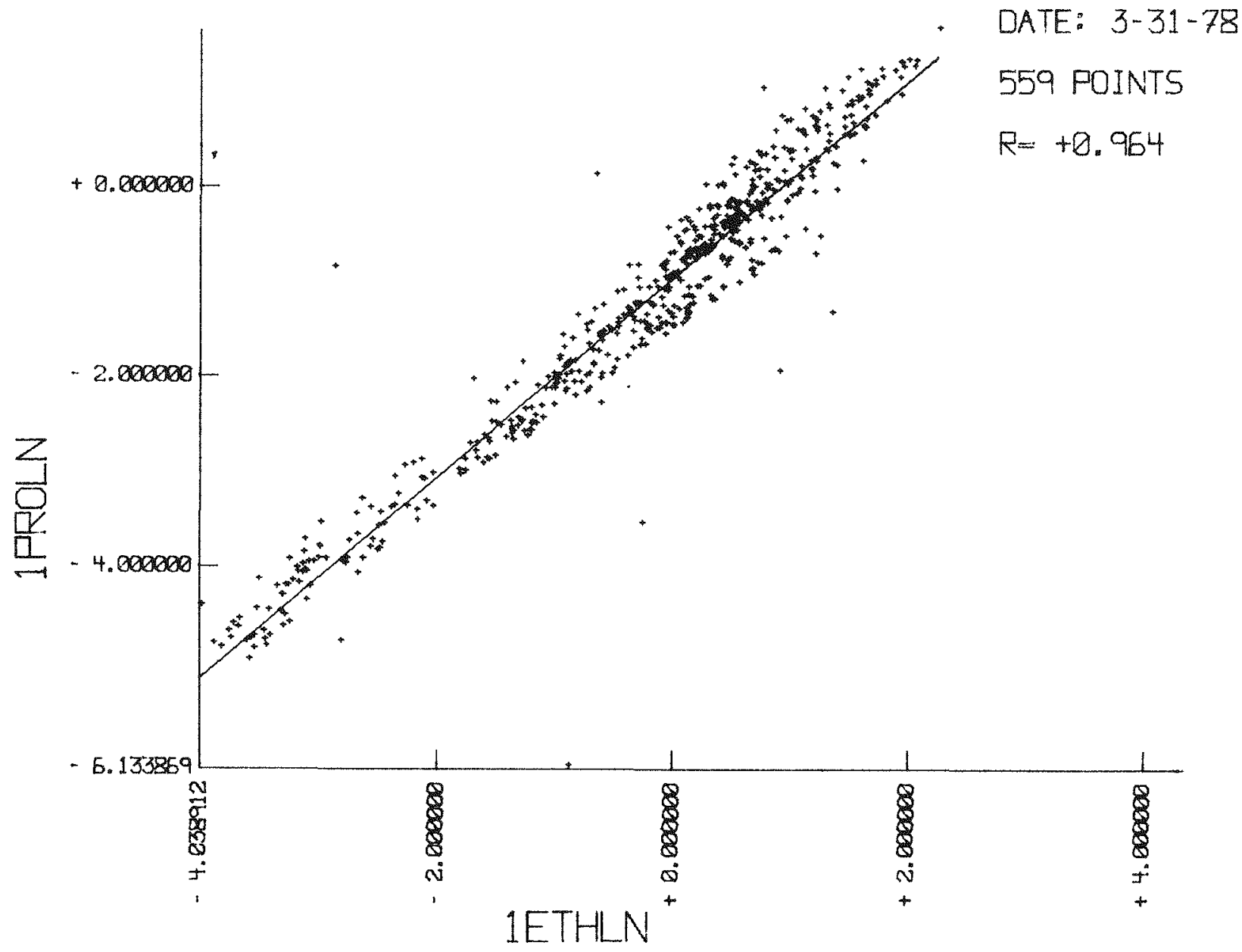

FIGURE 39. - Correlation cloud cross-plot of log propane to log ethane.

the relationship of ethane to methane to be less linear indicating the trend for methane towards uniqueness. A regression line of moisture content to surface area in the cluster cloud plot in figure 41 does not appear to follow the direction of maximum density of points, but there seems to be a slight relationship present. Figure 42 merely indicates how a log-normal distribution

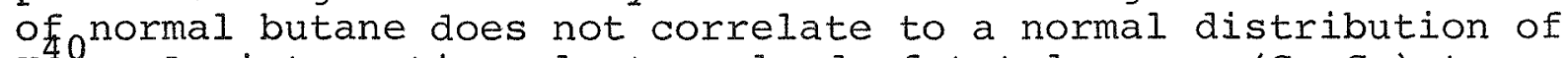
$\mathrm{K}$. An interesting cluster cloud of total gases $\left(\mathrm{C}_{2}-\mathrm{C}_{4}\right)$ to soil $\mathrm{pH}$, figure 43, reveals a bimodal distribution of $\mathrm{pH}$ values with the highest gas values present in the high $\mathrm{pH}$ cluster. The last cluster cloud, figure 44, shows little correlation of surface area of methane content, however, the triangular shape to the cloud bears evidence to the fact that a possible saturation point for methane content exists which is limited by either the surface area available in the soil or other unidentified soil parameters. 


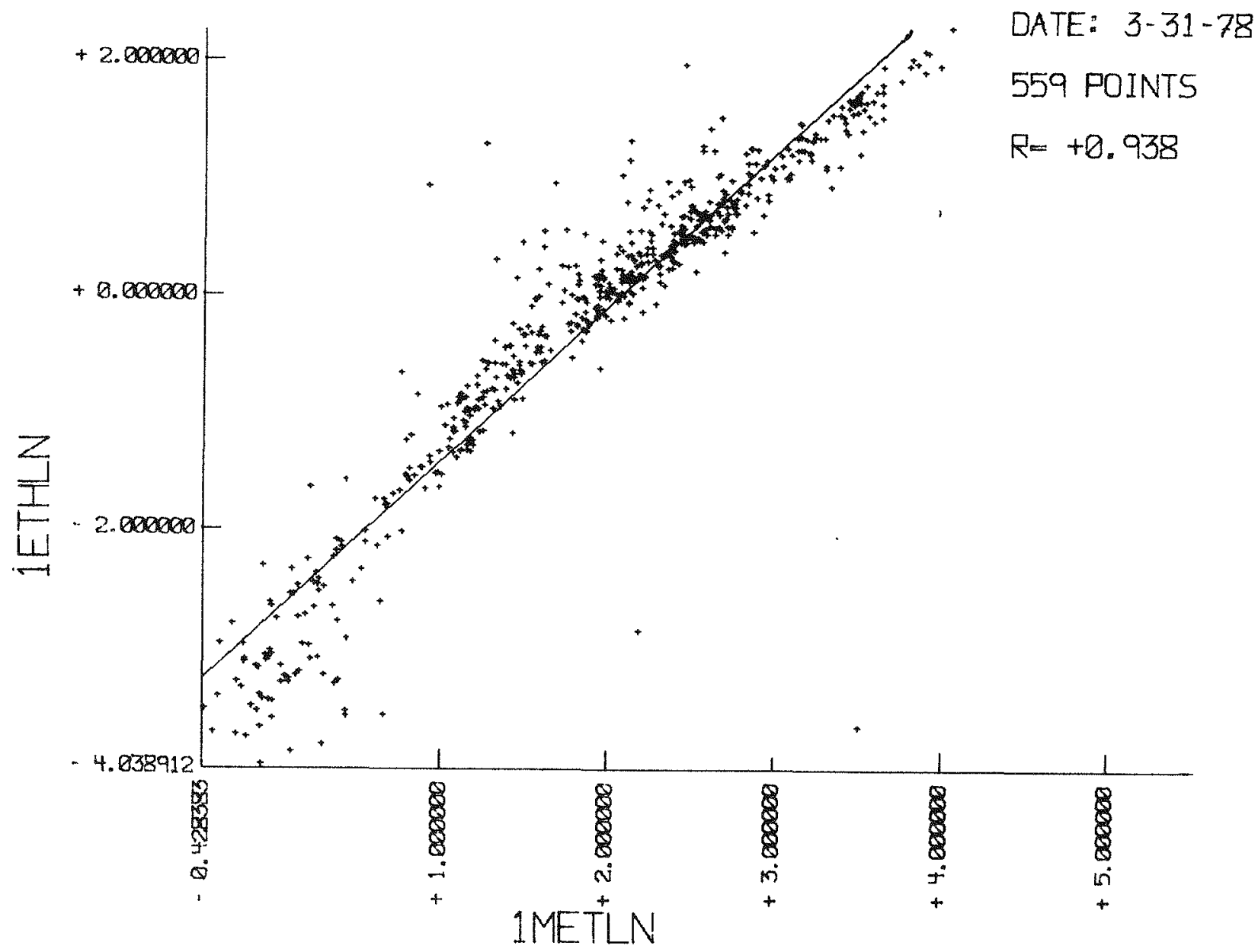

FIGURE 40. - Correlation cloud cross-plot of log ethane to log methane.

Radiation patterns for the survey area are more difficult in determining the possible interrelationships of parameters. Potassium-40, the most abundant element measured, showed high concentrations in the "hill area", sections $7,8,17,18$, and 20, and showed fairly level concentrations over the rest of the survey area. The exception to this description is in the southwest quarter of section 10, an area near the top of a hill, which shows a severe low area. Bismuth data show a system of low areas over the "hill area" (except in section 7) extending up through section 9 and down through section 19. Two high areas, one in section 23 and the other in the southwest quarter of section 10, are present. Thallium also shows low areas over the "hill area" and low areas in sections 24 and 13 .

The low areas of thallium in sections 13 and 24 correlate to $\mathrm{pH}$, conductivity, and topographical features. The low areas in 


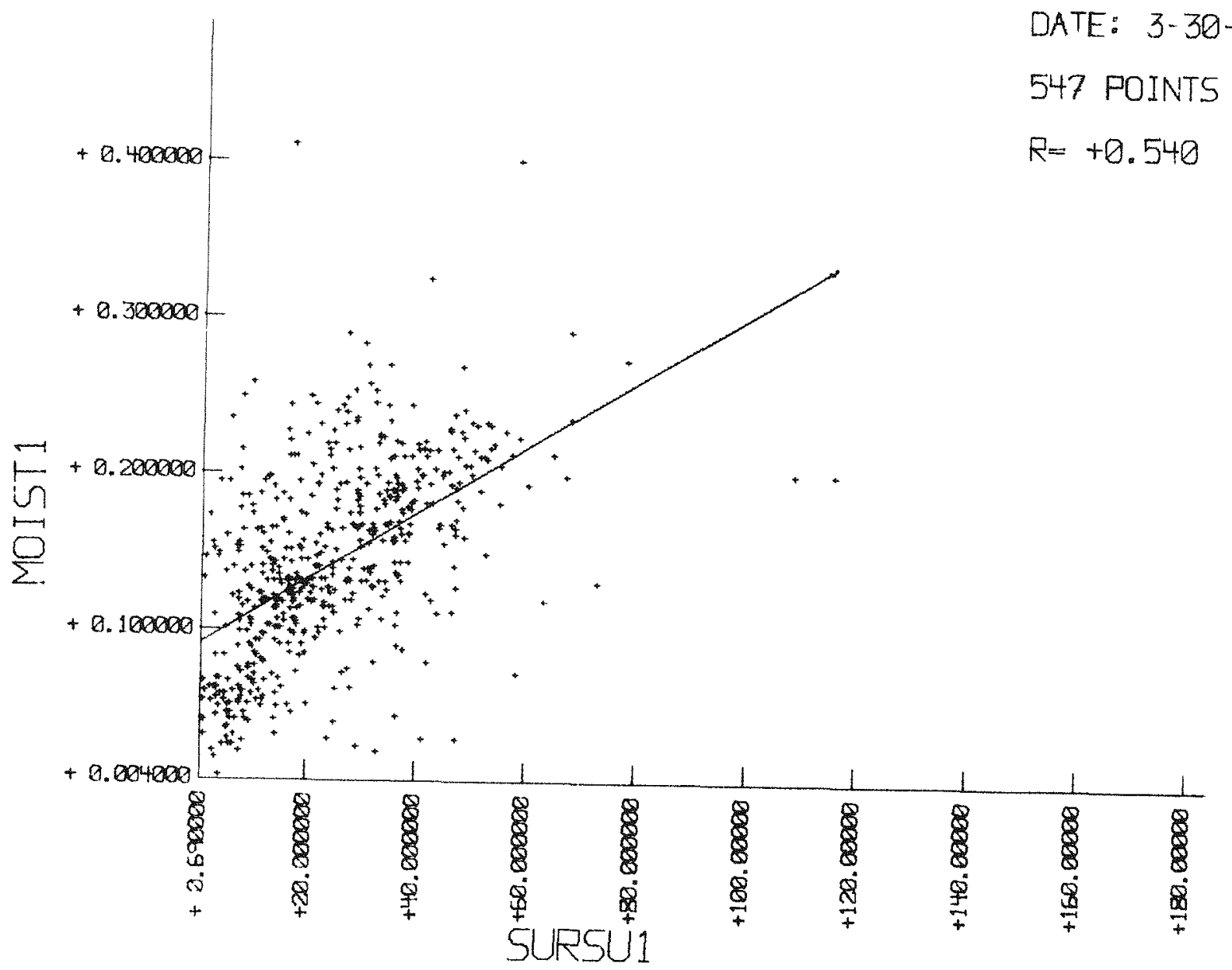

FIGURE 41. - Cluster cloud cross-plot of moisture with surface area.

sections 8,18 , and 17 also relate to topography in that al1 lows are on the high side of a large elevation gradient. Low bismuth data in the "hill area" possibly depict the elevation gradient and top of the hill, but no other relationships are seen for the rest of the survey area. The "hill area" shows high potassium content, but no other relationship apparently exists. The west half of section 10 does appear to have an anomalously low amount of potassium.

Low values of soil-gas and potassium are located in the southwest quarter of section 10. This area corresponds to the theorized anomalous area for soil-gas and potassium. The thalIium data show no features in this area, and the bismuth data show a high in this area. A second area, in the east-central portion of section 15, shows a low bismuth and low soil-gas area, but thallium and potassium show no features in this area. 


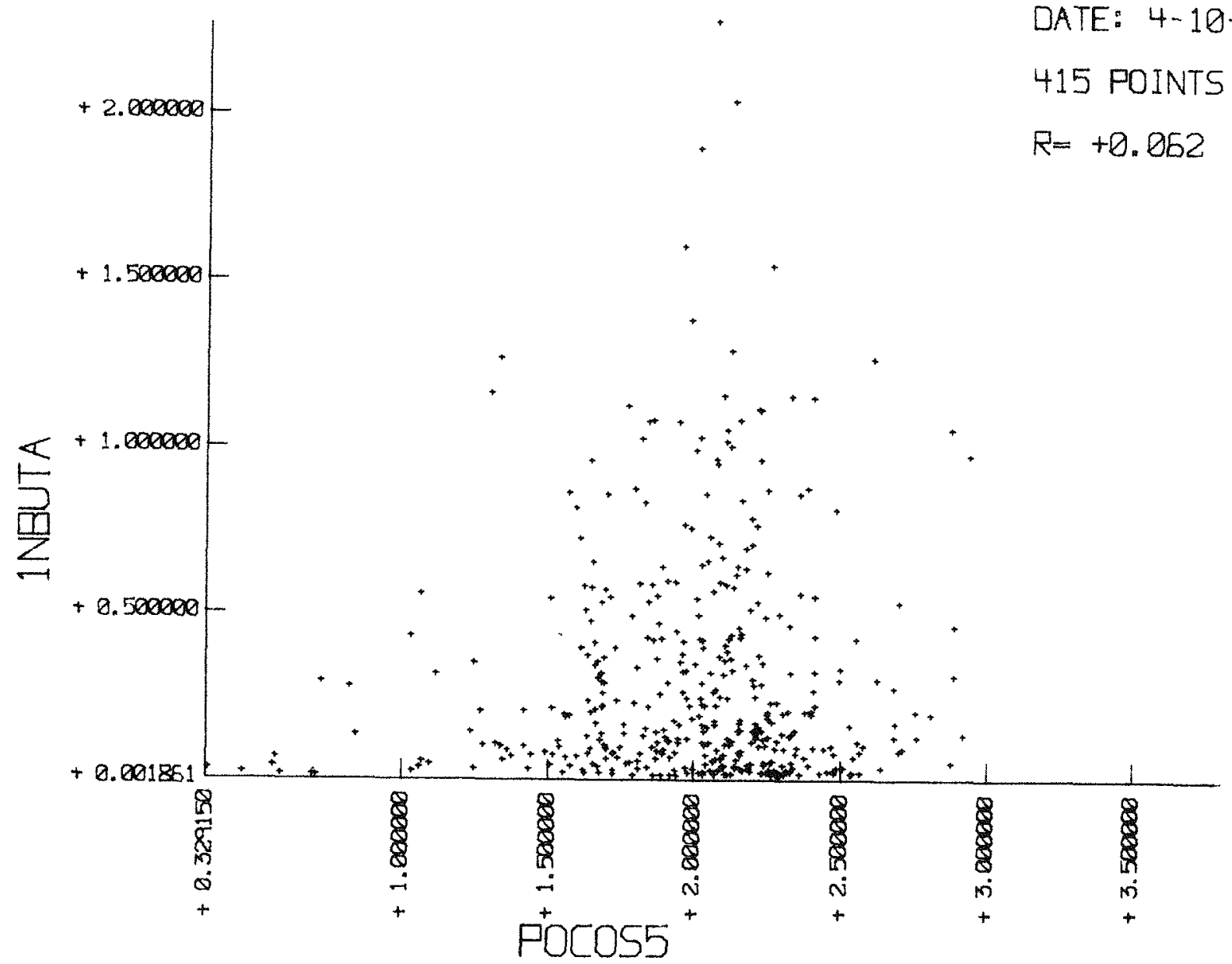

FIGURE 42. - Cluster cloud cross-plot of normal butane to potassium 40 .

The "cup" data (figure 32) show a contour value of "8" near the producing oil field. Other areas showing values in this region are section 24 (value of "8"), section 16 (value of "9"), and section 9 (value of "7"). The area in section 9 closely approximates the soil gas-radiation area in section 10 . The aerial hydrocarbon survey also shows microseepages in the areas in sections $9-10$, and 24 .

\section{Additional Survey Areas}

Rosalia Field

The Rosalia Field is located in sections 2, 11 , and 12 of township 25S, Range 1IE, in Kansas. The field produces from the Squirrel sandstone, a member of the Cherokee group, Desmoinesian stage, middle Pennsylvanian series, Pennsylvanian system of Kansas. The field was discovered in 1965. Waterflood with treated 


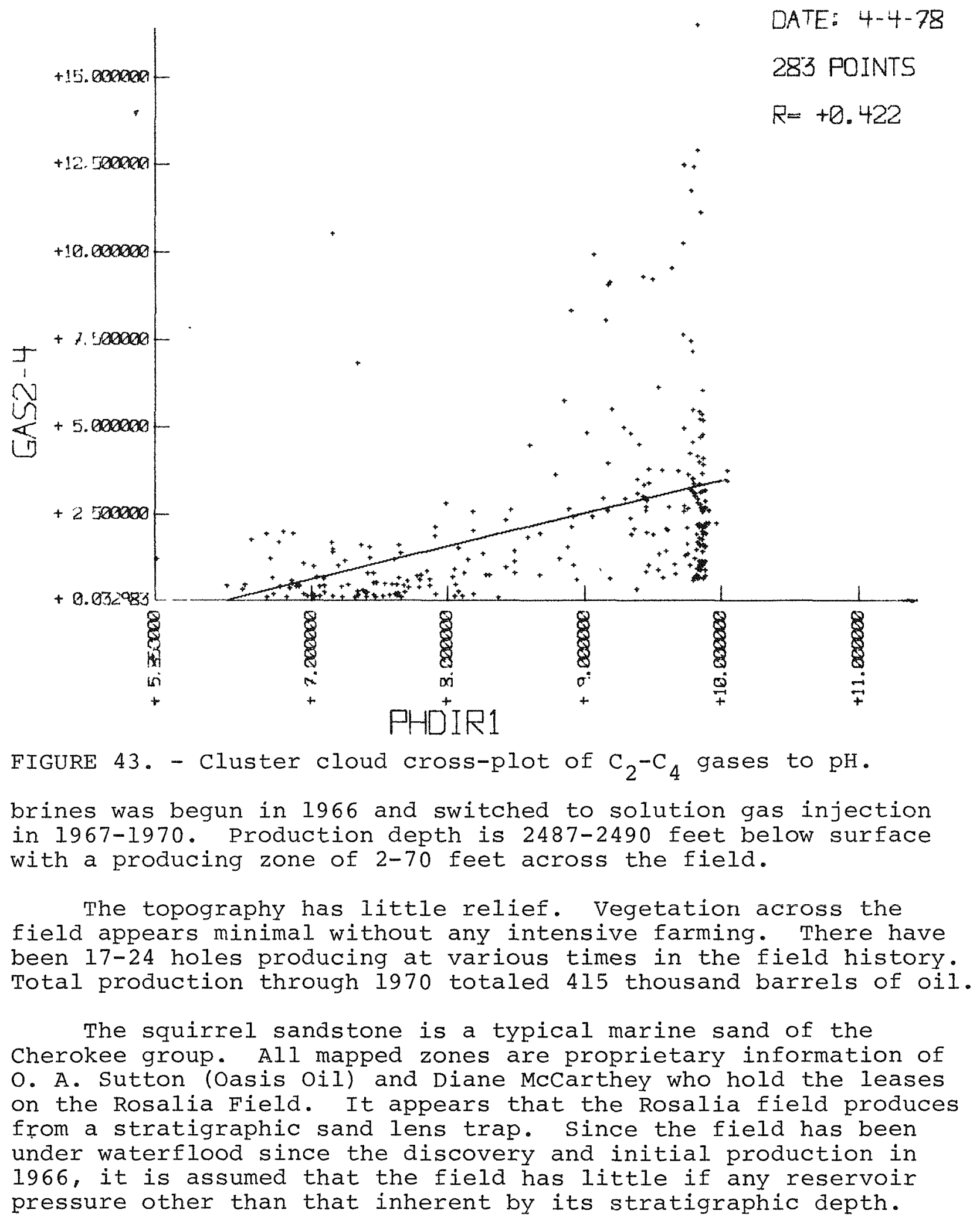




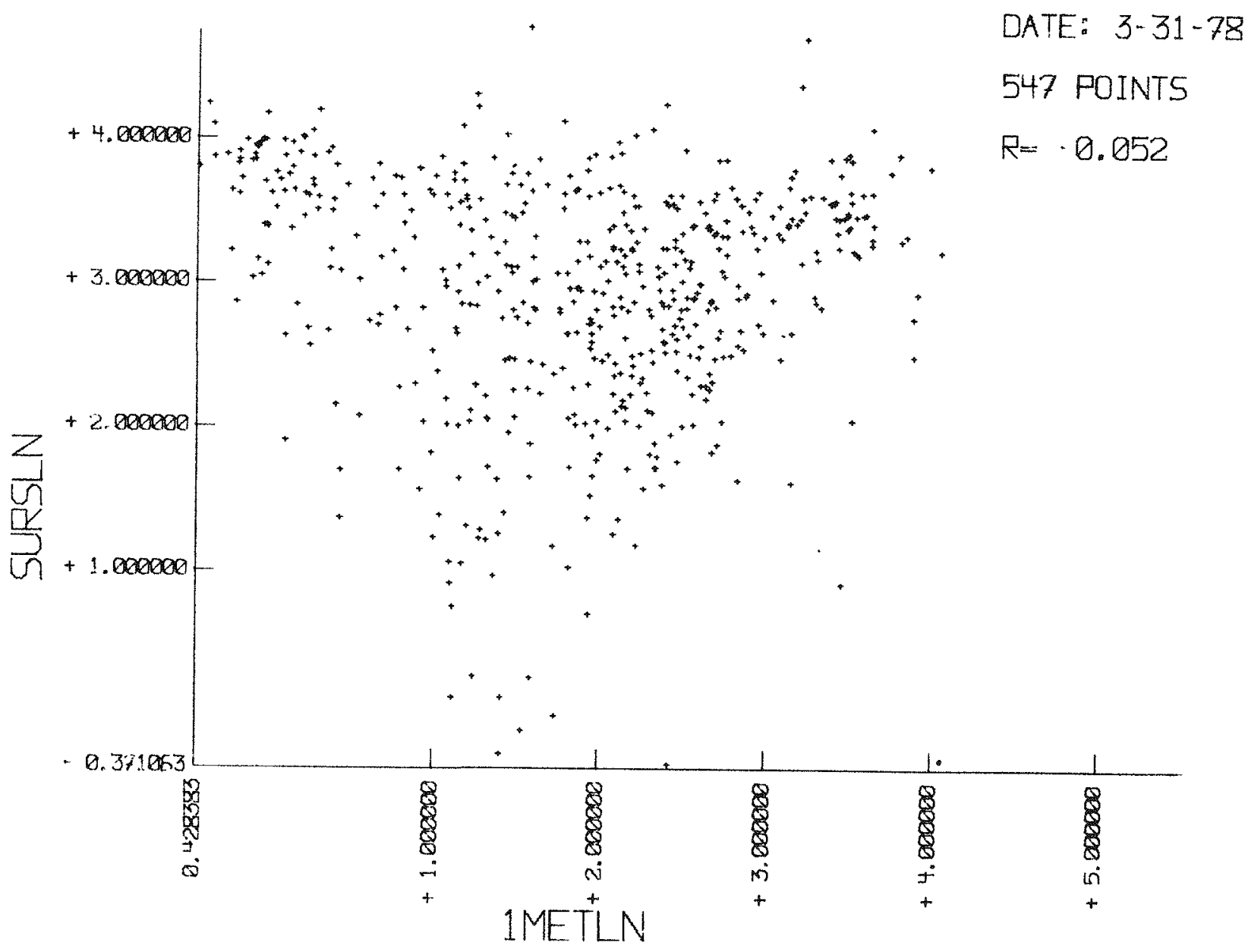

FIGURE 44. - Cluster cloud cross-plot of log surface area to log methane.

The Rosalia Field does not appear to be a shoestring or stringer sand. The nearest producing field is over 6 miles away and does not appear to trend in parallel or opposite directions. Because of its isolated nature, low reservoir pressure and waterflood production history, this field from a geologic standpoint presents a limited potential for migration to develop through any mechanism other than buoyancy.

Geosensors, Incorporated, Dallas, was contracted to perform an airborne gamma-ray and magnetometer survey of the Rosalia test site in Butler County, Kansas, on July 31, 1972. A shake-down test survey of the same site was made with our field truck equipment. The radiation data from the field truck did not correlate very closely to the airborne radiation data. 
Figure 45 shows the resulting contour map of field truck data from the thallium-208 window. Dimensions of the data file are 21 rows, one quarter mile apart, by 49 columns, one eighth mile apart. The lowest radiation level is 1736 counts per two minute counting period, and the contour interval is 121 counts per two minute counting period. Producing oil wells are shown as octagon/triangles; dry holes are octagon/pluses; and gas wells are octagons. The close contour lines going north and south on the far right follow the topography of the land very well. There is a low over the field which is shifted slightly to the right.

Figure 46 shows a contour map of the airborne magnetometer readings from the Rosalia oil field. The well locations are indicated on the map. The small contour circles scattered in a SW by $N E$ direction on the right side of the map are caused by metal buildings, tanks, and pipe yards from the Thrall-Aagard, Wikerson, Teichgraber, and the Sallyards oil fields as shown on the map. Grid lines are one-quarter mile by one-quarter mile.

To see where the high and the low contour values are located, the same magnetic data are plotted as a three-dimensional map in figure 47. All highs and lows are immediately seen, including the metal debris of the various oil fields.

This test site was 10 miles wide and 20 miles long, encompassing both old and new production sites. Access permits for surface work was acquired and the area was flown by magnetometer and multichannel gamma-ray equipment. Our radiometric field survey unit covered 30 square miles of this surface area.

A voluminous amount of data was received from the airborne gamma-ray and magnetic surveys. A large amount of data was assembled based on the Department of Agriculture soil analyses. These soil data were used to give a one-to-one correlation record between soil type and gamma-ray record number. Correlations were attempted on both airborne and ground-based gamma-ray data using the soil type data.

Haskell Area

The Haskell soil gas and radiometric surveys were conducted in Township $15 \mathrm{~N}$, Range 15E, sections 3,4,9, 10 and 11 of oklahoma. Section 10 was the only complete section in this survey. The survey covered an area surrounding two gas-producing wells in section 4 .

This area of eastern oklahoma is a well drilled, known production area for both oil and gas. The survey area itself is located within 2 miles of Haskell, Oklahoma. 


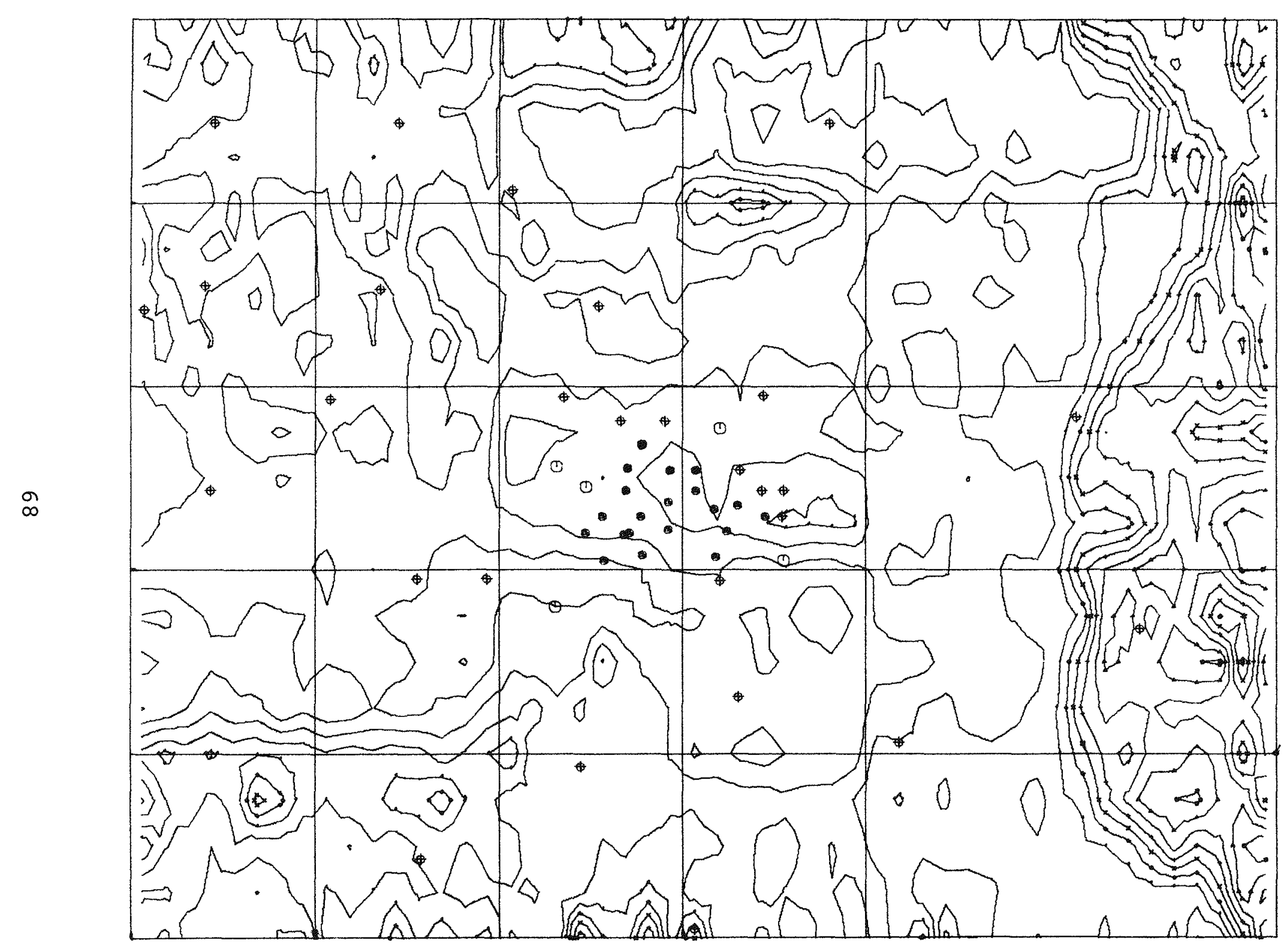

FIGURE 45. - Contour map of TI ${ }^{208}$ in Rosalia. 


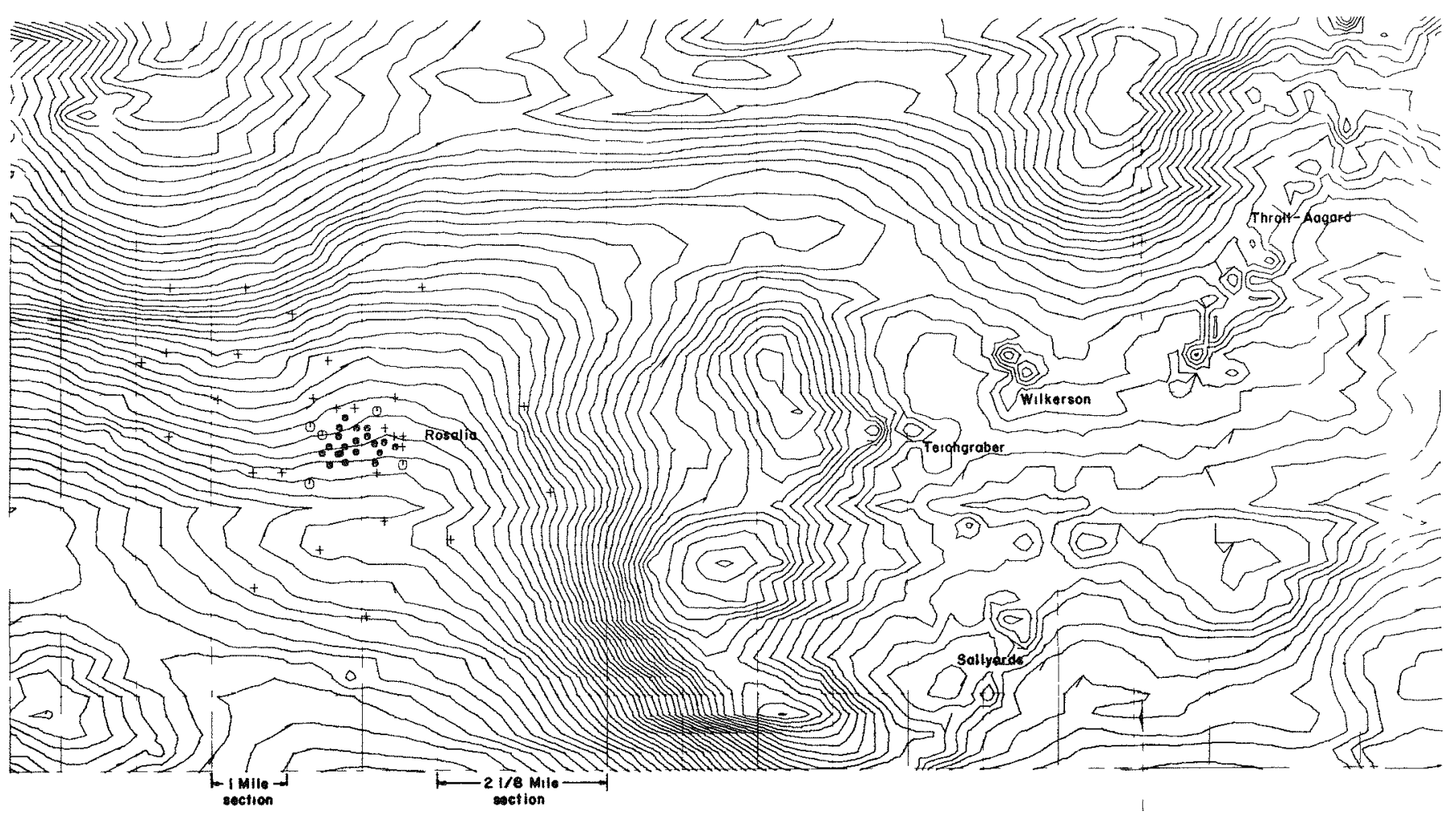

FIGURE 46. - Contour map of airborne magnetic readings over Rosalia. 


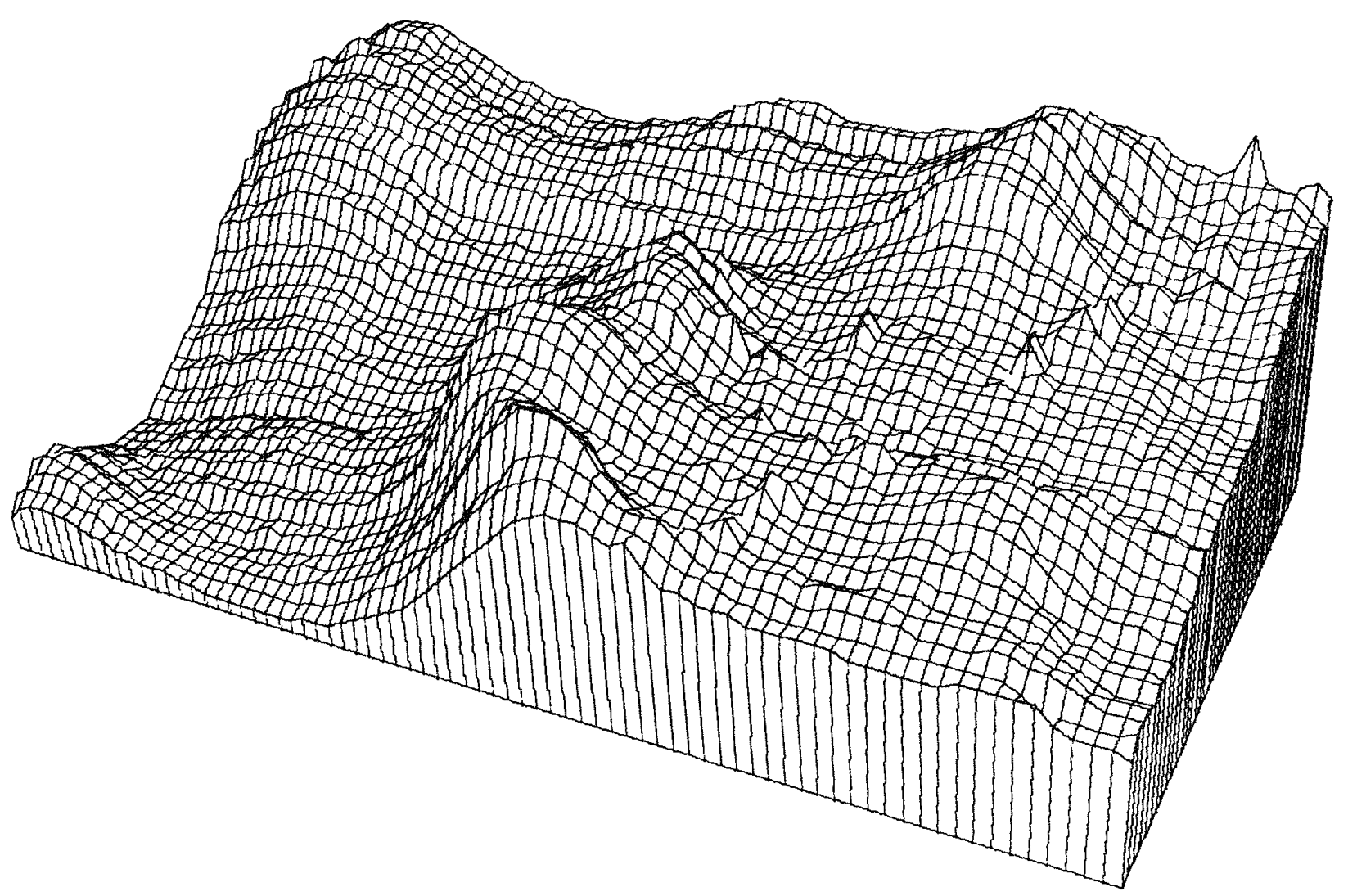

FIGURE 47. - Three-dimensional image of Rosalia magnetic data.

The Haskell survey area has a maximum of 50 feet of relief in section 3. Most of the survey area is low lying with intermittent streams. The streams have wide flood plains in sections 2, 10 and 11. The soil horizon is well developed in sections 2, 10 and 11 with rock outcropping along the 3-4 section boundary.

The producing gas wells in section 4 produce gas from the Dutcher sands which is Upper Dornick Hills in group, Atokan in Series, Pennsylvanian in system, below the Cherokee sands of the Booch, Bartlesville and Burgess which also produce in the area. Oil production in the area comes from the first and second Wilcox and the Tyner sands, (Ordovician in system).

The general area is in the central oklahoma Platform (Northeast oklahoma Platform) which merges to the north with the Cherokee basin of Kansas (see Sutherland field geologic section). The Booch sand is used as a gas storage area to the south of the survey area. The first producible sand lens below the Desmoinesian Cherokee sands is the Dutcher sand. The Dutcher has been assigned to all producing zones between the Booch sand and the top of the Mississippian.

The Dutcher consists of numerous interbedded lenses of 
sandstones, many of which cannot be correlated between wells less than one-quarter mile apart. The interbedded shales are black, shaly and often silty. Generally, three Dutcher zones are found. In descending order they are the Morris, Glen and Field sands. often these are locally referred to as upper, middle and lower Dutcher sands.

In the Haskell area, the Dutcher is followed by the Pitkin Lime marker and then Mississippian sequence. Below the Mississippian there are numerous oil producing sands in the area. The Kinderhook-Chattanooga shales signal the entrance into these producing sands and limes.

The Misener sand at the top of the Devonian is often an oil producer. The Hunton lime in this area is thin and often absent. The Viola Lime, then the Simpson Sand (often called Wilcox) followed by the Tyner sands compose the ordovician production group in the Haskell area. These sands and porous limes produce throughout the Haskell area and are limited to stratigraphic, minor anticlinal axis production. It is easy to "water-out" in any of these porous lenses. The red and green shales at the base of the Simpson group signal the end of past-producing lenses in this area of Oklahoma.

Since the Haskell area lies to the North of the Hinge Lime between the Northeast oklahoma platform and the Arkoma Basin, most production is felt to come from minor anticlinal ripples creating subtle stratigraphic and water-drive traps which are limited in areal extent rather than tetonic or fault related features.

Three survey types were investigated in the Muskogee County (Haskell), oklahoma, survey area: Radiation survey, soil-gas survey, and free-gas survey.

The radiation survey was performed using a five-spot pattern for data measurements. These raw data were corrected for daily variations and cross-channeling interference by using the same computer algorithms and procedures used in the sutherland area. The resultant contour maps, shown in figures 48, 49, and 50, for the three radiation elements show a relative high radiation area on the east side of section 3 and low radiation levels in the center of section 10 and southeast quarter of section 4. As can be seen in these figures, the area surveyed is irregular in shape and contains a small area of roughly 1440 acres.

The soil-gas survey included the northwest quarter of section 11 and the northeast quarter of section 9. The total area for this survey is about 1760 acres. Figure 51 shows the contour plot of the methane data collected. Figure 52 shows 

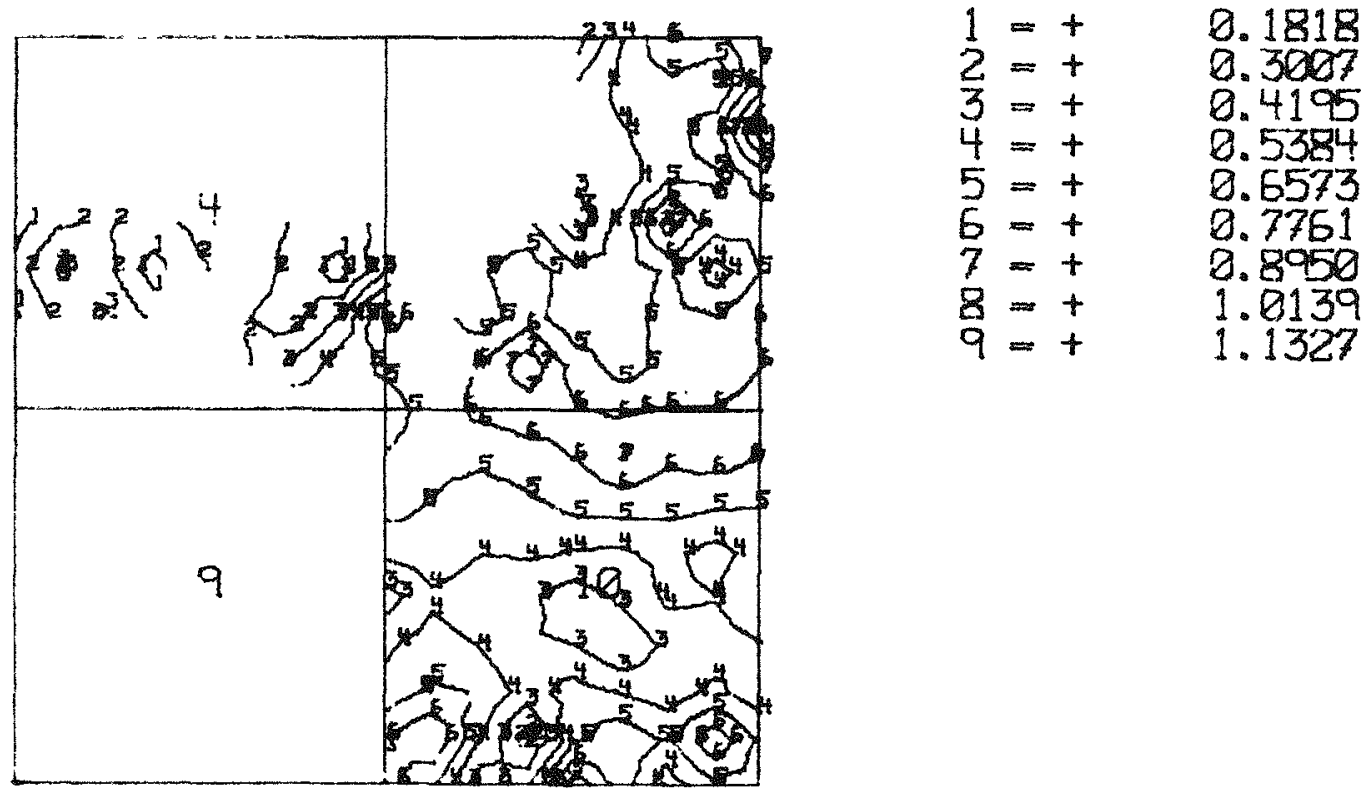

DATE: $12-31-77 \quad \cdots$

DATA FILE MUPOCO. DA

9 LEVEL CONTOUR

FIGURE 48. - Contour map of $\mathrm{K}^{40}$ in Haskell.

the frequency distribution is log-normal with a possible anomalous region in the +20 to +45 microliters methane per 50 gram sample concentration range. The anomalous region is found in sections 3 and 10, in the northeast corner of section 3, the northwest corner of section 10 , and on the northern part of the eastern edge in section 10 (see figure 51). The high gas value in the northwest corner of section 10 is highly suspect in that the oil wells are north of this site and the site is located in a ditch below these wells.

The free-gas (methane) survey was conducted by Geophysical System, corporation, using a truck-mounted sensing device. This survey was conducted differently from the other surveys in that the survey work was conducted from existing roads only. The interpretation from personnel conducting this survey indicated weak areas of microseepage are found in the southeast quarter of section 3, northwest quarter of section 10, and northeast quarter of section 9. These areas appear to be an extension of the southwest area in the $\mathrm{SW}$ quarter of section 3 .

Two deep tests were drilled after the soil gas and surface radiometric surveys were run. Analysis of the surveys showed low hydrocarbon concentrations in sections 3 and 10. This was combined with average gradient slopes of the topography. These areas also showed low radiometric readings.

The two tests were drilled by Mcoil Drilling Company, Muskogee, who was contracted by the lease owner, J. J. Simmons of 


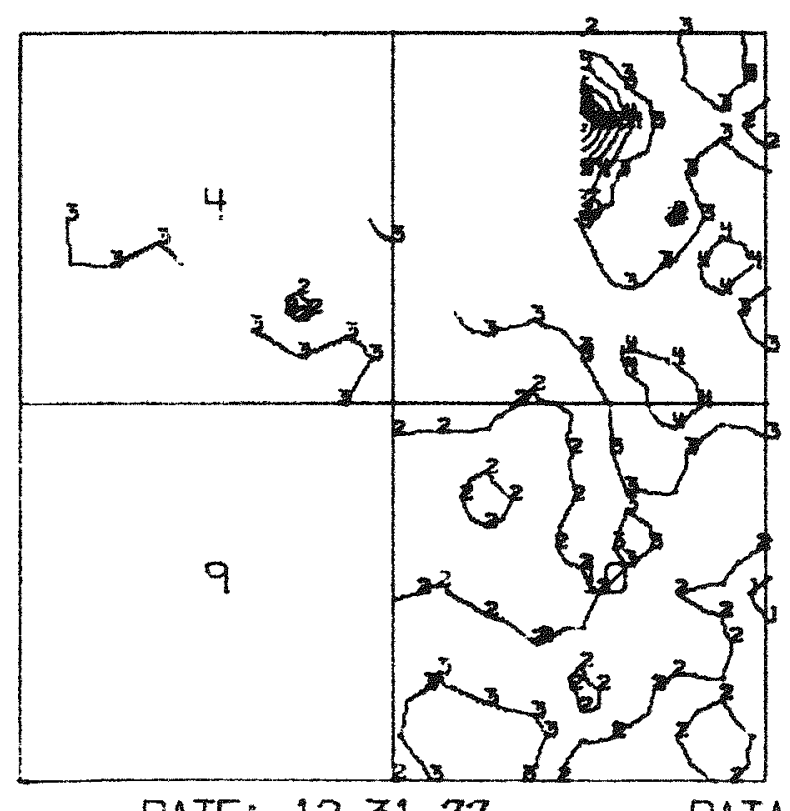

$\begin{array}{ll}1=t & 0.2679 \\ 2=+ & 0.7052 \\ 3=+ & 1.1424 \\ 4=+ & 1.5796 \\ 5=+ & 2.0159 \\ 5=t & 2.4541 \\ 7=+ & 2.8913 \\ 8=+ & 3.3285 \\ 9=+ & 3.7658\end{array}$

DATE: $12-31-77$ DATA FILF MUICO.DA

FIGURE 49. - Contour map of $\mathrm{Bi}^{214}$ in Haskell. 

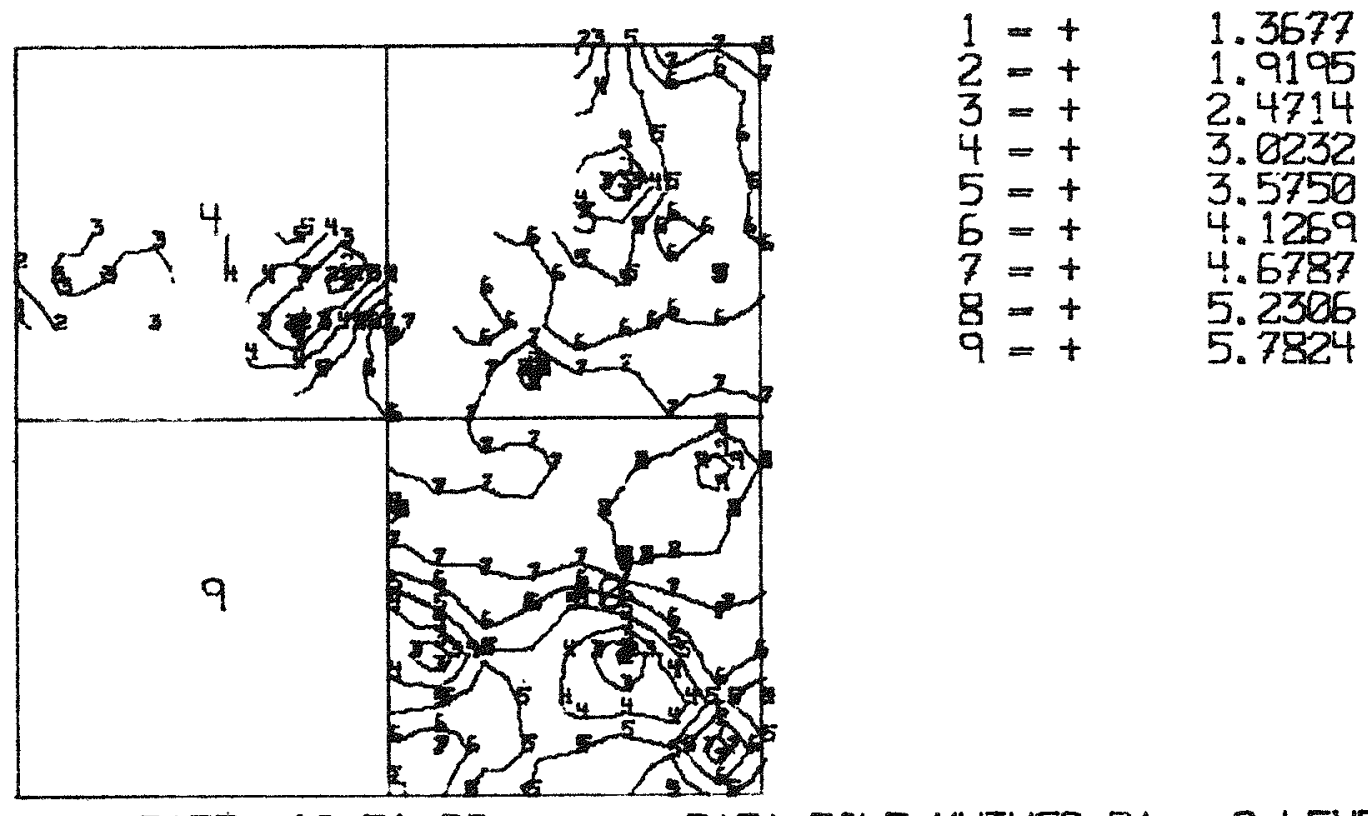

DATE: $12-31-77$

FIGURE 50. - Contour map of $\mathrm{TI}^{208}$ in Haskell. 

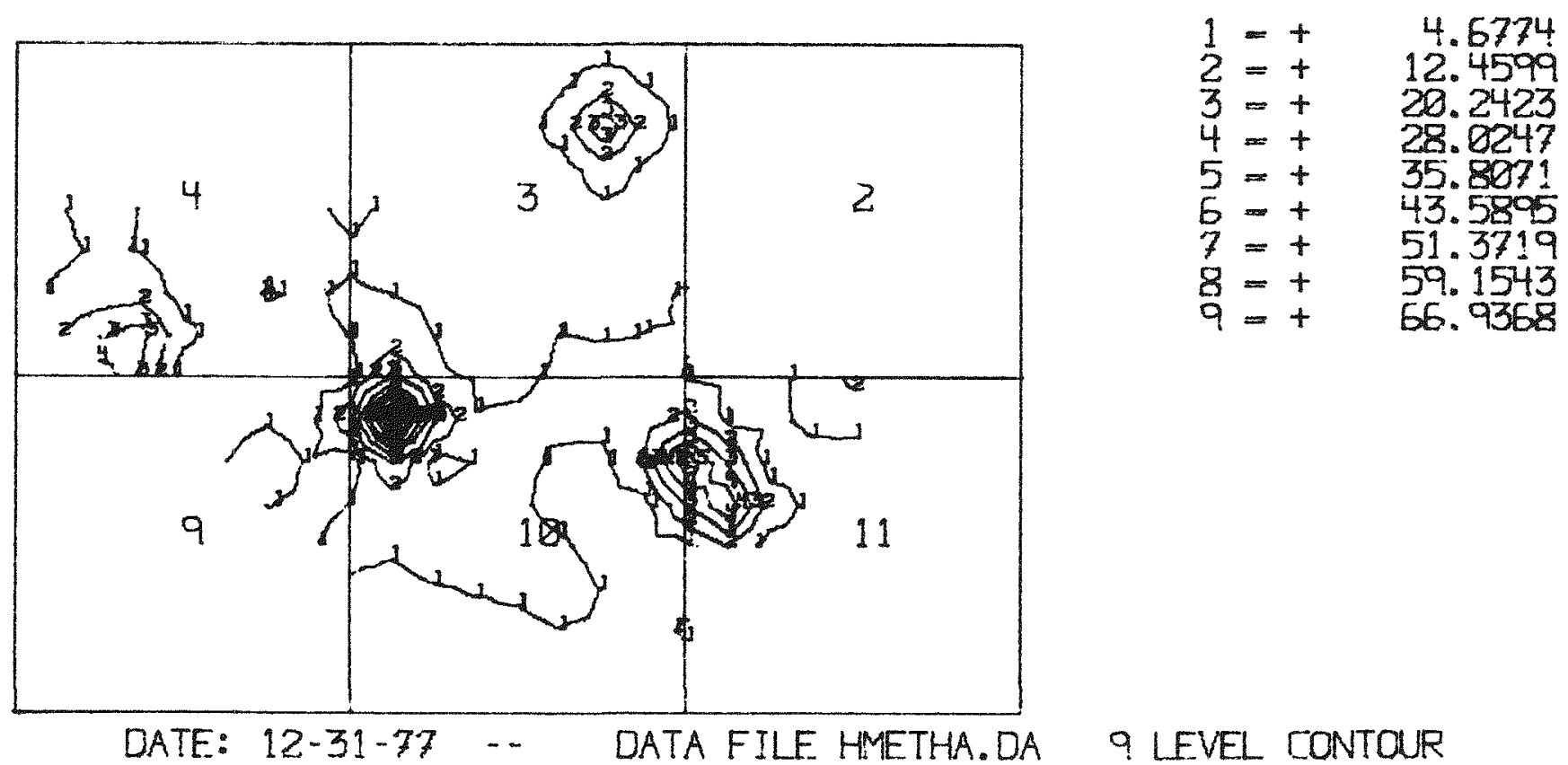

FIGURE 5.1. - Contour map of methane in Haskell. 


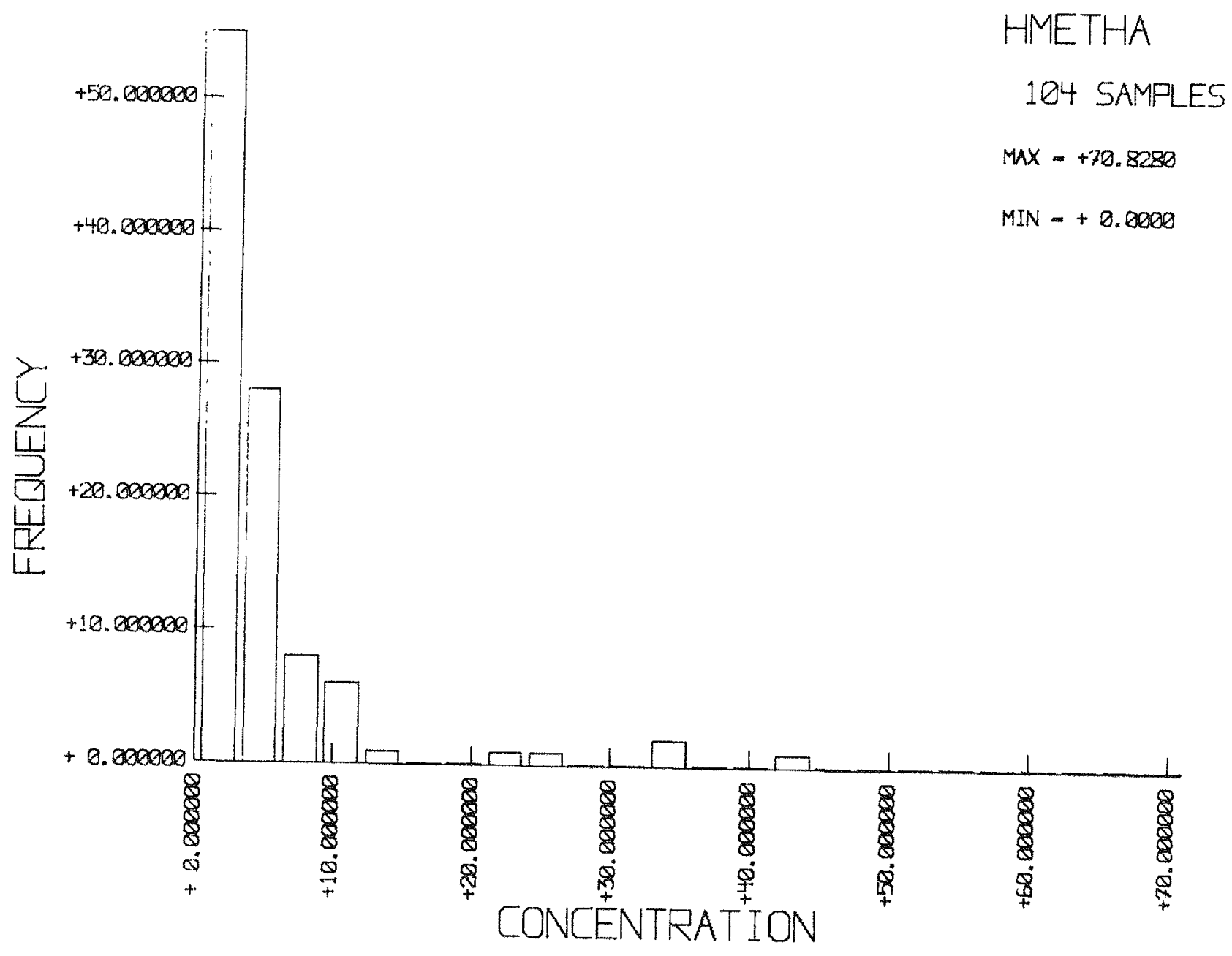

FIGURE 52. - Frequency histogram of methane in Haskell.

Muskogee, Oklahoma. Mud logging performed on the first test by Sens-Anom from Oklahoma City proved to be unacceptable. Mud logging by Baroid on the second test provided interesting results. open hole logging was contracted by the government from Schlumberger. The open hole logs performed were dual induction-laterog, compensated neutron-formation density, proximity log-microlog, borehole compensated sonic and fracture identification logs. A synergetic log system, Coriband, was run on the logs after logging was finished. No coring was performed on these two deep tests.

The first test was the simmons \#1-A, CW 1/2 NE section 10, T15N, R15E, Muskogee County, Oklahoma. Elevation was 611 feet K.B. and the total depth drilled was 1808 feet. 
The target formations were the Dutcher, Misener, Viola, Simpson and Tyner sands. No drill stem tests were run by the operator, so the results from open-hole logging analysis is the only objective evaluation of this test available at present.

The second test was the coburn \#1-C, NE SW NE, section 3, T15N, R15E, Muskogee Co., Oklahoma. Elevation was 618 feet K.B. and the total depth drilled was 1827 feet.

The target formations were the Dutcher, Misener, Viola, simpson and Tyner sands. No drill-stem tests were run by the operator. The results from the open-hole logging analysis and the mud-logging work performed at government cost are the only objective evaluations of this test that are presently available.

On the first test, Simmons \#1-A, log analysis shows several gas zones of producible interest from 1100-1250 feet. An interesting hydrocarbon concentration was found at 1560-1570 feet, but it appears to be water saturated. Hydrocarbons in the intervals from 1640-1780 feet are marginal accumulations with high percentages of water saturation. Since there were no production or drill-stem tests run, the producibility of this well is questionable. This well does have several zones of potential gas and oil production.

On the second test, coburn \#1-C, extremely high amounts of gas were encountered in the mud logging of the well. In addition to a high "kick" in the lower Dutcher, 1208-1214 feet, the Caney unit of the Missippian marks extremely high gas throughout the 1365-1475 feet range. The caney, although a shale, has a high percentage of sand and lime in the cuttings. The caney in other areas of Oklahoma is an excellent gas producing zone. The Sylamore sand at 1653-1656 feet produced a significant kick and the cuttings were stained when viewed microscopically. The Tyner sands also produced minor gas kicks and showed some staining when examined.

The analysis of the open-hole logs on the second test showed three possible gas-producing zones from 1070-1220 feet with the most promising from 1200-1208 feet. Throughout the caney interval, 1365-1475 feet, there were no log indications of gas, but discussions with the log analysts indicated that the shaliness of the formation may have masked the actual presence of hydrocarbons. Hydrocarbon indications from 1470-1590 feet all appear to have a high degree of water saturation. Once again, the Tyner sands appear to have good oil, but the zones also have a high degree of water saturation. Since there were no production or drill-stem tests run, the evaluation of the well is again questionable. This well does have several possibly producible zones of both gas and oil. 
Survey Cross-Comparisons and Analysis - Haskell

The high-gas areas in the Haskell area apparently conform to the theory postulated in the sutherland field analysis which states the high gas concentrations in a survey area would be expected on top of or below a topographical gradient (on the $\mathrm{pH}$ and conductivity gradients). Unfortunately, soil pH and conductivity values were not measured for this area. All gases except ethylene show the same high-gas areas as methane (figure 51). One particular problem associated with computerized contouring is that an abnormally high reading will cause a severe loss in sensitivity to contour values depicting the true data.

All radiation contours show low-radiation for the eastcentral part of section 4. All radiation data also show lows just below the center in section 10 and extending westward to the section line. Only the oil-producing area -- east-central part of section 4 and far west-central part of section 3 -- shows low gas and low radiation.

Referring to figures 48 and 51, low methane soil-gas is shown for the northeast quarter of section 3 with a partial "halo" of high potassium. The survey area in reality is not large enough, and edge effects such as the extreme high in the NE quarter of section 3 in figure 49 are common. Therefore, the northeast quarter of section 3, inside the potassium "halo" appears to be a promising area for oil and/or gas.

Free gas data show the southern half of section 3 , the northeast corner of section 9 , and the northwest quarter of section 10 to have weak microseepages of gas. The northeast quarter of section 3 shows about the same amount of seepage, but it is weaker than that previously described.

\section{Sutherland - Haskell Area Comparisons}

Comparisons between the Sutherland (Kansas) and Haskell (oklahoma) survey areas are limited to radiation and soil-gas data. Personnel and time limitations excluded tests to determine surface area, pH, moisture, and conductivity in the Haskell survey area.

Table 5 shows a brief summary of the data collected. The column for the average values measured shows the Sutherland area has roughly twice as much adsorbed soil-gas as the Haskell area, but the maximum values are far greater in the Haskell area than in the sutherland area. Radiation data for the average values show the Sutherland area ranges from 3 to 5 times higher than the Haskell area. The minimum Thallium value in sutherland is 29 percent higher than the highest Thallium value in Haskell. 
TABLE 5. - SUMMARY OF SUTHERLAND AND HASKELL DATA

\begin{tabular}{|c|c|c|c|c|c|}
\hline $\begin{array}{c}\text { Survey } \\
\text { Area }\end{array}$ & Test Element & $\begin{array}{l}\text { Max. } \\
\text { Value }\end{array}$ & $\begin{array}{l}\text { Min. } \\
\text { Value }\end{array}$ & $\begin{array}{l}\text { Avg. } \\
\text { Value }\end{array}$ & Units \\
\hline \multirow[t]{9}{*}{ Sutherland } & Methane & 56.7 & 0.7 & 10.1 & $\mu 1 / 50 \mathrm{~g}$ sample \\
\hline & Ethane & 9.5 & 0.0 & 1.5 & do. \\
\hline & Ethylene & 0.6 & 0.0 &.$I$ & do. \\
\hline & Propane & 5.2 & 0.0 & .6 & do. \\
\hline & Iso-Butane & 2.4 & 0.0 & .2 & do. \\
\hline & $\mathrm{N}$-Butane & 2.3 & 0.0 & .3 & do. \\
\hline & Potassium & 2.9 & 0.3 & 1.9 & pct. \\
\hline & Bismuth & 9.3 & 1.2 & 4.9 & $\mathrm{ppm}$ \\
\hline & Thallium & 21.4 & 8.6 & 16.7 & $\mathrm{ppm}$ \\
\hline \multirow[t]{9}{*}{ Haskell } & Methane & 70.8 & 0.8 & 5.5 & $\mu 1 / 50 \mathrm{~g}$ sample \\
\hline & Ethane & 14.1 & 0.0 & 0.9 & do. \\
\hline & Ethylene & 0.2 & 0.0 & 0.0 & do. \\
\hline & Propane & 5.9 & 0.0 & 0.3 & do. \\
\hline & Iso-Butane & 1.7 & 0.0 & 0.1 & do. \\
\hline & $\mathrm{N}$-Butane & 2.3 & 0.0 & 0.1 & do. \\
\hline & Potassium & 1.2 & 0.1 & 0.6 & pct. \\
\hline & Bismuth & 4.0 & 0.0 & 1.0 & ppm \\
\hline & Thallium & 6.1 & 1.1 & 3.9 & ppm \\
\hline
\end{tabular}


This comparison of radiation and soil-gas data may not be valid due to the small size of the Haskell survey area and the lack of specific soil data. The average values reported may specifically be biased since most of the Haskell survey area is within a mile of an oil and gas-producing area and contains a considerable amount of topographic and vegetation change. The comparison between two areas would be ideal if the two areas were similar as to topographic features, soil type and composition, and were tested during similar ambient conditions. The dissimilar features of the two test areas due to one containing an oil (or gas) producing zone versus none would then be pronounced.

\section{CONCLUSIONS}

Statements of fact in the literature indicate a relationship exists between petroleum at depth and observable gamma radiation anomalies at the surface and that this relationship can be correlated to light hydrocarbons, gas anomalies at the surface. From studies on the field data made thus far, however, neither of these stated facts can be substantiated. Although the presence of anomalies in the levels of natural radiation and hydrocarbon gases at the earth's surface was measured and observed in this study, their uniqueness to an oil reservoir has not been proven.

Results from this study have shown the soil-gas data to be affected by soil parameters, such as $\mathrm{pH}$ and conductivity, and a correlation exists, either directly or indirectly, between topography and soil gas. Surface areas of the soil samples showed a unique relationship to soil-gas as evidenced in the cluster cloud figure 44. The straight-edge cut-off of high gas to surface area is believed to be caused by a saturation effect of gas in the soil. The "cut-off" of low gas to surface area is believed to be caused by soil factors such as pH, conductivity, moisture, and soil components.

Radiometric data show a relationship with topography. This relationship is due to either detector geometry or differing soil conditions due to environmental factors, or a combination of both. Additional studies are required to determine the exact causes and specific methods to reduce the topographic effect. Studies of raw data and corrected data show the corrections for cross-channel interference significantly change the data and reduce the statistical variation to a minimum. The calibration of the detection equipment on large standardization pads and the subsequent corrections for daily variations were found to be most important for accurate determination of radiation anomalies.

The first conclusion which can be drawn from the results is that there are anomalies detected in the field data gathered. This is seen in both the histogram plots of methane and in the 
three-dimensional picture of n-butane.

To dismiss the prospecting value of soil-gas analysis as being questionable as some have (16), would be the simplest way to conclude our efforts at this point. However, there are still many questions concerning the soil hydrocarbon phenomenon that have not been answered. The problem is a very complex one and will only be solved by many years of hard work by dedicated investigators.

In view of the complexities presented in using the adsorbed gas, soil-sample method, greater promise may lie in the direction of a free soil-gas analysis system as other investigators have indicated (10). Possibly the presence of radon gas at the surface could be measured in conjunction with the detection of free hydrocarbon gases in the soil.

A good working knowledge of the general occurrence of geochemical anomalies has been gained by the surface examination of a few chosen field sites. Thus far, more knowledge pertaining to the distribution of these anomalies and to their relationship with deep-drilled wells, has evolved. The geochemical principles involved may be obtained perhaps through a more diligent search of the data collected.

\section{RECOMMENDATIONS}

1. The initial work described in this report on the free hydrocarbon gas has shown measurable amounts of hydrocarbon gases are present at the earth's surface. Theoretically a higher level of these gases should be present over or near an accumulation of oil and/or gas. We recommend more work in the field to determine the levels of free hydrocarbon gas, using both the airborne and surface cup collection techniques, and determine any correlation between surface gases and petroleum deposits at depth.

2. Any study using surface cup-collection techniques should be expanded to include a comparative study between surfacecollected free radon gas and free hydrocarbon gas.

3. A follow-up study of color-intensification patterns in Landsat images should be made in association with the anomalous hydrocarbon ridge found in this study. Hydrocarboninduced chemical changes may produce subtle surface color variations in patterns similar to those found for $\mathrm{pH}$ and conductivity. Also, potassium anomalies could be compared with surface vegetation effects. 
4. Due to the apparent effects of $\mathrm{pH}$ and topography on the level and/or distribution of soil-gases, the survey techniques should be determined in a strikingly different terrain from that used in this study. Southwestern Texas and parts of Wyoming contain areas which are topographically flat, are fairly uniform in vegetation, contain productive and nonproductivity areas, and would significantly lower the inherent number of variables associated with soil-gas, free gas, and natural radiation measurements. Thus any true relationships of hydrocarbon gas distribution and radiation profiles over known oil-fields, gas-fields, and nonproducing areas could be determined accurately. Effects of interfering phenomena could then be studied and applicable corrections made.

5. The radiation data collected in this study show anomalous regions in the survey area. The range of daily variations in calibration measurements indicated diurnal variation could be misconstrued as being anomalous unless some form of calibration scheme is employed. The frequent measurement of a control point was used in this study and applies very well to small, easily accessible areas. For large areas, a stationary control monitoring station should be used to allow for daily variations in radiation levels.

\section{ACKNOWLEDGMENTS}

The authors thank the following individuals for their cooperation in carrying out this study. Listed by field they are in Rosalia: G. Bell, G. Fisher, G. Hefton, H. Hobart, G. Kirk, B. Liggett, W. Liggett, M. McCarthy, A. Nobel, E. Parks, W. Paulson, R. Prewitt, C. Rowland, F. Sanford, R. Smith, J. Stanhope, N. Sundgren, J. Teter, T. Thomas, R. Vestring, C. Walls, J. Wisley, R. Zebold, and R. Zimmerman; in Sutherland: T. Baysinger, I. Biggs, R. Bock, C. Bonczkowski, J. Cox, G. Fankhouser, W. Godfrey, C. Hamer, R. Howard, E. Huber, G. Jackson, C. Johnson, C. Kopfman, M. Ledford, W. Lockard, H. Lose, E. Porter, L. Rhodes, G. Sage, O. Stauffer, C. Storrer, E. Stuck, L. Tatman, C. Ulrich, W. Volkman, and W. Waymire; and in Haskell: J. J. Simmons.

Special appreciation is given to R. Bock, C. Bonczkowski, W. Lockard, O. Stauffer, and J. J. Simmons for their help in the drilling of exploratory wells.

The authors also extend special recognition to $F$. E. Armstrong, now retired, for initiating this investigation. 


\section{REFERENCES}

1. Armstrong, F.E. and R. J. Heemstra. Radiation Halos and Hydrocarbon Reservoirs: A Review. BuMines IC 8579, $1973,52 \mathrm{pp}$.

2. Armstróng, F. E., T. C. Wesson, and M. D. Quigley. Exploration Methods for Small operator offered. Oil and Gas J., V. 74, No. 20, May 17, 1976, pp. 264-270.

3. Berbezier, J. B. Blangy, J. Guitton, and C. Lallemant. Methods of Car-borne and Air-borne Prospecting: The Techniques of Radiation Prospecting by Energy Discrimination. U.S.A.E.C.A/Conf. 15/P/1249 (pp. 799-814 in 2nd International Conference on Peaceful Uses of Atomic Energy, Geneva, 1958.)

4. Chapman, R. E. Petroleum Geology. A Concise Study. Elsevier Scientific Publishing Co., Amsterdam, 1973, 291 pp. , p. 39.

5. Heemstra, R. J., R. M. Ray, and J. R. Abrams. Minicomputer Graphic Methods for Geochemical Surveys. BERC/IC-78/2 May $1978,68 \mathrm{pp}$.

6. Horvitz, L. On Geochemical Prospecting. Geophysics, v. 4, No. 3, 1939, pp. 210-228.

7. Karasev, B. V. Determination of the Isotopic Composition of Uranium in Soil. Geokhimiya, No. 2, 1970, pp. 261-263; transl. available in Geochemistry Internat., v. 7, No. 1, October 1970, p. 203.

8. Kellogg, W. C. Observation and Interpretation of Radioactive Patterns Over Some California Oil Fields. Mines Magazine, v. 47, No. 7, July 1957, pp. 26-28.

9. Levinson, A. A. Introduction to Exploration Geochemistry. Applied Publishing Ltd. Calgary, Alberta, Canada, 612 pp., $1974, \mathrm{p} .124,537-543$.

10. McCrossan, R. G., N. L. Ball, L. R. Snowdon. An Evaluation of Surface Geochemical Prospecting for Petroleum, OldsCaroline Area, Alberta. Geological Survey of Canada, Paper 71-31, Information Canada, Ottawa, 1972, 101 pp.

11. Moore, R. C., J. C. Frye, J. M. Jewett, W. Lee, and H. G. O'Connor. The Kansas Rock Column. State Geological Survey of Kansas, University of Kansas Publications, Bull. 89, January 1951, 132 pp. 


\section{REFERENCES-Continued}

12. Ray, R. M. and T. C. Wesson. An Apparatus for Rapid and Precise Surface Area Measurements of Unconsolidated Geologic Materials. BERC/RI-78/8.

13. Rosaire, E. E. Discussion of Geochemical Exploration (Soil Analysis). Bull. Am. Assoc. Petrol. Geologists, v. 24, No. 8, 1940, pp. 1434-1463.

14. Rose, A. W. Statistical Interpretation Techniques in Geochemical Exploration. AIME, Soc. of Mining Eng., Transactions V. 252, No. 3, pp. 233-239, September 1972.

15. Sikka, D. B. Vozmozhnyye puti obrazovaniya radiometricheslikh anomaliy (Possible Modes of Formation of Radiometric Anomalies). Akad. Nauk SSR, Izvestiia Seriia Geologicheskila, v. 28, No. 6, 1963, pp. 73-86; abs. in Geophysical Abs., No. 206, March 1964, p. 227, No. 206-265.

16. Smith, G. H. and M. M. Ellis. Chromatographic Analysis of Gases from Soils and Vegetation, Related to Geochemical Prospecting for Petroleum. Bull. Am. Assoc. of Pet. Geologists, v. 47, No. 11, November 1963, pp. 1897-1903.

17. Sokolov, V. A. The Theoretical Foundations of Geochemical Prospecting for Petroleum and Natural Gas and the Tendencies of Its Development. (Proc., 3rd Inter. Geochemical Exploration Symp., Toronto, April 16-18, 1970), Geochemical Exploration. The Canadian Institute of Mining and Metallurgy, Special V. II, 197I, pp. 544-549.

18. Tripp, R. M. Thermodynamics of a Gas Migrating Vertically Through the sedimentary Column. Geophysics, v. 10, No. 2, April 1945, pp. 229-237.

19. Wesson, T. C. and F. E. Armstrong. The Determination of $\mathrm{C}_{1}-\mathrm{C}_{4}$ Hydrocarbons Adsorbed on Soils. BERC/RI-75/13, $1975,14 \mathrm{pp}$. 